\title{
The Pump-Leak/Donnan ion homeostasis strategies of skeletal muscle fibers and neurons
}

\author{
Béla Joos ${ }^{1,2}$ and Catherine E Morris 2,3 \\ ${ }^{1}$ Department of Physics, University of Ottawa, 150 Louis Pasteur Priv., Ottawa, Ontario, Canada \\ K1N 6N5 \\ ${ }^{2}$ Center for Neural Dynamics, University of Ottawa, Ottawa, Ontario, Canada \\ ${ }^{3}$ Neuroscience, Ottawa Hospital Research Institute, 451 Smyth Road, Ottawa, Ontario, Canada, \\ $\mathrm{K} 1 \mathrm{H}-8 \mathrm{M} 5$
}




\section{ABSTRACT}

Skeletal muscle fibers (SMFs) and neurons are low and high duty-cycle excitable cells constituting exceptionally large and extraordinarily small fractions of vertebrate bodies. The immense CIC-1-based chloride-permeability ( $\mathrm{P}_{\mathrm{Cl}}$ ) of SMFs has thwarted understanding of their Pump-Leak/Donnan (P-L/D) ion homeostasis. After formally defining P-L/D set-points and feedbacks, we therefore devise a simple yet demonstrably realistic model for SMFs. Hyper-stimulated, it approximates rodent fibers' ouabainsensitive ATP-consumption. Size-matched neuron-model/SMF-model comparisons reveal steady-states occupying two ends of an energetics/resilience P-L/D continuum. Excitable neurons' costly vulnerable process is Pump-Leak dominated. Electrically-reluctant SMFs' robust low-cost process is Donnan dominated: collaboratively, Donnan effectors and [big $P_{\mathrm{Cl}}$ ] stabilize $\mathrm{V}_{\text {rest, }}$, while $S M F s^{\prime}$ exquisitely small $\mathrm{P}_{\mathrm{Na}}$ minimizes ATP-consumption, thus maximizing resilience. "Classic" excitable cell homeostasis ([small $\mathrm{P}_{\mathrm{Cl}}\left[\right.$ [big $\left.I_{\text {Naleak }}\right]$ ), de rigueur for electrically-agile neurons, is untenable for vertebrates' (including humans') major tissue. Vertebrate bodies evolved thanks to syncytially-efficient SMFs using a Donnan dominated ([big $\left.\mathrm{P}_{\mathrm{cl}}\right][$ small I Naleak $]$ ) ion homeostatic strategy.

\section{INTRODUCTION}

\section{lon Homeostasis is a Pump-Leak/Donnan (P-L/D) feedback process}

Ion homeostasis is the energy-consuming feedback process by which a cell maintains its steadystate volume $\left(\mathrm{Vol}_{\text {cell }}\right)$, membrane potential $\left(\mathrm{V}_{\mathrm{m}}\right)$ and ion concentrations $\left([i o n]_{i}\right)$, returning autonomously to steady-state after ionic perturbations by sensing a change and transiently adjusting its fluxes and energy consumption till steady-state is restored. In the classic feedback control situation, thermostatic regulation of room temperature, a temperature sensor/effector system alters the output of a heat source in proportion to deviations from a chosen temperature set point. As per Figure 1A and legend, ion homeostatic feedback too, has sensor/effector elements and a set point. For any particular cell-type, the ion homeostasis set point is a steady-state collection -- $\left.\left\{\mathrm{Vol}_{\text {cell, }} \mathrm{V}_{\mathrm{m}} \text {, [ion }\right]_{i}\right\}--$ "chosen" by evolution. Evolution furnishes that cell-type with: a particular quantity (Usher-Smith et al, 2009) of anionic Donnan effectors, an $\mathrm{H}_{2} \mathrm{O}$-preamble membrane of a particular area $\left(\mathrm{C}_{\mathrm{m}}\right)$ equipped with particular densities of $\mathrm{Na}^{+}, \mathrm{K}^{+}$and $\mathrm{Cl}^{-}$permeant pathways $\left(\mathrm{P}_{\mathrm{Na}}, \mathrm{P}_{\mathrm{K}}, \mathrm{P}_{\mathrm{Cl}}\right)$, and electrogenic $\left(3 \mathrm{Na}^{+} / 2 \mathrm{~K}^{+}\right.$-ATPase) pumps sufficient to sustain steady-state and restore it after perturbations of the size expected for that cell-type. Quantitative cell-type specific differences for these components account for different ion homeostatic set points. The minimal components for self-regulating Pump-Leak/Donnan (P-L/D) ion homeostasis are depicted in Figure 1B. In virtually all cells, ion homeostasis will be non-minimal since most deploy additional ion transporters and channels to address nuanced physiological requirements (Fraser and Huang 2004), but these components tune rather that cause P-L/D ion homeostasis and so are addressed here only peripherally.

\section{Evolutionary context for muscle and nerve ion homeostatic strategies}

Skeletal muscle is the human body's biggest tissue ( 40\%; Janssen et al 2000). This tissue's fundamental ion homeostatic mechanisms evolved to meet the needs of our early vertebrate ancestors. Their bodies comprised, perhaps, 40-60\% skeletal muscle fiber (SMF) (see Table 1). Then, as now, SMFs would have been low duty-cycle excitable cells (i.e., at $\mathrm{V}_{\text {rest }}$ except during brief, infrequent action potentials (APs)). Also then as now, vertebrate neurons would have been high duty-cycle electrically-agile input-summing cells tasked by the whole-organism with overseeing sensory processing and controlling the timing of muscle contractions. For those ancestral vertebrates, a low-cost SMF resting-state would 
have been an enormous boon, while, given the tiny body portion devoted to brain in early vertebrates (Table 1), heavy ion homeostatic spending on neurons would have been even more tolerable than (say) in modern mammals. That ancient tissue-mass difference plus the starkly different electrophysiological lifestyles of skeletal muscle and neurons likely governed the evolution of the distinctive ion homeostatic strategies we identify here as operative in modern mammals (and modern amphibians, etc).

\section{lon homeostasis modeling via the charge difference approach}

To explain the self-restoring $\mathrm{V}_{\text {rest }}$ of frog SMFs and the $\mathrm{Na}^{+}$-transporter regulation of SMF volume, Fraser and Huang (2004) introduced a charge difference (CD) approach. It explicitly includes Donnan effectors and counts all transmembrane ion and $\mathrm{H}_{2} \mathrm{O}$ movements. This enables simultaneous computation of steady-state $\mathrm{Vol}_{\text {cell, }}[\text { ion }]_{i}$ and $\mathrm{V}_{\mathrm{m}}$ (via charge on $\mathrm{C}_{\mathrm{m}}$ ) (Fraser and Huang 2007, Ushersmith et al 2009; Kay 2018; Dmitriev et al 2019). Where relevant issues warrant it, CD-model trajectories of perturbed (non-steady-state) systems can be examined on timescales from milliseconds to days. Fraser and Huang's (2004) seminal work described non-excitable SMFs. A later elaboration addresses APs and ion homeostasis in t-tubules (Fraser et al 2011). SM-CD, the excitable SMF model devised is as simple as an autonomous ion homeostasis model can be. It depicts not an entire multinucleate SMF but, to enable direct comparison with CN-CD, an existing (Dijkstra et al 2016) CD model for cortical neurons (Figure 8 $\mathbf{A}, \mathbf{B}, \mathbf{C}$ ) an iterable fraction of a SMF (Tables $\mathbf{1}$ and 2, Figure 8C,D).

CD modeling comparisons here highlight two overlooked facets of SMF physiology: 1) the collaboration of CIC-1 channels with Donnan effectors is imperative for SMF ion homeostasis (not just for low SMF excitability (Jentsch and Pusch, 2018; Jeng et al 2020) and 2) the extraordinary smallness of the (unidentified) SMF $\mathrm{P}_{\mathrm{Na}}$ renders it pivotal (via its [small $I_{\text {Naleak}}$ ]) to the robustness of SMF ion homeostasis.

\section{Donnan forces finessed as "found free-energy" for volume homeostasis}

Though ion homeostasis is commonly referred to as a Pump-Leak process, dropping "Donnan" abrogates the P-L/D process; the Donnan-mediated volume feature is mandatory. Figure 1B (and legend) introduces the simple but novel idea that at steady-state, P-L/D ion homeostasis can be Donnan dominated or Pump-Leak dominated. Each of the two systems depicted has the minimal components required for autonomous $\mathrm{P}-\mathrm{L} / \mathrm{D}$ ion homeostasis; they differ in relative densities of always-open ("resting" or "leak") channels, $\mathrm{P}_{\mathrm{Cl}}, \mathrm{P}_{\mathrm{K}}$ and $\mathrm{P}_{\mathrm{Na}}$.

At steady-state in the Donnan dominated system, the transmembrane flux of ions is due mostly to $\mathrm{Cl}^{-}$ions, with influx and efflux perfectly balanced thanks to the cytoplasm's impermeant anions, while at steady-state in the Pump-Leak dominated system, the transmembrane ion flux is due mostly to cations, with passive $\mathrm{Na}^{+}$-influx and $\mathrm{K}^{+}$-efflux perfectly balanced by active (pumped) counterfluxes. Animal cells' ever-present Donnan forces are seen as a potentially lethal problem for cells to solve. When pumps falter, after all, $\left[\mathrm{Na}^{+}+\mathrm{Cl}^{-}+\mathrm{H}_{2} \mathrm{O}\right]$ entry kills cells as a direct consequence of Donnan forces. Animal cells handle the $\left[\mathrm{Na}^{+}+\mathrm{Cl}^{-}+\mathrm{H}_{2} \mathrm{O}\right]$-danger by sequestering the perilous free energy. Neurons use [small $\mathrm{P}_{\mathrm{Cl}}$, SMFs use [small $\mathrm{P}_{\mathrm{Na}}$ ].

Neuronal steady-state is thus a [small $\mathrm{P}_{\mathrm{cl}}$ [big $\mathrm{I}_{\text {Naleak}}$ ] Pump-Leak dominated process while SMF steady-state is a [big $\left.\mathrm{P}_{\mathrm{CI}}\right]\left[s m a l l I_{\text {Naleak }}\right]$ Donnan dominated process. Till now however, the distinction between Donnan dominated and Pump-Leak dominated strategies has, however, gone unrecognized (or at least unnamed). ClC-1 channels, expressed abundantly and exclusively in SMFs, are the major component (Pedersen et al 2016) of their [big P $\mathrm{Pl}_{\mathrm{c}}$. Discovered in 1991 by the Jentsch lab (Steinmeyer et al 1991) via close homology to elasmobranch ClC-0 (see Miller 2015), their role is described in 
electrophysiological terms; i.e, ClC-1 passively stabilizes the hyperpolarized $V_{\text {rest }}$ (Jentsch \& Pusch 2018). The P-L/D framework shows that, simultaneously, CIC-1 is crucial for SMF ion homeostasis. A counterfactual model (a big $\mathrm{P}_{\mathrm{K}}$ SMF-analog P-L/D) helps clarify this point.

Cytoplasmic proteins did not evolve to serve ion homeostasis. Nevertheless the unavoidable "colligative-charge" attribute that makes them Donnan effectors is a source of "found free energy", one that cells use in a sensor/effector role for ion homeostatic feedback (Figure 1A). Low-excitability SMFs evolved finessing their Donnan effector/sensor system, making it a high-conductance (=low-impedance) stabilizer of their low-cost ion homeostatic steady-state $\left(\mathrm{E}_{\mathrm{Cl}}=\mathrm{V}_{\text {rest }}\right)$. Modeling here reveals how, by maintaining [small $I_{\text {Naleak }}$ ] and exploiting that found free energy, SMFs obtain superb operational resilience. Donnan dominated SMF ion homeostasis, we propose, played an important role in the vertebrate lineage. Our initial motivation was, however, to understand SMF longevity in Duchenne muscular dystrophy (DMD) patients (Allen et al 2016; Gerhalter et al 2019) where SMFs experience chronic ion homeostatic stresses that rapidly kill neurons. In a companion paper (Morris et al submitted), SM-CD, the P-L/D model for SMF ion homeostasis explained here, is used to address that issue.

\section{RESULTS}

\section{$\underline{\text { SM-CD passes a stress-test }}$}

How SM-CD was devised is explained in Methods. Because SM-CD is new, we begin by demonstrating its general merit via a "reality check" (Figure 2A). Clausen (2015) summarized experimental findings (Nielsen and Clausen 1997) as follows: "In isolated rat soleus... after $10 \mathrm{sec}$ of stimulation at $120 \mathrm{~Hz}$, the net $\mathrm{Na}^{+}$re-extrusion measured in the subsequent $30 \mathrm{sec}$ of rest reaches a 22-fold increase in $\mathrm{Na}^{+}, \mathrm{K}^{+}$pump activity corresponding to $97 \%$ of the theoretical maximum rate of active $\mathrm{Na}^{+}, \mathrm{K}^{+}$pumping measured and calculated on the basis of total content of ${ }^{3} \mathrm{H}$-ouabain binding sites". Figure $2 \mathrm{~A}$ follows $\mathrm{V}_{\mathrm{m}}$ $\left[\mathrm{Na}^{+}\right]_{i},\left[\mathrm{Cl}^{-}\right]_{i}, \mathrm{Vol}_{\text {cell }}$ and ATP-consumption in SM-CD while 1200 APs fire and the while SM-CD fully restores itself to steady-state. The "Na+ re-extrusion" time course is reassuringly similar to rat soleus. In SM-CD, the maximal $\uparrow I_{\text {pump }}$ is 11.1-fold. When increased to 22.2-fold (Figure Sup1A) ATP-consumption(t) responds accordingly. Figure 2B shows one EPSC-elicited AP in SM-CD and the trajectories (milliseconds, minutes) of its ion homeostatic parameters. Having demonstrated SM-CD's response to challenge, we compare neuron versus SMF P-L/D processes. The biophysics of single AP ion homeostasis will be addressed later (Figure 6).

\section{Steady-state, anoxic rundown, recovery: P-L/D systems without excitability}

If their sole energy-generator (hyperpolarizing $I_{\text {pump }}$ ) is eliminated, P-L/D systems degrade towards Donnan equilibrium (DE). Dijkstra et al (2016) mimicked brain-slice anoxia in CN-CD, making switch-off gradual (like wash-in of pump-inhibitors). Here, for biophysical clarity, "pump-off/on" is instantaneous.

In Figure 3, to examine steady-state P-L/D components only, all V-gated channels are zeroed $(*)$. For $\mathrm{CN}$ - or $\mathrm{CN}^{*}-\mathrm{CD}$ and for $\mathrm{SM}$ - or $\mathrm{SM}^{*}-\mathrm{CD}$, steady-states are identical. Before $\mathrm{t}=0$, currents=zero and $\mathrm{Vol}_{\text {cell, }} \mathrm{V}_{\text {rest, }}$ [ion $]_{i}$ and ATP-consumption are as per $\mathrm{CN}-\mathrm{CD}, \mathrm{SM}-\mathrm{CD}$, Table 2. At pump-off $(\mathrm{t}=0)$, rundown commences. Pumping is restored at 105 minutes (before swelling to rupture point, and long before "notional" DE; see Table 2, Miscellaneous).

Before $\mathrm{t}=0$, steady-state ATP-consumption already tells a major story: $\mathrm{CN}^{*}$-CD maintains $\mathrm{V}_{\text {rest }}=-$ $65.5 \mathrm{mV}$ for $270.9 \mathrm{amol} / \mathrm{s}$, whereas $\mathrm{SM}^{*}$-CD maintain $\mathrm{V}_{\text {rest }}=-86 \mathrm{mV}$ for $51.1 \mathrm{amol} / \mathrm{s}$. 
The frugality of $S M^{*}-C D$ reflects the fact that ATP-consumption directly mirrors $I_{\text {Naleak }}$ (as per Figure $1 B$ ) and $S M^{*}-C D$ is a [big $\left.P_{C I}\right]\left[s m a l l ~ I_{\text {Naleak }}\right]$ system while $C^{*}{ }_{-} C D$ is a [small $\left.P_{C I}\right]\left[b i g I_{\text {Naleak }}\right.$ system. $\mathrm{CN}-\mathrm{CD}$ is non-minimal, but that negligibly affects its ATP-consumption (confirm by comparing CN-CD to $M N-C D$, Table 2). $I_{\text {Naleak }}$ depends on $P_{N a}$ and the electrodiffusive driving force (Equations $\mathbf{2}$ and $\mathbf{3}$ ). Though the $\mathrm{Na}^{+}$driving force is $21 \mathrm{mV}$ bigger in $\mathrm{SM}^{*}-\mathrm{CD}$ than $\mathrm{CN}^{*}-\mathrm{CD}$ at their respective $\mathrm{V}_{\text {rest, }}$, this is outweighed by $\mathrm{P}_{\mathrm{Na}}$ being $67 \mathrm{X}$ smaller in $\mathrm{SM} \mathrm{M}_{-} \mathrm{CD}$. Because $\mathrm{I}_{\text {pump }}=-I_{\text {Naleak, }}$ "instantaneous" $(\mathrm{t}=0) \mathrm{I}_{\mathrm{Na}}$ (Figure $3 \mathrm{~A}, \mathrm{~B}$ ) directly shows the crucial I Inaleak difference that makes steady-state ATP-consumption by SM(*)-CD $<1 / 5.3$ that of $\mathrm{CN}\left({ }^{*}\right)-\mathrm{CD}$ (see also Figure 9Ai).

Generally-speaking, electrically-leakier systems deteriorate faster. Based on total leak permeabilities (see Figure $8 A$ ) SM*-CD $\left(40.3 \mu \mathrm{m}^{3} / \mathrm{s}\right)$ is electrically-leakier than CN*-CD $\left(24.5 \mu \mathrm{m}^{3} / \mathrm{s}\right)$. Why, then, the markedly slower anoxic rundown (gradient dissipation, $V_{m}$ decay, swelling) of $S^{*}$-CD? Because in $\mathrm{P}$-L/D systems, rate-limiting permeabilities govern rundown, not globlal electrical-conductivity (Figure 3 legend provides more specifics). $C N^{*}-C D$, with $P_{C I}$ small relative to (its major permeability) $P_{K}$, represents "generic neuron" where, famously, the [small $P_{c I}$ ] slows anoxic swelling (Rungta et al 2015). Therefore, the physiologically noteworthy take-home from this rundown comparison is: in [big $\mathrm{P}_{\mathrm{cl}}$ ] SMFs, the extremely small $\mathrm{P}_{\mathrm{Na}}$ confers substantially more safety from anoxic swelling than [small $\mathrm{P}_{\mathrm{Cl}}$ ] does in [big I Naleak] neurons.

A priori, in P-L/D systems with unchanging permeabilities, a pump-strength sufficient to sustain steady-state gradients is also sufficient to restore systems after anoxic dissipation. Figure $\mathbf{3}$ confirms this. $S M^{*}-C D$, being less dissipated than $C N^{*}-C D$ at 105 minutes, recovers sooner, but whatever the rundown time, full recovery is assured (not shown).

\section{Electrophysiological lifestyles and excitable cell anoxia}

Neurons can respond sensitively to small incoming currents because their input impedance is relatively large and their $\mathrm{V}_{\text {rest }}$ lies close to firing threshold. SMFs, by contrast, keep $\mathrm{V}_{\text {rest }}$ hyperpolarized far below firing threshold and their smaller input impedance (from [big $\left.P_{c l}\right]$ ) prevents firing except in response to large excitatory postsynaptic currents (EPSCs) that, in situ, occur infrequently.

During anoxia (Figure 4) the behaviors of the P-L/D systems adapted for these distinctive "electrophysiological lifestyles" differ to an extreme degree; neurons perish rapidly and SMFs remain safe for prolonged periods. Figure 4 follows $C N-C D$ and $S M-C D$ anoxic rundowns for 50 min (details in legend). Post-anoxic restoration is addressed elsewhere (for CN-CD, see Dijkstra et al (2016) and for SM-CD, see Morris et al submitted); suffice it to say that in both models post-anoxic recovery occurs only if $I_{\text {pump }}$ is restored before ectopic firing ceases.

Instantaneous pump-off depolarization in CN-CD depolarizes $V_{m}$ to firing threshold (Figure 4A). As ectopic APs fire for $\sim 1$ minute, Nav and Kv channel opening precipitously dissipates the cation gradients. In CN-CD, a pathological voltage-activated $\mathrm{Cl}^{-}$channel (Rungta et al 2015) hastens swelling. At at 50 minutes, $C N-C D$ is $3 X$ its initial volume (versus $2 X$ for $C N^{*}-C D$ ).

50 minutes into anoxia, the condition of SM-CD (Figure 4B) is equally disastrous. Having generated a half minute ectopic firing burst, it too has swollen $3 \mathrm{X}$ (versus only $1.2 \mathrm{X}$ for $\mathrm{SM} \mathrm{M}^{*} \mathrm{CD}$ ). The massive cation fluxes via Nav and $\mathrm{Kv}$ plus concurrently a catastrophically large $\left[\mathrm{Cl}^{-}+\mathrm{H}_{2} \mathrm{O}\right]$ influx. A different story is evident, however, when comparing systems, say, 20 minutes into anoxia. For 22.7 minutes, anoxic SM-CD avoids the Donnan-mediated swelling catastrophe, its prolonged rundown thanks to its hyperpolarized $V_{\text {rest }}$ plus [small $I_{\text {Naleak }}$ ]. Ancillary to [small $I_{\text {Naleak }}$ ], moreover, its pump-off depolarization is small. 
SMFs require [big $\mathrm{P}_{\mathrm{Cl}}$ ] as part of their no-added-cost "low-internal-resistance Donnan battery"; the feature keeping $V_{m}$ near $V_{\text {rest }}$ during (non-EPSC) current perturbations. Until firing threshold is reached, that $\left[\right.$ big $P_{C l}$ is unproblematic. During those 22.7 minutes, in spite of [big $P_{c l}$ ], the minimal $P-L / D$ system keeps $\mathrm{Cl}^{-}$influx small because $\mathrm{Cl}^{-}$feels no driving force at $\mathrm{t}=0$ (steady-state $\mathrm{E}_{\mathrm{Cl}}=\mathrm{V}_{\text {rest }}$ and during rundown $E_{C l}$ tracks $V_{m}$ ). Though $S M-C D$ 's $P_{k}$ is small (compared to $C N-C D$ ), $P_{k}>>P_{N a}$, so Na entry through $\mathrm{P}_{\mathrm{Na}}$ is mostly neutralized by $\mathrm{K}^{+}$exit. With $\mathrm{Cl}^{-}+\mathrm{H}_{2} \mathrm{O}$ entry minimal, $\mathrm{SM}-\mathrm{CD}$ at 22.7 minutes into anoxia has swollen a mere $1.05 \mathrm{X}$. The tightly coupled $\mathrm{Cl}^{-}+\mathrm{H}_{2} \mathrm{O}$ entry over this period is plotted at lower left, Figure 3B.

In SM-CD, anoxic depolarization from $-75 \mathrm{mV} \rightarrow-65 \mathrm{mV}$ takes 12 minutes. This accords well with the report (Clausen and Flatman 1977) that in ouabain-poisoned rat soleus fibers $V_{m}$ runs down at $\sim 10$ $\mathrm{mV} / 10$ minutes.

In $\mathrm{SM}-\mathrm{CD}, \mathrm{a} \pm 10$-fold $\Delta \mathrm{P}_{\mathrm{Cl}}$ does not affect $\mathrm{V}_{\text {rest }}$ and rundown at $10 \mathrm{X} \mathrm{P}_{\mathrm{Cl}}$ and $0.1 \mathrm{X} \mathrm{P}_{\mathrm{Cl}}$ takes 23.8 and 20.7 minutes to ectopic firing, respectively. Thus, its importance in stabilizing SMF $V_{\text {rest }}$ notwithstanding, [big $\mathrm{P}_{\mathrm{Cl}}$ ] does not influence the value of $\mathrm{V}_{\text {rest }}$ (see Figure 10) and has little impact on its decay. As further evidence of the primacy, here, of [small $I_{\text {Naleak }}$ ]: a mere $27 \% \mathrm{P}_{\mathrm{Na}}$ decrease $\left(\rightarrow \mathrm{V}_{\text {rest }}=-90 \mathrm{mV}\right)$, as illustrated in Morris et al submitted, lengthens rundown-to-ectopic firing from 22.7 to 34 minutes.

\section{WD-CD: a counterfactual Pump-Leak dominated SM-CD analog}

Many key physiological traits of SM-CD depend directly on [small $I_{\text {Naleak }}$ ] independent of [big $\left.\mathrm{P}_{\mathrm{cl}}\right]$ : SM-CD's low resting ATP-consumption and consequently its large pump-reserve (ratio of maximal to resting ATP-consumption), its strongly hyperpolarized $V_{\text {rest, }}$ its slow anoxic rundown. It can be easy to lose sight of what [big $\mathrm{P}_{\mathrm{cl}}$ ] contributes to Donnan dominated ([big $\left.\mathrm{P}_{\mathrm{cl}}\right]$ [small I $\left._{\text {Naleak }}\right]$ ) ion homeostasis.

To illustrate quantitatively, we use WD-CD (Weak Donnan, Tables 1 and 2), a counterfactual Pump-Leak dominated analog of SM-CD with the same input impedance and $\mathrm{V}_{\text {rest }}(-86 \mathrm{mV})$. Its assigned $P_{C l}$ is that of a physiologically-bonafide Pump-Leak dominated system (i.e., $C N-C D$ ) and its $P_{N a}: P_{K}$ ratio is that of $S M-C D$, but with larger absolute values to attain the input impedance of SM-CD. In counterfactual WD-CD, therefore, $P_{K}$ (not $P_{C l}$ ) is the major contributor to low input impedance. Like SM-CD, WD-CD is a minimal P-L/D system. Its [big $I_{\text {Naleak }}$ ] puts resting ATP-consumption at $3.5 X$ that of SM-CD; its pumpreserve is only 3.1-fold. Though spending 3.5X more for steady-state $\mathrm{Na}^{+}$extrusion than $\mathrm{SM}-\mathrm{CD}$, its $\left[\mathrm{Na}^{+}\right]_{i}$ is almost twice that of SM-CD, leaving it less able than SM-CD to support SMF's $\mathrm{E}_{\mathrm{Na}}$-dissipating $\mathrm{Na}^{+}-$ transporters.

In [big $\mathrm{P}_{\mathrm{Cl}}$ ] $\mathrm{SM}-\mathrm{CD}$, excitability modulation is straightforward $\left(\Delta \mathrm{P}_{\mathrm{Cl}}\right.$ leaves ATP-consumption and $V_{\text {rest }}$ unchanged) but WD-CD modulation is complex. Altering its input impedance via $\Delta P_{k} \rightarrow \Delta V_{\text {rest. }}$. Modulating it with no $\Delta V_{\text {rest }}$ requires changing $P_{K}$ and $P_{N a}$ at fixed ratio. Any $\uparrow P_{N a} \rightarrow \uparrow A T P$-consumption.

Ischemic episodes occur in the normal course of events for SMFs, making SM-CD's exceptionally slow anoxic rundown a "time-is-money" benefit. Slow rundown makes it likelier that blood-flow resumes before ectopic firing triggers damaging contractures and cytotoxic swelling. Figure $\mathbf{5}$ shows WD-CD anoxic rundown. Thanks to [small $\mathrm{P}_{\mathrm{Cl}}$ ] and initially zero $\mathrm{Cl}^{-}$driving force, swelling prior to ectopic-APs is inconsequential (a neuron-like attribute). Nevertheless, due to its [big $I_{\text {Naleak }}$ W WD-CD rundown-to-firing is $4 \mathrm{X}$ faster than in SM-CD $(-75 \rightarrow-65 \mathrm{mV}$ in 2.9 minutes versus $12 \mathrm{~min}$ for SM-CD). Exacerbating this perilous rapidity is WD-CD's $5.5 \mathrm{mV}$ pump-off depolarization (versus $<2 \mathrm{mV}$ in $\mathrm{SM}-\mathrm{CD}$ ).

\section{Evolution chose Donnan dominated ion homeostasis for SMFs}

Like a neuron, a "WD-CD SMF" must continually "pay the pump" a) for its costlier $V_{\text {rest }}$ and b) for most (i.e., the non- $P_{C I}$ portion) of its resting conductance. Like a neuron, WD-CD, is vulnerable to ischemia. An organism using Pump-Leak dominated "WD-CD muscles" for all its mostly-quiescent SMFs would 
chronically elevate its whole-body expenditure, jeopardizing fuel supplies for contractility. Figure Sup01C shows that WD-CD (see the ATP-consumption trace) handles the 1200 AP stress-test as well as SM-CD. Its base-line energy consumption, however, is $>3.5 \mathrm{X}$ higher.

For neurons and the whole-organism that supplies their ATP, payback for use of a costly PumpLeak dominated system is their agile, nuanced integration of diverse information-rich electrical inputs. This merits the expenditure and the added vulnerability. By leaving SMF decision-making (when to contract?) entirely to remotely-located groupings of high-cost neurons, vertebrate SMFs could benefit from their robust low-cost Donnan dominated homeostasis strategy, allowing more ATP for contractility.

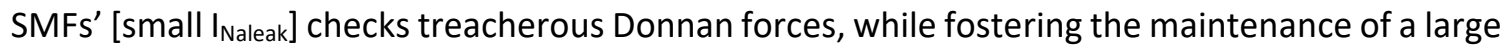
pump-reserve and a strongly hyperpolarized, exceptionally low-cost $\mathrm{V}_{\text {rest }}$ that, thanks to SMF's "pre-paid" $\mathrm{Cl}^{-}$-battery (i.e. [big $\left.\mathrm{P}_{\mathrm{Cl}}\right]+[$ Donnan effectors]), is not readily perturbed.

\section{The slow ion homeostatic response to a fast SMF electrical event}

The canonical ionic perturbation of SMF ion homeostasis is a cholinergic motorneuron-triggered AP (Figure 2B). For 3 minimal P-L/D models, Donnan dominated SM-CD (green), its ischemic (30\% pumpstrength) variant, LA-CD (blue), and (counterfactual) Pump-Leak dominated WD-CD (red) (see Tables 1 and 2), Figure 6 details the response to an EPSC-triggered AP. Here, overlying the SM-CD AP of Figure 2B are almost-identical LA-CD and WD-CD APs. Time-axes and the various $Y$-axes are varied to resolve fast AP-related perturbations and the slower P-L/D responses. Single-AP ion and volume responses would be immeasurably small, but Figure 2A,B showed (for SM-CD) that the cumulative perturbation from 1200 APs elicits larger-magnitude P-L/D responses of nearly the same duration as for one AP. By 1200-APs in $\mathrm{SM}-\mathrm{CD}$ (Figure $2 \mathrm{~A}$ ), $\left[\mathrm{Na}^{+}\right]_{\text {, }}$ rises almost $25 \mathrm{mM}$ above steady-state whereas post-one-AP, [ $\left.\mathrm{Na}^{+}\right]_{1}$ increases $<0.05 \mathrm{mM}$. For contraction-inhibited SMFs (current or voltage-clamped), a new 4-microelectrode technique enables simultaneous monitoring of multiple [ion] $]_{i}$ (Heiny et al 2019; DiFranco et al 2019; for measurably-large perturbations, an AP train (not a single AP) would be needed).

Figure 6 dissects the underlying P-L/D processes.

The ATP-consumption trajectories are straightforward: after rapid double-jumps (responding to

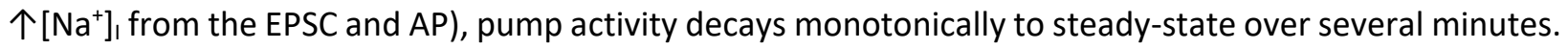
WD-CD's trajectory is off-scale near $180 \mathrm{amol} / \mathrm{s}$ but otherwise like that of SM-CD (see Y-axis ranges, double-jump boxes) and so the $\mathrm{Na}^{+}$-extrusion and $\mathrm{K}^{+}$-uptake (difference) trajectories for $\mathrm{SM}-\mathrm{CD}$ and WDCD overlap, while weaker pump-strength LA-CD lags.

Return to steady-state $\left[\mathrm{Cl}^{-}\right]$and $\mathrm{Vol}_{\text {cell, }}$ rather than being monotonic, involves a single oscillation, reflecting the interplay of P-L/D systems' two sensor/effector processes. Once AP channels close, $V_{m}(t)$ reflects hyperpolarizing $I_{\text {pump }}(t)$. After 1200 APs in SM-CD (Figure 2A; see also Figure Supp01B,Cii), $V_{m}(t)$ hyperpolarizes and temporally aligned oscillations of $\left[\mathrm{Cl}^{-}\right]_{i}(\mathrm{t})$ and $\mathrm{Vol}_{\text {cell }}(\mathrm{t})$ occur as in Figure 6 , but writ large.

All 3 models oscillate, their distinctive features revealing the forces at work (detailed in legend). Why the oscillation? Open AChR channels support mostly $\mathrm{Na}^{+}$entry, then Nav channels open before Kv channels. Immediately after any excess $\mathrm{Na}^{+}$entry (see AP-induced $\mathrm{H}_{2} \mathrm{O}$ blip), cells are $\mathrm{Na}^{+}$and $\mathrm{H}_{2} \mathrm{O}$ and $\mathrm{Cl}^{-}$overloaded. $\left[\mathrm{Na}^{+}\right]_{i}$-stimulated electrogenic $\mathrm{I}_{\text {pump }}$ extrudes $3 \mathrm{Na}^{+}$per $2 \mathrm{~K}^{+}$imported, slightly hyperpolarizing the $\mathrm{V}_{\mathrm{m}}$ (top panel, right). Shortly, the ongoing $\mathrm{Na}^{+}$-extrusion makes the swollen cells shrink below normal because the pump keeps expelling $3 \mathrm{Na}^{+}$per $2 \mathrm{~K}^{+}$imported, and neutralizing- $\mathrm{Cl}^{-}$plus osmo-balancing- $\mathrm{H}_{2} \mathrm{O}$ accompany the extruded $\mathrm{Na}^{+}$(i.e. they exit the cell). [ $\left.\mathrm{Cl}^{-}\right]_{i}$ and $\mathrm{Vol}_{\text {cell }}$ thus drop below their steady-state levels until, as $\left[\mathrm{Na}^{+}\right]_{1}$ continues falling, $I_{\text {pump }}$ and $I_{\text {Naleak }}$ equalize and steady-state is reattained.

The ion homeostatic feedback oscillation of Vol cell $(\mathrm{t})$ and $\left[\mathrm{Cl}^{-}\right]_{i}(\mathrm{t})$, we call a "Donnan bounce". The Vol $_{\text {cell }}(\mathrm{t})$ panel (right) shows that the Donnan bounce amplitude of Pump-leak dominated WD-CD is 
$<1 / 10^{\text {th }}$ that of Donnan dominated SM-CD. A P-L/D system's Donnan bounce is bigger when $\mathrm{P}_{\mathrm{Cl}}$ is bigger and slower when pump-strength is weaker.

Based on the Figure 6 single-AP responses, one might ask:

1) Since WD-CD performs well post-AP, why would Pump-Leak dominated neurons (say) not go a step further, eliminate $\mathrm{Cl}^{-}$channels, and use Pump-Leak homeostasis? The answer: this could work only if APrelated $\mathrm{Na}^{+}$and $\mathrm{K}^{+}$fluxes and the $\mathrm{Na}^{+}$and $\mathrm{K}^{+}$driving forces were precisely adjusted to yield zero excess $\mathrm{Na}^{+}$entry (AP-induced " $\mathrm{H}_{2} \mathrm{O}$ blips" would drop fully) AND if pumps were electroneutral (electrogenic pumping polarizes $V_{m}$, altering any perfectly-tuned driving forces). This zero- $P_{C l}$ system would have zero physiological latitude.

2) WD-CD experiences a smaller $\mathrm{H}_{2} \mathrm{O}$ blip and thus a smaller Donnan bounce; is that not preferable? Inside a cranium, $\Delta \mathrm{Vol}_{\text {cell }}$ is undesirable, but for SMFs the $\Delta \mathrm{Vol}_{\text {cell }}$ of $\mathrm{SM}-\mathrm{CD}$ is vanishingly small, physiologicallyspeaking, whereas WD-CD's chronic 3.5X个ATP-consumption is an untenably large differential that, for low-duty-cycle SMFs, disqualifies the Pump-Leak dominated analog even ignoring its overly-fast anoxic rundown (Figure 5B).

\section{SM-CD, ion homeostatic thresholds and bistability}

SMF pump-strength varies up/down through hormonal modulation and misadventure (interrupted blood flow, toxins, sarcolemma bleb-damage) (Pirkmajer and Chibalin 2016). Given SMF's interacting non-linear $\mathrm{Na}^{+}$-flux mechanisms $\left(\mathrm{I}_{\text {pump }}\left(\left[\mathrm{Na}^{+}\right]_{i}\right)\right.$ and $\mathrm{I}_{\mathrm{Nav}}\left(\mathrm{V}_{\mathrm{m}}\right)$ (Figure $\left.\mathbf{9 A , C}\right)$, and the non-linear driving forces acting on permeant ions, it is to be expected that fibers' P-L/D steady-states would vary non-linearly with pump-strength. Bifurcation plots for SM-CD (Figure 7) encapsulate these non-linearites.

For neurons in general and CN-CD in particular (Dijkstra et al 2016), it was shown (Hubel et al 2014) that pump-strength changes cause smoothly-varying (albeit non-linear) changes in steady-state values, until a system-specific unstable threshold is encountered. Here we examine this property for SMCD. Figure 7Aii is the SM-CD destabilization trajectory (normal-pump-strength $\rightarrow$ saddle-node-pumpstrength). Once spontaneous destabilization (ectopic firing) commences, the minimal-pump-strength system quickly degrades then slowly continues (not to $\mathrm{DE}$, since pump-strength $>0$ ) to a "DE-like" pathological steady-state. SM-CD can now only return to a physiological steady-state (Figure Sup02 Ci,ii,iii) if it up-regulates its pump-strength (=个个hyperpolarizing $I_{\text {maxpump }}$ ) enough to repolarize itself to a different unstable threshold ( $\rightarrow$ more ectopic firing) from which (post-APs) it repolarizes to a physiological steady-state. This bistable two-thresholds scenario ("ion homeostatic excitability") is a feature of excitable P-L/D systems (Hubel et al 2014; Morris 2018).

The parameter-specific bifurcation plots for a P-L/D system coincide; to know SM-CD's steadystate $\mathrm{V}_{\mathrm{m}},\left[\mathrm{Na}^{+}\right]_{i}, \mathrm{Vol}_{\text {cell, }}$, etc at, say, $10 \%$ pump-strength, consult each plot at that $\mathrm{X}$-axis value. Furthermore, $\mathrm{SM}-\mathrm{CD} / \mathrm{CN}-\mathrm{CD}$ comparisons are informative because their $100 \%$ pump-strength and $\mathrm{C}_{\mathrm{m}}$ values are identical. For $\mathrm{SM}-\mathrm{CD}$, the lowest pump-strength able to sustain a physiological steady-state is marginally $<8 \%$ (the saddle-node is $\sim 7.9 \%$ ). Comparison of saddle-node pump-strengths ( 8\%(SM-CD), 65\%(CNCD)) re-emphasizes the impressive ion homeostatic robustness of SM-CD. Due to $3 X \uparrow N a v$ density, $V_{m}$ at SM-CD's saddle-node is less depolarized than for CN-CD (Figure 7Ai); but note that SM-CD, at its saddlenode, though profoundly $\mathrm{Na}^{+}$-loaded, is hardly swollen (7Bi,Cii). Thus, unlike CN-CD, SM-CD can be profoundly ischemic and $\mathrm{Na}^{+}$-loaded with very little swelling. In humans, various methodologies including ${ }^{23} \mathrm{Na}$-proton-MRI, point to "non-osmotic $\mathrm{Na}^{+}$-loading" in connection with myotonia (Weber et al 2006), over-exertion pain (Yu et al 2013), anaerobic exertion (Hammon et al 2015), and the chronically $\mathrm{Na}^{+}-$ overloaded fibers of DMD patients (Gerhalter et al 2019).

The Vol cell plot (Figure $7 \mathrm{Ci}$ ) emphasizes the far-from-equilibrium state of healthy cells and the potency of the Donnan forces held in check by ion homeostasis by plotting the full range between DE and 
physiological Vol cell (black line) levels. 7Cii,iii then bring the focus to the physiological region. Very little swelling is tolerated by CN-CD, but even SM-CD, whose saddle-node is reached at $2088 \mu \mathrm{m}^{3}$, swells only $\sim 5 \%$ ( $\left.\uparrow V_{\text {cell }}\right)$. Working SMFs can safely withstand greater substantial swelling at healthier pumpstrengths with $\mathrm{Na}^{+}$-transporters operative (Usher-smith et al 2009; Lindinger et al 2011).

The Figure 7Aii trajectory follows SM-CD to a degraded ATP-consuming pathological steady-state. If (implausibly) a SMF survived the ectopic firing/contractures and stabilized there, it would occupy a pathological steady-state point on the continuum (blue) directly above the black $\mathbf{X}$. Recovery would require this degraded system to up-regulate its pump-strength to \#. For completeness, Figure Sup02Cii,iii shows SM-CD's $V_{m}(t)$ trajectory when pump-strength is increased from $338 \%$ to $339 \%(\#)$, whence it destabilizes and converges on the physiological steady-state continuum (directly below \#).

Though peril clearly awaits if a saddle-node is encountered, ischemic SMFs are profoundly safer than ischemic neurons. If CN-CD drops $100 \% \rightarrow 65 \%$, only doubling its pump-strength (pink \#) will save it. By contrast, SM-CD's physiological continuum extends down to $8 \%$; over this entire ischemic range, any pump-strength improvement, no matter how small, moves the system smoothly back towards $100 \%$ (Figure 7Bii). SMFs commonly experience transient benign $\downarrow$ blood-flow (e.g., from sitting on one's foot). The slowness of anoxic/ischemic rundown times (7Aii inset), together with 7Bii (recoverability) signifies that resting SMFs are well adapted to prolonged deep ischemic bouts (provided bouts end before myotonic firing commences and/or before motorneurons trigger APs).

Bifurcation analysis of SM-CD is congruent with the clinical situation, compartment syndrome, where, a normally-robust system harbours a treacherous threshold. Compartment syndrome describes progressive potentially life-threatening (gangrene) muscle ischemia, usually involving a limb, typically post-trauma. Johnstone and Ball (2019) indicate that "membrane injury and subsequent significant dysfunction is the central factor leading to irreversible $\{\mathrm{SMF}\}$ injury" and emphasize that because SMFs' remarkable tolerance of progressive ischemia ends abruptly, a fundamental requirement for better diagnoses is a means (intramuscular $\mathrm{pH}$, perhaps) of identifying the ischemic threshold.

\section{SM-CD dynamic range: up-regulated pumps and/or down-regulated $\mathbf{P}_{\mathrm{Na}}$}

Intermittently, locomotory, thoracic, vocal, diaphragm and other muscles experience upsurges of ion homeostatic demand. Figure $2 \mathrm{~A}$ showed a realistic hyper-stimulation of $\mathrm{V}$-gated channels. In situ, $\mathrm{Na}^{+}-$ transporters too would need to be supported. As Fraser and Huang (2004) show, use of NKCC, a cationchloride cotransporter, would $\uparrow\left[\mathrm{Na}^{+}\right]_{\mathrm{l}}, \uparrow\left[\mathrm{Cl}^{-}\right]_{\mathrm{i}}, \uparrow \mathrm{Vol}_{\text {cell, }} \downarrow\left[\mathrm{K}^{+}\right]_{\mathrm{i}}$, depolarize $\mathrm{V}_{\mathrm{m}}$ and $\uparrow \mathrm{I}_{\text {pump. }}$. To extend its physiological dynamic range for excitability and transport, SM-CD shows us, a SMF could optimize its ATP consumption as described next.

Embedded in the physiological steady-state $\left[\mathrm{Na}^{+}\right]_{\mathbf{i}}$ continuum, Figure $\mathbf{7 B i}$, is an easily-overlooked $\mathrm{P}-\mathrm{L} / \mathrm{D}$ feature germane to physiological dynamic range. That plot's "boring" flattish region implies that no metabolic penalty is incurred for keeping pump-density chronically up-regulated (i.e., extra-large pumpreserves). Large $\uparrow$ pump-strength has little affect on $\left[\mathrm{Na}^{+}\right]_{\mathrm{i}}$ (Figure 7Bii). Increasing SM-CD pump-strength $100 \rightarrow 200 \%$ (pump-reserve $=11 \rightarrow 22$-fold, a level reported for rat soleus (Clausen 2015)) decreases $\left[\mathrm{Na}^{+}\right]_{\mathrm{i}}$ to $2.9 \mathrm{mM}$ (7Bii), hyperpolarizes $\mathrm{V}_{\text {rest }}$ minimally (7Ai) leaving ATP-consumption at $51.1 \mathrm{amol} / \mathrm{s}$ (Figure 9Bii; $X=2.9 \mathrm{mM}, 200 \%$-curve $\mathrm{Y}$-axis intersect). Figure Sup01A illustrates that pump-reserve $=22$-fold accelerates post-stress-test recovery.

Temperate-climate amphibians and reptiles confront "scheduled" (i.e., seasonal) bouts of extreme ischemia. This requires modulation of excitable cell ion homeostasis (Pérez-Pinzón et al 1992; Donohue et al 2000). A testable prediction emerging from SM-CD is that, prior to entering hibernation, hibernators would increase SMF pump-density. Following the deep super-prolonged ischemic rundown of hibernation, this would expedite springtime recovery. If borne out, regulatory signaling systems could be sought. Another prediction: hibernators would simultaneously reduce $\mathrm{P}_{\mathrm{Na}}$ for reasons outlined next. 
A $\downarrow P_{N a}$ would improve a SMF's dynamic range. Why? Because $\downarrow P_{\text {Na } \rightarrow \downarrow} \downarrow l_{\text {pump. }}$. It also counteracts $\mathrm{Na}^{+}$-cotransporter-induced depolarization. For example, reducing $\mathrm{P}_{\mathrm{Na}}$ from $0.3 \mu \mathrm{m}^{3} / \mathrm{s}$ to $0.22 \mu \mathrm{m}^{3} / \mathrm{s}$ hyperpolarizes SM-CD V rest by $4 \mathrm{mV}$ (to $-90 \mathrm{mV}$; see Figure 10). Because $\downarrow$ [small $\left.I_{\text {Naleak }}\right] \rightarrow \downarrow I_{\text {pump }}$, ATPconsumption drops $\sim 25 \%$ ( $51.1 \mathrm{amol} / \mathrm{s} \rightarrow 38.7 \mathrm{amol} / \mathrm{s})$. This hypothetical change illustrates, yet again, the energetically pivotal role of SMFs' [small $I_{\text {Naleak }}$ ] and hence of their small $P_{\mathrm{Na}}$. Had we picked $-90 \mathrm{mV}$ as $V_{\text {rest }}$ for SM-CD, the SM-CD/CN-CD ATP-consumption comparison would have been 1/7.0 instead of 1/5.3.

\section{SMFs' small $P_{\text {Na }}$ in GHK versus P-L/D settings}

The immense physiological importance of SMFs' small $\mathrm{P}_{\mathrm{Na}}$ has gone largely unrecognized. It is understood that $\mathrm{V}_{\text {rest }}$ depends on $\mathrm{P}_{\mathrm{Na}}: \mathrm{P}_{\mathrm{K}}$. It is understood that $\mathrm{P}_{\mathrm{Na}}$ is the conduit for $\mathrm{I}_{\text {Naleak, }}$, the determinant of $I_{\text {pump }}\left(=-I_{\text {Naleak }}\right)$. It is understood that $P_{\text {Na }}$ thereby establishes the pump's small direct contribution (several millivolts) to $V_{\text {rest }}$ (e.g., Sperelakis 2012). However, in spite of Fraser and Huang (2004)'s thorough exposition, it is under-recognized that for cells performing ion homeostasis (living cells) the zero-current Goldman-Hodgkin-Katz (GHK) equation is an inappropriate $V_{\text {rest }}$ descriptor. This is not biophysical nitpicking.

Decreasing a small $\mathrm{P}_{\mathrm{Na}}$ in a $\mathrm{P}_{\mathrm{K}}>\mathrm{P}_{\mathrm{Na}}$ GHK setting simply renders it increasingly inconsequential, and $P_{K}$ more dominant. By contrast, in a $P-L / D$ setting, as just illustrated for SM-CD, decreasing an alreadysmall $P_{N a}$ has physiologically consequential ramifications: $\downarrow P_{N a} \rightarrow \downarrow A T P$-consumption and $\uparrow$ pumpreserve. And in a transiently anoxic P-L/D system, $\downarrow \mathrm{P}_{\mathrm{Na}} \rightarrow$ slower rundown and then faster recovery.

\section{The unidentified $\mathbf{P}_{\mathrm{Na}}$ of SMFs}

In SMFs, $\mathrm{P}_{\mathrm{Na}}$ (and $\Delta \mathrm{P}_{\mathrm{Na}}$ ) has impressive physiological heft, but what is $\mathrm{P}_{\mathrm{Na}}$ ? Neurons, smooth muscle and pancreatic cells use Na-Leak-Channel-Nonselective (NALCN) as a hormonally-regulated $\mathrm{P}_{\mathrm{Na}}$ (Lu et al 2007; Senatore and Spafford 2013; Cochet-Bissuel et al 2014; Lutas et al 2018; Philippart et al 2018), but to date, NALCN has not been found in SMFs. Identifying the SMF $\mathrm{P}_{\mathrm{Na}}$ and understanding its variability is considered critical in connection with myotonia (Metzger 2020). Persistent Nav channels (Gage et al 1989) might contribute, but since tetrodotoxin does not hyperpolarize $V_{\text {rest }}$ in healthy fibers (e.g., Pickar et al 1991) this seems unlikely. The SMF $P_{N a}$ could, like NALCN, be a cation channel (see Morris et al submitted). SMFs have several identified cation channels (see Metzger et al 2020) plus their routinelydetected unidentified mechanosensitive cation channel (Guharay and Sachs 1984; 1985; not a Piezochannel (Suchyna 2017)). A precedent is worth recalling here: Aplysia neurons' serotonin and arachidonic acid regulated resting $\mathrm{K}^{+}$-channels (Belardetti et al 1986) are adventitiously mechanosensitive (e.g., see Vandorpe et al 1994; Morris and Horn 1991; Methfessel et al 1986; Zhang and Hamill, 2000; Zhang et al 2000; Morris 2012). Likewise for SMF mechanosensitive cation channels, but decades on, they have no attributed function (Lansman 2015; Suchyna 2017). A hypothesis worth pursuing: this cation channel does for SMFs what NALCN does for smooth muscle (e.g. Reinl et al 2018). Jointly, $P_{k}$ and $P_{N a}$ establish $V_{\text {rest. }}$ Another critical and unresolved issue for SMF ion homeostasis, therefore, is whether/how they are jointly modulated (Kuba and Nohmi 1987; Donohue et al 2000; DiFranco et al 2015). Molecular identification of $\mathrm{P}_{\mathrm{Na}}$ in SMFs could empower broad-reaching lines of biological and biomedical inquiry.

\section{DISCUSSION}

\section{lon homeostasis needs Donnan effectors}

Comparative modeling of simple yet reassuringly realistic P-L/D systems here shows that, to serve distinctive electrophysiological lifestyles, SMFs and neurons evolved distinctive ion homeostatic strategies. Neuronal ion homeostasis biophysics was recently explained (Dijkstra et al 2016), but notwithstanding the foundational Fraser and Huang (2004) paper, SMF ion homeostasis mostly gets by- 
passed. For animal cells in general, moreover, the physiological necessity of [Donnan effectors $+\mathrm{P}_{\mathrm{cl}}$ ] for achieving ion homeostasis remains under-appreciated (Dmitriev et al 2019; Kay 2018).

To clarify the integral role of Donnan effectors in ion homeostasis, we outline first principles -set point, sensor/effector feedbacks (Figure 1A)-- in their evolutionary context. This reveals ion homeostasis as a Pump-Leak/Donnan process. We depict "minimal" P-L/D systems at steady-state (Figure 1B), characterizing those P-L/D systems permeable mostly to anions as Donnan dominated, and those permeable mostly to cations as Pump-Leak dominated.

Computationally meshing the Fraser and Huang (2004) SMF model and the more accessible (compare pump descriptors) model of cortical neurons (Dijkstra et al 2017) we generated SM-CD, a minimal Donnan dominated excitable model for a SMF "ion homeostatic unit" (Figure 8A; Tables 1, 2).

Using SM-CD (and variant models) we demonstrate how low duty-cycle, low-excitability syncytial SMFs and more broadly, skeletal muscle, benefits from SMFs' Donnan dominated strategy. The robust [big $P_{c l}$ [small $I_{\text {Naleak }}$ process makes an ion homeostatic/electrophysiologic virtue of the unavoidable "vice" of Donnan effectors. Neurons' Pump-Leak dominated [small $P_{\text {cl] }}$ [big $I_{\text {Naleak }}$ ] strategy, though far costlier and more imperiled by ischemia, is necessary for an information-processing lifestyle. For early vertebrates, the whole-organism contexts (Table 2) for these two strategies would have been an extreme version of the situation for humans: a low-cost Donnan dominated strategy for the body's largest tissue and a costly pump-Leak dominated strategy for the small fractional mass of neurons. Table $\mathbf{3}$ identifies and summarizes quantitatively several of the differences.

\section{lon homeostatic efficiency and SMF morphology}

Even beyond Table 3's list of CN-CD/SM-CD comparisons, ancestral vertebrates would have benefitted enormously from Donnan dominated ion homeostasis. This assertion assumes that then, as now, SMFs were syncytial (mammal SMFs have hundreds to thousands of nuclei (Ganassi et al 2018; for myonuclear domains, see Ross et al 2018). SM-CD and CN-CD have the same $2000 \mu \mathrm{m}^{2}$ surface area (SA) $\left(C_{m}\right)$ and volume (Figure 8A,Bii,Cii). In situ however, SM-CD would not be mononucleate. It would be one of many cross-sectional slices of a "cylindrical" SMF comprised of hundreds to thousands of such slices (Figure 8C,D). By spherical geometry, $2000 \mu \mathrm{m}^{2}$ can fully enclose at most $8419 \mu \mathrm{m}^{3}$, while by cylindrical geometry, the maximal volume encircled by $2000 \mu \mathrm{m}^{2}$ varies inversely with "ring"-width; for example, disposed as a $10 \mu \mathrm{m}$ slice, $2000 \mu \mathrm{m}^{2}$ of sarcolemma (no slack) encircles $\sim 32,000 \mu \mathrm{m}^{3}$ (see Figure 8Di,ii).

Syncytial morphology thus increases the cytoplasmic volume served (ion homeostatically) by a "unit" of sarcolemmal SA. SMFs are usually at steady-state, and crucially, steady-state ATP-consumption is independent of SA/Vol cell. SA/Vol $_{\text {cell }}$ does, however, matter during ionic perturbations: scaling linearly, for fixed-SA, both anoxic rundown times and ion homeostatic recovery times lengthen with $\uparrow \mathrm{Vol}_{\text {cell. }}$ For low duty-cycle SMFs, the advantages conferred by slower rundown would, overall, substantially outweigh any drawbacks of slower recovery.

\section{The SM-CD "ion homeostatic unit" and myonuclear domain volume}

For mouse, data from Harris et al (2005); Mantilla et al (2008); Egner et al (2016) indicate: SMF radius $\sim 15-30 \mu \mathrm{m}$, myonuclear density $\sim 50 / \mathrm{mm}$, myonuclear domain volume $15,000-30,000 \mu \mathrm{m}^{3}$. For mouse SMFs, SM-CD's $2000 \mu \mathrm{m}^{2}$ "ion homeostatic unit" would encircle more myoplasmic volume than depicted in Figure 8Bii. If mouse SMF nuclear density is $\sim 1$ nucleus $/ 20 \mu \mathrm{m}$ ( $\sim 50$ nuclei/mm $\rightarrow \sim 0.5$ nucleus $(10 \mu \mathrm{m})$, a plausible "volume-corrected" SM-CD would be a $20 \mu \mathrm{m}$ slice of $15 \mu \mathrm{m}$ radius. If it had $\mathrm{SA}=1885 \mu \mathrm{m}^{2}$ plus a slack $115 \mu \mathrm{m}^{2}$ for passive tension-buffering (1.06-fold swelling) that would be 2000 $\mu \mathrm{m}^{2}$ encircling 14,137 $\mu \mathrm{m}^{3}$. (Sarcolemma's dynamic tension-buffering (Sinha et al 2011; Lo et al 2016; Morris 2018) is not modeled here). A SM-CD unit such as this would be serving 1 myonuclear domain.

The $2000 \mu \mathrm{m}^{2}$ "ion homeostatic unit" of SM-CD was picked with no consideration of myonuclear domain volume, but in retrospect, it is reasonable that a roughly comparable unit of SA would serve (and 
be serviced by) one nucleus in both neurons and SMFs. For neurons, one nucleus serves soma, dendrites and axon, except when neurons become "giants" and either massively amplify their DNA-content in one nucleus (Lasek and Dower 1971) or become multinucleate (Mackie 1990).

Thus for these radically different cytomorphologies, the SA value taken from neurons to facilitate inter-model ion-flux comparisons seems roughly appropriate to associate with one myonucleus, but this remains a speculation; myonuclear domain volumes are routinely reported (e.g. Schwartz et al 2016) for SMFs, but we found no data on sarcolemmal-SA per myonuclear domain.

\section{Switching off excitability for SM-CD robustness}

An elevated risk accompanies the energetic benefits of syncytial morphology: loss of thousands of nuclei from one sarcolemmal tear. SMFs mitigate this danger via impressively reliable repair mechanisms (Andrews et al 2014; Barthélémy et al 2018; Manoharan et al 2019). Almost certainly the large pump-reserve facilitated by SMFs' Donnan dominated strategy would be critical for re-establishing ion gradients post-tear. Imperative too would be diminished excitability. Whereas inexcitable SM*-CD recovers fully after $>250$ minutes of anoxic-rundown, at 25 minutes, excitable SM-CD having fired ectopically has swollen catastrophically. In the contexts of both ischemia and sarcolemmal tearing ( McElhanon and Bhattacharya 2018; Hotfiel 2018), entry of Nav1.4 channels into slow-inactivated states (Webb et al 2009) needs to be studied.

\section{P-L/D steady-states for real cells}

"Set point" for ion homeostatic systems is a particular collection of steady-state values $\left\{\left.V_{\text {ol }}\right|_{\text {cell, }}, V_{m}\right.$, [ion $\left.]_{i}\right\}$ (Figure 1A). "Set point" may sound like a system "goal", but we reiterate, deviations from "set point" values are not what is sensed operationally in a perturbed P-L/D system; the $\left\{V_{\text {ol }} \mathrm{l}_{\text {cell, }} \mathrm{V}_{\mathrm{m}}\right.$, [ion] $\}$ valueset is the CONSEQUENCE, not "the goal" of the P-L/D system's feedback processes.

Clarity here makes it easier to see how, in large real cells (unlike in models) non-negligible distances and real diffusion times will yield "fuzzy" steady-state value-sets without abrogating the P-L/D concepts. Consider a quiescent $5 \mathrm{~cm}$ sartorius SMF or a $50 \mathrm{~cm}$ motorneuron. There is ad libitum ATP, axial resistance, and the densities of leak-channels and pumps are inhomogenous. All along the cell, the P-L/D systems' two sensor/effector mechanisms (Figure 1A) are continually sensing/effecting. According

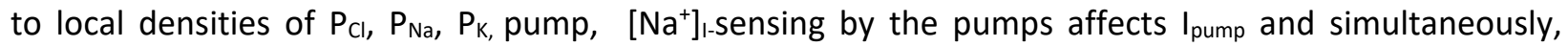
deviations from osmo-balance and compartment neutrality are stochastically/electrostatically sensed/countered via passive $\mathrm{H}_{2} \mathrm{O}$ and $\mathrm{Cl}^{-}$fluxes. At, say, the axon terminal, " $\mathrm{V}_{\text {rest" }}$ " will likely differ from " $\mathrm{V}_{\text {rest }}$ " $50 \mathrm{~cm}$ away at the soma. Thus, at steady-state there would be standing [ion], gradients and steadystate axial currents. In quiescent SMFs, with their endplate specializations and extensive t-tubular invaginations contiguous with the sarcolemma (Pedersen at al 2001; Fraser et al 2011), true steady-state will likewise be spatially inhomogeneous. Rhythmically-active excitable cells' ion homeostatic steadystates are limit cycles (see Cha and Noma, 2012); thus, P-L/D set points can also be inhomogeneous in the temporal domain.

\section{Excitable cells and P-L/D biotechnology}

Symmorphosis (Fogarty and Sieck 2019), the evolutionary concept of economy of biological design, predicts that structural properties will be matched to functional demands. To analyze excitable cell ion homeostasis via a comparable conceptual filter, an ideal case would be the electric fish Electrophorus electricus (Gallant et al 2014; Catania 2015, 2019), given its low-duty-cycle syncytial SMFs and (derived evolutionarily from them) 3 subclasses of high-duty-cycle syncytial electrocytes (Traeger et al 2017). Available molecular (e.g., Nav channels, Kv, pumps) and morphological data for both cell types (Ching et al 2015, 2016; Thornhill et al 2003; Schwartz et al 1975; Marchado et al 1983) could be 
augmented with comparative proteomics (e.g., how much if any ClC-1 is expressed in electrocytes?). Molecular evolution data are available for $\mathrm{O}_{2}$-delivery (globin-dependent) to SMFs and the electrocyte sub-classes (Tian et al 2017). Questions of ion homeostatic design economy/robustness/agility are intriguing from the perspective of evolutionary biology, and also increasingly, in the context of creative new biomimetic ventures such as the bioinspired engineering of "soft power sources" (Schroeder et al 2017) and the development of optogenetic skeletal muscle bioactuators and resilient self-healing musclemachine interfaces (Raman et al 2016, 2017, 2019).

\section{Prospects}

Recently-developed cell-physiological techniques (Heiny et al 2019; DiFranco et al 2019) could make it possible to obtain concurrent SMF [ion $]_{i}$ data (plus $V_{m}(t)$ ) along the lines of Figure $2 A$, while for whole tissue in humans, MRI advances are allowing for the non-invasive probing of ion homeostatic parameters in healthy, injured and diseased subjects (e.g., Hammon et al 2015; Dahlmann et al 2016, Gerhalter et al 2017, 2019; Zhang et al 2020). The accessible theoretical framework process presented here for SMF ion homeostasis as a P-L/D process should help guide investigative directions and facilitate interpretation of new data streams.

Though SM-CD is radically simple, adding and modifying components as appropriate is entirely feasible. A little-exploited but thoroughly rigorous cardiomyocyte CD-approach model (Cha and Noma 2012) demonstrates that even with a plethora of channels, transporters, compartments and binding reactions, a properly-designed CD-approach model will converge on steady-state. But, even in its present minimal state, SM-CD has provided comparative physiological insight relevant to vertebrate evolution. It also helps explain how the ischemic membrane-damaged SMFs of DMD patients can survive for decades (Morris et al submitted). Given appropriate refinements, SM-CD modeling should be helpful in connection with muscle fatigue, endurance, trauma, volume regulation, ischemia-reperfusion injury, ion channelopathies, hibernation, cold tolerance, sarcopenia and more (e.g., Donohue et al 2000; Lindinger et al 2011; dePaoli et al 2013; Yu et al 2013; Clausen 2015; Ammar et al 2015; Bækgaard Nielsen et al 2017; Boërio et al 2018; Hostrup and Bangsbo 2017; Hotfiel et al 2018; Cannon 2018; Copithorne and Rice 2019; Li et al 2020; Metzger et al 2020; Altamura et al 2020; Surkar et al 2020; Thoma et al 2020).

\section{METHODS}

\section{A Pump-Leak/Donnan (P-L/D) model for SMFs}

Skeletal muscle fiber (SMF) ion homeostasis is modeled (SM-CD) by a single compartment limited by a semipermeable membrane in an "infinite" (fixed concentrations) extracellular volume (Figure 8, Table 2). SM-CD constitutes a single P-L/D "ion homeostatic unit"; an actual multinucleate SMF would be comprised of hundreds or even thousands of such units (depending on sarcolemma area; see Figure Meth 01C,D) would likely have a smaller SA/V (surface area to volume) ratio than SM-CD (thus, slower $\Delta[\text { ion }]_{i}$ dynamics). The SM-CD membrane encloses a fixed quantity of Donnan effectors: $A^{-}$ , impermeant monovalent anions. The extracellular medium has a small fixed $A^{-}$concentration. The membrane is permeable to $\mathrm{Na}^{+}, \mathrm{K}^{+}$, and $\mathrm{Cl}^{-}$, ions whose extracellular concentrations are fixed. $\mathrm{SM}-\mathrm{CD}$ has the same physical characteristics as the Dijkstra et al (2016) neuronal cell, CN-CD (see Table 2): a

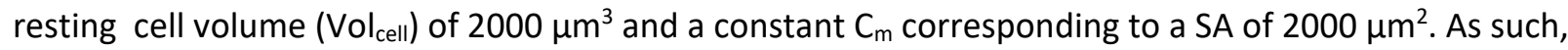
resting state cells are flaccid, i.e., not maximally inflated (Figure 8 ). Lipid bilayers tolerate little lateral expansion, but unless a model-cell inflated to spherical its membrane would not be subject to tension and rupture. The permeation pathways of SM-CD and CN-CD (given below) include "resting leak 
conductances" (i.e., permeation pathways) for $I_{\mathrm{Na}^{+}}^{L} I_{\mathrm{K}^{+}}^{L}$, and $I_{\mathrm{Cl}^{-}}^{L}$ and voltage-gated conductances (permeation pathways) for a transient sodium current, $I_{\mathrm{Na}^{+}}^{T}$, for delayed rectifier potassium current, $I_{K^{+}}^{D}$, and (CN-CD only) a voltage-dependent chloride current, $I_{\mathrm{Cl}^{-}}^{G}$. Driving forces acting on ions are, in all cases, electrodiffusive, as depicted by Goldman Hodgkin Katz (GHK) current equations (Hille, 2001). The same $3 \mathrm{Na}^{+}{ }_{\text {out }} / 2 \mathrm{~K}^{+}$in ATPase pump model (Hamada et al 2003) is used throughout. It produces hyperpolarizing current

$$
I_{\text {pump }}^{N a^{+}}=3 I_{\text {pump }}=-\frac{3}{2} I_{\text {pump }}^{K^{+}},
$$

in response to the intracellular $\left[\mathrm{Na}^{+}\right]$(as per Figure 9). In $\mathrm{CN}-\mathrm{CD}$ only there is a $\mathrm{K}^{+} / \mathrm{Cl}^{-}$co-transporter for ion flow, $J_{K a}$.

Since animal cells cannot sustain osmotic pressures, intra/extracellular osmolyte concentration inequalities produce a $\mathrm{H}_{2} \mathrm{O}$ flow till osmotic balance is restored; this results in Vol cell changes at rates set by the smaller of the two components giving rise, at any time, to osmotic loading, i.e. to net $\left[\mathrm{Na}^{+}+\mathrm{Cl}^{-}\right]$ entry.

\section{Choice of leak permeabilities}

Whereas CN-CD is precisely the Dijkstra et al (2016) model, the SMF version (SM-CD) has a leak permeability ratio $P_{\mathrm{Na}^{+}}^{L}: P_{K^{+}}^{L}: P_{\mathrm{C}^{-}}^{L}$ broadly consistent with Fraser and Huang (2004); for more detail see Setting $\mathbf{V}_{\mathrm{m}}$ below.

\section{GHK driving forces}

Currents through open channels (permeability pathways), ion-specific or not, are modeled with the GHK formulation (Hille, 2001). For ion $\mathrm{X}=\mathrm{Na}^{+}, \mathrm{K}^{+}$, or $\mathrm{Cl}^{-}$, the $\mathrm{GHK}$ current is given by:

$$
I_{G H K}\left(X, P_{X}, V\right)=P_{X}\left(z_{X} F\right) \frac{z_{X} F V}{R T} \frac{[X]_{i}-[X]_{e} \exp \left(-\frac{z_{X} F V}{R T}\right)}{1-\exp \left(-\frac{z_{X} F V}{R T}\right)},
$$

where $P_{X}$ is the permeability, $z_{X}$ the valence, and $[X]_{i}$ and $[X]_{\mathrm{e}}$ the intra- and extra-cellular concentrations of $X$ respectively.

\section{Leak currents}

"Leak" permeability mechanisms use the GHK formulation:

$$
I_{X}^{L}=I_{G H K}\left(X, P_{X}^{L}, V\right),
$$

where $X$ is either $\mathrm{Na}^{+}, \mathrm{K}^{+}$or $\mathrm{Cl}^{-}$. Leak permeability $\left(P_{X}^{L}\right)$ values were adjusted for model variants used here (Table 2 ) in the context of appropriate setting of $V_{\text {rest. }}$

\section{Cation channel currents}

For non-selective cation channels, we use a $P_{\mathrm{K}}: P_{\mathrm{Na}}$ ratio of 1:1.11 and the formulation:

$$
I_{\text {CatLeak }}(t)=I_{G H K}\left(N a^{+}, P_{N a^{+}}^{\text {CatLeak }}, V\right)+I_{G H K}\left(K^{+}, P_{K^{+}}^{\text {CatLeak }}, V\right) \text {. }
$$


In the present models, cation channel leaks do not contribute to healthy steady-states - they are either transient stimulatory currents through SMF-endplate type AChR channels, or pathological leaks (hence "leaky" cation channels).

\section{Transient voltage-gated $\mathrm{Na}^{+}$current}

$$
I_{N a^{+}}^{T}=m^{3} h I_{G H K}\left(N a^{+}, P_{N a^{+}}^{T}, V\right) .
$$

$P_{\mathrm{Na}^{+}}^{T}$ is the maximal membrane permeability to $\mathrm{Na}^{+}$through a V-gated channel (operating in a HodgkinHuxley $\left(\mathrm{H}-\mathrm{H}\right.$ ) fashion). $m$ is the $\mathrm{H}-\mathrm{H} \mathrm{Na}^{+}$channel activation/deactivation gating variable and $h$ is the $\mathrm{H}-$ $\mathrm{H} \mathrm{Na}^{+}$channel inactivation/recovery gating variable. The current's driving force also follows the GHK form of Equation 1.

\section{Delayed rectifier $\mathrm{K}^{+}$current}

$$
I_{K^{+}}^{D}=n^{2} I_{G H K}\left(K^{+}, P_{K^{+}}^{D}, V\right) .
$$

$P_{K^{+}}^{D}$ is the maximal membrane permeability of $\mathrm{K}^{+}$through a V-gated channel (operating in a $\mathrm{H}-\mathrm{H}$ fashion). $n$ is the delayed rectifier $\mathrm{K}^{+}$channel activation/deactivation gate variable.

\section{Voltage-dependent gating}

The non-dimensional gating parameters $m, h, n$ evolve in time according to:

$$
\frac{d q}{d t}=\alpha_{q}(V)(1-q)-\beta_{q}(V) q,
$$

where $q \in\{m, h, n\}$ are as defined above, and the voltage dependent $\alpha_{\mathrm{q}}(V)$ and $\beta_{\mathrm{q}}(V)$ refer, for $m$ and $n$ to gate activation and deactivation and, for $h$ to inactivation and recovery from inactivation. Table 4 gives the voltage dependences for the relevant rate constants.

\section{Voltage-dependent $\mathrm{Cl}^{-}$current}

The SLC26A11 ion exchanger based voltage-dependent $\mathrm{Cl}^{-}$conductance (Rungta et al, 2015) is as described by Dijkstra et al (2016):

$$
I_{C l^{-}}^{S L C}=\frac{I_{G H K}\left(C l^{-}, P_{C l^{-}}^{S L C}, V\right)}{1+\exp \left(-\frac{V+10 \mathrm{mV}}{10 \mathrm{mV}}\right)} .
$$

Except in $\mathrm{CN}-\mathrm{CD}$ and $\mathrm{MN}-\mathrm{CD}$, this pathological cortical neuron specific conductance is set at zero.

\section{$\underline{\mathrm{K}^{+} / \mathrm{Cl}^{-} \text {cotransporter }}$}

This cotransporter (strength $U_{K C I}$ ) is present only in $\mathrm{CN}-\mathrm{CD}$ (it is not evident in skeletal muscle; Pedersen et al 2016) where (as per Dijkstra et al 2016) it is given by

$$
J_{K C l}=U_{K C l} \frac{R T}{F} \ln \left(\frac{\left[\mathrm{K}^{+}\right]_{i}\left[\mathrm{Cl}^{-}\right]_{i}}{\left[\mathrm{~K}^{+}\right]_{e}\left[\mathrm{Cl}^{-}\right]_{e}}\right)
$$

(except that there is an error in the log term of Eq. (6) in Dijkstra et al 2016). 


\section{$3 \mathrm{Na}^{+} / 2 \mathrm{~K}^{+}$ATPase pump current}

The electrogenic $3 \mathrm{Na}^{+}$(out) $/ 2 \mathrm{~K}^{+}$(in) ATPase modeled here is that of Hamada et al (2003):

$$
\frac{I_{\text {pump }}}{Q_{\text {pump }}}=\frac{0.62}{1+\left(\frac{6.7 \mathrm{mM}}{\left[N a^{+}\right]_{i}}\right)^{3}}+\frac{0.38}{1+\left(\frac{67.6 \mathrm{mM}}{\left[N a^{+}\right]_{i}}\right)^{3}},
$$

where

$$
\begin{aligned}
I_{\text {pump }}=I_{\text {pump }}^{N a^{+}}+I_{\text {pump }}^{K^{+}} \text {or } \\
I_{\text {pump }}=\frac{1}{3} I_{\text {pump }}^{N a^{+}}=-\frac{1}{2} I_{\text {pump }}^{K^{+}} .
\end{aligned}
$$

Thus $I_{\text {pump }}$ signifies a net hyperpolarizing $\mathrm{Na}^{+}$outflow. The Hamada et al (2003) formulation (Figure 9) is appropriate for models that assume an invariant extracellular medium. It depicts the pump's two intracellular $\mathrm{Na}^{+}$-binding sites (with 10-fold different affinities) but has no term for the extracellular $\mathrm{K}^{+}$binding site. Here, pump-strength $\left(Q_{\text {pump }}\right)$ is varied in many computations (e.g., it is set to zero to depict anoxia, diminished towards zero to depict ischemia and multiplied for up-regulation).

\section{ATP-Consumption}

ATP-consumption by the $\mathrm{Na}^{+} / \mathrm{K}^{+}$ATPase pump in the all the $\mathrm{CD}$ models is given as

$$
A T P / s=\frac{I_{\text {pump }}}{e N_{A}}
$$

where $e$ is the electronic charge $\left(1.6 \times 10^{-19} \mathrm{Coul}\right)$ and $N_{A}$ is the Avogadro number. In other words, I pump of $1 \mathrm{pA}$ is equivalent to an ATP-consumption of $10.38 \mathrm{amol} / \mathrm{s}$.

\section{Cell Volume}

Cellular swelling is driven by an influx of water at rates that depend on the transmembrane osmotic gradient. The rate of change of cell volume, Volcell, due to water influx is given by:

$$
\frac{\mathrm{dVol}}{\mathrm{d} t}=J_{\mathrm{H}_{2} \mathrm{O}}=L_{\mathrm{H}_{2} \mathrm{O}} \Delta \pi
$$

where $\Delta \pi=R T\left([S]_{i}-[S]_{e}\right)$, and $[S]_{i}$ and $[S]_{e}$ denote total concentrations of intra- and extracellular solutes and $L_{\mathrm{H}_{2} \mathrm{O}}$ is the effective membrane water permeability. This equilibration is typically assumed to be nearly instantaneous relative to the ion flows (Fraser and Huang, 2004; Dijkstra et al 2016; Kay, 2017; though see also Dmitriev et al 2019). Accordingly, in modeling here, osmotic ion fluxes, not the $\mathrm{H}_{2} \mathrm{O}$ fluxes what limit the rate of osmotic swelling or shrinkage.

\section{Nernst potentials}

The equilibrium potential (Nernst potential) for each ion

$$
E_{x}=-\frac{z_{x} R T}{F} \log \left(\frac{[X]_{i}}{[X]_{e}}\right),
$$

where $X$ is either $\mathrm{Na}^{+}, \mathrm{K}^{+}$, or $\mathrm{Cl}^{-}$ions and $Z_{X}$ is the valence of each ion. 


\section{Charge difference and membrane potential}

Because CD models keep track of the absolute number of ions flowing across the cell membrane (of capacitance $C_{m}$ ) no differential equation is needed for $V_{m}$. Instead, an accounting equation is used, made simple because the extracellular space is kept neutral:

$$
V_{m}=\frac{F}{C_{m}}\left(N_{i}^{N a^{+}}+N_{i}^{K^{+}}-N_{i}^{C l^{-}}-N_{i}^{A^{-}}\right)=\frac{F}{C_{m}}\left(d N_{\mathrm{Na}^{+}}+d N_{K^{+}}-d N_{\mathrm{Cl}^{-}}-d N_{A^{-}}\right),
$$

where $d N_{X}=N_{i}^{X}-N_{i, 0}^{X}$ is the difference in the number of ions of species $x$, between its present value $N_{i}^{X}$ and a reference value $N_{i, 0}^{X}$. The reference values are those yielding $V_{m}=0 \mathrm{~V}$, which is

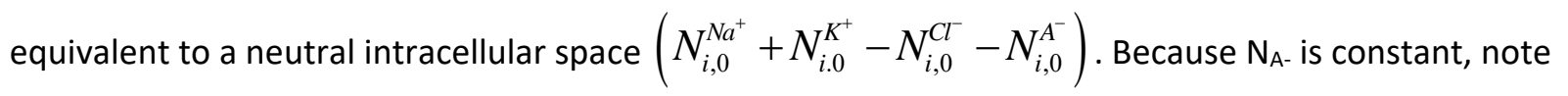
that $d N_{A^{-}}=0$ in Equation 15. Number differences, $d N_{x^{\prime}}$, are easier to work with than total numbers of ions $N_{x}$ (or than concentrations). For typical cell $\mathrm{C}_{\mathrm{m}}$ values, voltages in the $\mathrm{mV}$ range correspond to net intracellular charge differences (measured as a number of singly charged ions) of the order of attomoles $\left(10^{-18} \mathrm{moles}\right)$. For instance, when $V_{m}$ varies in the range $[-100 \mathrm{mV}, 100 \mathrm{mV}]$ this corresponds to a change in net singly charged ions of $[-20.7,+20.7]$ amol. With our $V o l_{\text {cell }}=2000 \mu \mathrm{m}^{3}$, this yields tiny concentration changes $[-0.01,0.01] \mathrm{mM}$. For solutions whose concentrations are in the 1-100 mM range, there could be 4-5 orders of magnitude difference between steady-state values and the changes (in the 0.0001 to $0.01 \mathrm{mM}$ range). Computations based on concentrations, therefore, tend to be unstable. For this reason, calculations in this study are based on changes in ion numbers (in amol units).

\section{Number of intracellular ions}

CD models account for the change in intracellular ions at any given moment (Fraser et al 2004; Dijkstra et al 2016), via the following simple relationships of the respective currents:

$$
\begin{gathered}
\frac{\mathrm{d} N_{\mathrm{Na}^{+}}}{\mathrm{d} t}=-\frac{1}{F}\left(I_{\mathrm{Na}^{+}}^{T}+I_{\mathrm{Na}^{+}}^{L}+3 I_{\text {pump }}\right) \\
\frac{\mathrm{d} N_{K^{+}}}{\mathrm{d} t}=-\frac{1}{F}\left(I_{K^{+}}^{D}+I_{K^{+}}^{L}-2 I_{\text {pump }}\right)-J_{K C l} \\
\frac{\mathrm{d} N_{C l^{-}}}{\mathrm{d} t}=\frac{1}{F}\left(I_{C l^{-}}^{G}+I_{C l^{-}}^{L}\right)-J_{K C l}
\end{gathered}
$$

\section{Setting $\mathrm{V}_{\text {rest }}$ in SM-CD and other CD models}

Experimentally, excitable cells' $V_{\text {rest }}$ (i.e., steady-state $V_{m}$ ) values are generally more accessible than cytoplasmic ion concentrations or cell volume, making it useful to anchor a model with a consensus $V_{\text {rest }}$ value. For $S M-C D$, we chose $V_{\text {rest }}=-86$, with parameter determinants established in an iterative process as follows: first, a number is chosen for impermeant anions $N_{i, 0}^{A^{-}}$, consistent with the system's total cation concentration (as per the extracellular solution). We started with the CN-CD value, knowing that fine-tuning would be needed to meet our (self-imposed) requirement that SM-CD have the same 
resting Volcell as CN-CD. Thus, note in Table 2 the slightly different $N_{i, 0}^{A^{-}}$for CN-CD and SM-CD (likewise, LA-CD and SM-CD, to give identical resting Vol $\mathrm{Cell}_{\text {). }}$.

At rest, $\mathrm{Na}^{+}$and $\mathrm{K}^{+}$leak currents (for a system with a given pump-strength), must precisely balance. In other words, $V_{m}$ converges (along with ion concentrations and $\left.V_{\text {olll }}\right)$ on steady-state $\left(=V_{\text {rest }}\right.$ ) when

$$
\begin{aligned}
& \text { passive } \mathrm{Na}^{+} \text {influx }+ \text { active } \mathrm{Na}^{+} \text {outpump = zero } \\
& \text { AND } \\
& \text { passive } \mathrm{K}^{+} \text {efflux }+ \text { active } \mathrm{K}^{+} \text {inpump = zero. }
\end{aligned}
$$

For the $3 \mathrm{Na}^{+} / 2 \mathrm{~K}^{+}$ATPase pump current, this requirement is met when:

$$
I_{\text {pump }}^{\mathrm{Na}^{+}}=-I_{N a^{+}}^{L}=-\frac{3}{2} I_{\text {pump }}^{K^{+}}=-\frac{3}{2}\left(-I_{K^{+}}^{L}\right)
$$

For $\mathrm{P}$-L/D systems with a given pump-strength, $V_{\text {rest }}$ varies monotonically with $\mathrm{P}_{\mathrm{Na}}: \mathrm{P}_{\mathrm{K}}$ ratio; low ratios yield hyperpolarized $V_{\text {rest }}$ values, high ratios, depolarized ones (Figure 10). $\quad V_{\text {rest }}=-86 \mathrm{mV}$ for SM$C D$ requires $P_{N a}: P_{K}=0.03: 1$ (likewise for $W D-C D$ ). Absolute values for $P_{N a}$ and $P_{K}$, and for $P_{C l}$ (Table 2) were guided by the $P_{N_{2}}: P_{K}: P_{C I}$ ratio (0.02: 1: 3) reported for amphibian skeletal muscle (Fraser and Huang 2004). For absolute $P$ values, a straightforward constraint was the choice to give SM-CM the same area $\left(\mathrm{C}_{\mathrm{m}}\right)$ as $\mathrm{CN}-\mathrm{CD}$.

As per Equation 16, a pump stoichiometry other than $3 \mathrm{Na}^{+}$out $/ 2 \mathrm{~K}^{+}$in would, all else being equal, alter $\mathrm{V}_{\text {rest. }}$ Pump stoichiometry is invariant here, but see Dmitriev et al (2019).

\section{Excitability and safety factor for SM-CD}

For SM-CD to be hyperpolarized and appropriately excitable (i.e. "relatively inexcitable"), its input impedance had to be a) notably less than for $\mathrm{CN}-\mathrm{CD}$ and b) predominantly $\mathrm{P}_{\mathrm{cl}}$-based (Pedersen et al 2016). With resting-P values set, the need to trigger spikes near $-60 \mathrm{mV}$ (Fu et al 2011) with a reasonable-sized safety factor (Ruff 2011) had to be met. To achieve safety factor $\sim 1.5$, Nav and Kv "densities" in SM-CD were set at $3 \mathrm{X}$ the $\mathrm{CN}-\mathrm{CD}$ level (a larger $\mathrm{P}_{\mathrm{Cl}}$ would have required even greater Vgated channel densities). Thus, absolute $\mathrm{P}_{\mathrm{Cl}}, \mathrm{P}_{\mathrm{Na}}$ and $\mathrm{P}_{\mathrm{K}}$ values of $\mathrm{SM}-\mathrm{CD}$ are biologically appropriate, but leave room for physiological modulation (to, say, alter $\mathrm{V}_{\text {rest }}$ via $\Delta \mathrm{P}_{\mathrm{Na}}$ or $\Delta \mathrm{P}_{\mathrm{K}}$, or to modulate excitability by $\left.\Delta \mathrm{P}_{\mathrm{cl}}\right)$.

Table 2 shows that $\mathrm{m}^{3} \mathrm{~h}$ is vanishingly small at $\mathrm{V}_{\text {rest }}$ in $\mathrm{SM}-\mathrm{CD}$; for $\mathrm{CN}-\mathrm{CD}$ it adds an extremely small Nav channel contribution to the operational value of $P_{N a}$ that negligibly affects $V_{\text {rest. }}$.

\section{Cytoplasmic Donnan effectors}

Once $V_{\text {rest }}$ is set via $P_{\mathrm{Na}}$ and $P_{\mathrm{K}}$, the intracellular anion concentrations are determined uniquely for the resting state. If $\mathrm{Cl}^{-}$transport is purely passive (i.e., no involvement of secondary transport) as in $\mathrm{SM}-\mathrm{CD}$, then $\mathrm{E}_{\mathrm{Cl}}=\mathrm{V}_{\text {rest }}$ and therefore:

$$
\left[\mathrm{Cl}^{-}\right]_{i}=\left[\mathrm{Cl}^{-}\right]_{e} \exp \left(\frac{F V_{\text {rest }}}{R T}\right) .
$$

$\left[\mathrm{A}^{-}\right]_{\mathrm{i}}$ then follows from the voltage and osmotic balance requirements.

The voltage requirement yields:

$$
\left[\mathrm{Na}^{+}\right]_{i}+\left[\mathrm{K}^{+}\right]_{i}-\left[\mathrm{Cl}^{-}\right]_{i}-\left[\mathrm{A}^{-}\right]_{i}=-\Delta c
$$

where $\Delta c$ is the tiny excess concentration of anions associated with $V_{\text {rest }}$ and equal to [intracellular anions]-[intracellular cations]: 


$$
\Delta c=-V_{\text {rest }} C_{m} / F V_{\text {cell }} \text {. }
$$

$\Delta \mathrm{c}=0.00886 \mathrm{mM}$ for $V_{\text {rest }}=-86 \mathrm{mV}$. And the osmotic equilibrium condition is:

$$
\left[\mathrm{Na}^{+}\right]_{i}+\left[\mathrm{K}^{+}\right]_{i}+\left[\mathrm{Cl}^{-}\right]_{i}+\left[\mathrm{A}^{-}\right]_{i}=[S]_{i}=[S]_{e},
$$

where $[S]_{1}$ and $[S]_{e}$ are defined below Equation 13. Equations 21 and 23 yield:

$$
\left[A^{-}\right]_{i}=1 / 2\left([S]_{i}+\Delta C\right)-\left[C l^{-}\right]_{i} \text {. }
$$

A P-L/D model-cell's design for steady-state imposes its $\left[\mathrm{A}^{-}\right]_{\mathrm{i}}$. Cell volume adjusts to reflect that constraint $\mathrm{Vol}_{\text {cell }}=N_{i}^{A^{-}} /\left[A^{-}\right]_{i}$. As mentioned above, SM-CD's $N_{i}^{A^{-}}$was set to give resting $\mathrm{Vol}_{\text {cell }}=2000$ $\mu \mathrm{m}^{3}$, i.e. $N_{i}^{A^{-}}=\left[A^{-}\right]_{i} V o l_{\text {cell }}$. Here, the quantity of impermeant anions $N_{i}^{A^{-}}$is invariant, but for many in vivo circumstances, it would vary, and variations in $\mathrm{Vol}_{\text {cell }}$ would be expected in such cases.

\section{Instantaneous perturbations}

Experimental solution changes (e.g., as in brain slice experiments) typically require finite "washin/wash-out" times. Dijkstra et al (2016) mimicked such solution changes (affecting pump rates and channel gating etc) but here, doing so would have unnecessarily obscured mechanistic underpinnings of responses. Thus, pump-off (anoxia) and pump-on (restoration of pump-strength) changes and channel gating changes (Nav and cation channels open probabilities) are instantaneous.

\section{Maximum cell volume before lysis}

Both CN-CD and SM-CD have $C_{m}=20 p F$ and steady-state $V_{\text {ol }} I_{\text {cell }}=2000 \mu \mathrm{m}^{3}$. If $0.01 \mathrm{~F} / \mathrm{m}^{2}(=0.01$ $\mathrm{pF} / \mu \mathrm{m}^{2}$ ) is the specific capacitance of the bilayer, membrane area is $20 / 0.01=2000 \mu \mathrm{m}^{2}$. With $4 / 3 \pi R^{3}$ the volume of a spherical cell and $4 \pi R^{2}$ its surface area, maximum Volcell as the cell swells (to spherical) would be $=4 / 3 \pi(2000 / 4 \pi)^{3 / 2}=8410.4 \mu \mathrm{m}^{3}$. Given a $4 \%$ bilayer elasticity strain limit (yielding membrane area $=2080 \mu \mathrm{m}^{2}$ ), rupture would occur at $8920 \mu \mathrm{m}^{3}$. Thus, in bifurcation plots, the notional Donnan Equilibrium (DE) values indicated for reference, are unachievable by these models. Note too that present models depict neither surface area regulation nor membrane tension homeostasis (see Morris 2018).

\section{Excitatory post-synaptic current (EPSC) via AChR channels}

SM-CD action potentials are initiated by EPSCs, i.e. macroscopic end-plate currents through (acetylcholine receptors) AChRs, which are non-selective cation channels that pass $\mathrm{Na}^{+}$and $\mathrm{K}^{+}$as per the GHK formalism. The EPSC time course mimics the $g(t)$ reported in Wang et al (2004)(see Figure 1A top). As reported in Hille (2001), $P_{K^{+}}^{E P S C}=1.11 P_{\mathrm{Na}^{+}}^{E P S C}$. The function $g(t)$ has a maximum of 1 and $P_{\mathrm{Na}^{+}}^{E P S C}$ has a 1.5-fold safety factor (i.e., an amplitude adjusted to $1.5 \mathrm{X}$ the threshold required to elicit an AP in SMCD).

The end-plate current is:

$$
I_{E P S C}(t)=g(t)\left(I_{G H K}\left(N a^{+}, P_{N a^{+}}^{E P S C}, V\right)+I_{G H K}\left(K^{+}, P_{K^{+}}^{E P S C}, V\right)\right)
$$

\section{Computational methods}

Calculations involved solving sets of first order differential equations. These were done using Python with the ordinary differential equation solver odeint. 
bioRxiv preprint doi: https://doi.org/10.1101/2020.11.20.391813; this version posted November 20, 2020. The copyright holder for this preprint

(which was not certified by peer review) is the author/funder, who has granted bioRxiv a license to display the preprint in perpetuity. It is made available under aCC-BY-NC-ND 4.0 International license.

\section{ACKNOWLEDGEMENTS}

We acknowledge financial support from Natural Sciences and Engineering Council (Canada) (BJ and JJW) and support from the Ottawa Health Research Institute (CEM).

\section{COMPETING INTERESTS}

There are no competing interests. 


\section{REFERENCES}

Allen DG, Whitehead NP, Froehner SC. 2016. Absence of dystrophin disrupts skeletal muscle signaling: Roles of Ca ${ }^{2+}$, reactive oxygen species, and nitric oxide in the development of muscular dystrophy. Physiol Rev. 96:253-305. doi: 10.1152/physrev.00007.2015

Altamura C, Desaphy JF, Conte D, De Luca A, Imbrici P. 2020. Skeletal muscle CIC-1 chloride channels in health and diseases. Pflugers Arch: European Journal of Physiology 472:961-975. doi: 10.1007/s00424-020-02376-3

Ammar T, Lin W, Higgins A, Hayward LJ, Renaud JM. 2015. Understanding the physiology of the asymptomatic diaphragm of the M1592V hyperkalemic periodic paralysis mouse. J Gen Physiol. 146:509-525. doi: 10.1085/jgp.201511476

Andrews NW, Almeida PE, Corrotte M. 2014. Damage control: cellular mechanisms of plasma membrane repair. Trends Cell Biol. 24:734-742. doi:10.1016/j.tcb.2014.07.008

Bækgaard Nielsen O, de Paoli FV, Riisager A, Pedersen TH. 2017. Chloride channels take center stage in acute regulation of excitability in skeletal muscle: implications for fatigue. Physiology (Bethesda). 32:425-434. doi: 10.1152/physiol.00006.2015

Barthélémy F, Defour A, Lévy N, Krahn M, Bartoli M. 2018. Muscle cells fix breaches by orchestrating a membrane repair ballet. J Neuromuscul Dis. 5:21-28. doi: 10.3233/JND-170251

Belardetti F, Schacher S, Kandel ER, Siegelbaum SA. 1986. The growth cones of Aplysia sensory neurons: Modulation by serotonin of action potential duration and single potassium channel currents. Proc Natl Acad Sci U S A. 83:7094-7098. doi: 10.1073/pnas.83.18.7094

Bennett MVL. Electric Organs. 1971. In: Hoar WS, Randall DJ, editors. Fish Physiology. 5. New York: Academic Press; p. 347-491. doi: 10.1016/S1546-5098(08)60051-5

Boërio D, Corrêa TD, Jakob SM, Ackermann KA, Bostock H, Z'Graggen WJ. 2018. Muscle membrane properties in A pig sepsis model: Effect of norepinephrine. Muscle Nerve. 57:808-813. doi: 10.1002/mus.26013

Boucher P-A, Joós B, Morris CE. 2012. Coupled left-shift of Nav channels: modeling the Na+ loading and dysfunctional excitability of damaged neurons. J. Comput. Neurosci. 33:301-319. doi: 10.1007/s10827-012-0387-7

Casane D, Laurenti P. 2013. Why coelacanths are not 'living fossils': a review of molecular and morphological data. Bioessays 35:332-338. doi: 10.1002/bies.201200145

Cannon SC 2018. Sodium channelopathies of skeletal muscle. Handb Exp Pharmacol. 246:309-330. doi: 0.1007/9783-319-90284-5

Catania KC. 2015. Electric eels use high-voltage to track fast-moving prey. Nat Commun. 6:8638. doi: $10.1038 /$ ncomms 9638

Catania KC. The astonishing behavior of electric Eels. 2019. Front Integr Neurosci. 13:23. doi: 10.3389/fnint.2019.00023

Cha CY, Noma A. 2012. Steady-state solutions of cell volume in a cardiac myocyte model elaborated for membrane excitation, ion homeostasis and Ca2+dynamics. J Theor Biol. 307:70-81. doi: 10.1016/j.jtbi.2012.04.025 
Ching B, Woo JM, Hiong KC, Boo MV, Choo CY, Wong WP, Chew SF, Ip YK. 2015; Na+/K+-ATPase $\alpha$-subunit (nka $\alpha$ )

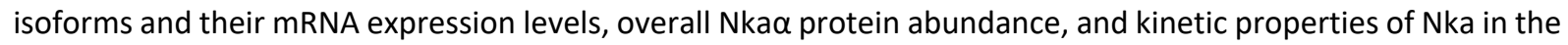
skeletal muscle and three electric organs of the electric eel, Electrophorus electricus. PLoS One 10:e0118352. doi: 10.1371/journal.pone.0118352

Ching B, Woo JM, Hiong KC, Boo MV, Wong WP, Chew SF, Ip YK. 2016. Voltage-Gated Na+ channel isoforms and their mRNA expression levels and protein abundance in three electric organs and the skeletal muscle of the electric eel Electrophorus electricus. PLoS One 11:e0167589. doi: 10.1371/journal.pone.0167589

Clausen T. 2013. Quantification of $\mathrm{Na}^{+}, \mathrm{K}^{+}$pumps and their transport rate in skeletal muscle: functional significance. J Gen Physiol. 142:327-345. doi:10.1085/jgp.201310980

Clausen T. 2015. Excitation of skeletal muscle is a self-limiting process, due to run-down of $\mathrm{Na}+\mathrm{K}+$ gradients, recoverable by stimulation of the $\mathrm{Na}+\mathrm{K}+$ pumps. Physiol. Rep. 3. e12373. doi: 10.14814/phy2.12373

Clausen T, Flatman JA. 1977. The effect of catecholamines on Na-K transport and membrane potential in rat soleus muscle. J Physiol. 270:383-414. doi: 10.1113/jphysiol.1977.sp011958

Cochet-Bissuel M, Lory P, Monteil A. 2014. The sodium leak channel, NALCN, in health and disease. Front Cell Neurosci. 8: 132. doi: 10.3389/fncel.2014.00132

Copithorne DB, Rice CL .2019.The effect of blood flow occlusion during acute low-intensity isometric elbow flexion exercise. Eur J Appl Physiol. 119:587-595. doi: 10.1007/s00421-019-04088-8

DahImann A, Kopp C, Linz P, Cavallaro A, Seuss H, Eckardt K, Luft FC., Titze J, Uder M, Hammon M. 2016. Quantitative assessment of muscle injury by ${ }^{23} \mathrm{Na}$ magnetic resonance imaging. Springerplus. 5: 661. doi: 10.1186/s40064016-2193-6

de Paoli FV, Broch-Lips M, Pedersen TH, Nielsen OB. 2013. Relationship between membrane Cl- conductance and contractile endurance in isolated rat muscles. J Physiol. 591:531-545. doi: 10.1113/jphysiol.2012.243246

DiFranco M, Yu C, Quiñonez M, Vergara JL. 2015. Inward rectifier potassium currents in mammalian skeletal muscle fibres. J Physiol. 593:1213-1238. doi:10.1113/jphysiol.2014.283648

DiFranco M, Quinonez M, Dziedzic RM, Spokoyny AM, Cannon SC. 2019. A highly-selective chloride microelectrode based on a mercuracarborand anion carrier. Sci Rep. 9:18860. doi: 10.1038/s41598-019-54885-6

Dijkstra K, Hofmeijer J, van Gils SA, van Putten MJ. 2016. A biophysical model for cytotoxic cell swelling. J Neurosci. 36:11881. doi: 10.1523/JNEUROSCI.1934-16.2016

Dmitriev AV, Dmitriev AA, Linsenmeier RA. 2019. The logic of ionic homeostasis: Cations are for voltage, but not for volume. PLoS Comput Biol. 15:e1006894. doi: 10.1371/journal.pcbi.1006894

Donohoe PH, West TG, Boutilier RG. 2000. Factors affecting membrane permeability and ionic homeostasis in the cold-submerged frog. J Exp Biol. 203(Pt 2):405-414. ISSN: 1477-9145.

Dutel H, Galland M, Tafforeau P, Long JA, Fagan MJ, Janvier P, Herrel A, Santin MD, Clément G, Herbin M. 2019. Neurocranial development of the coelacanth and the evolution of the sarcopterygian head. Nature 569:556-559. doi: 10.1038/s41586-019-1117-3

Egner IM, Bruusgaard JC, Gundersen K. 2016. Satellite cell depletion prevents fiber hypertrophy in skeletal muscle. Development 143:2898-2906. doi: 10.1242/dev.134411 
Fogarty MJ, Sieck GC. 2019. Evolution and functional differentiation of the diaphragm muscle of mammals. Compr Physiol. 9:715-766. doi: 10.1002/cphy.c180012

Fraser JA, Huang CL. 2004. A quantitative analysis of cell volume and resting potential determination and regulation in excitable cells. J Physiol. 559:459. doi: 10.1113/jphysiol.2004.065706

Fraser JA, Huang CL. 2007. Quantitative techniques for steady-state calculation and dynamic integrated modelling of membrane potential and intracellular ion concentrations. Prog Biophys Mol Biol. 94:336-372. doi: 10.1016/j.pbiomolbio.2006.10.001

Fraser JA, Huang CL, Pedersen TH. 2011. Relationships between resting conductances, excitability, and t-system ionic homeostasis in skeletal muscle. J Gen Physiol. 138:95-116. doi: 10.1085/jgp.201110617

Fu Y, Struyk A, Markin V, Cannon S. 2011. Gating behaviour of sodium currents in adult mouse muscle recorded with an improved two-electrode voltage clamp. J Physiol. 589:525-546. doi: 10.1113/jphysiol.2010.199430

Gage PW, Lamb GD, Wakefield BT. 1989. Transient and persistent sodium currents in normal and denervated mammalian skeletal muscle. J Physiol. 418:427-439. doi:10.1113/jphysiol.1989.sp017850Gage

Gallant JR, Traeger LL, Volkening JD, Moffett H, Chen PH, Novina CD, Phillips Jr.GN, Anand R, Wells GB, Pinch M, Güth R, Unguez GA, Albert JS, Zakon HH, Samanta MP, Sussman MR. 2014. Genomic basis for the convergent evolution of electric organs. Science 344:1522-1525. doi:10.1126/science.1254432

Ganassi M, Badodi S, Ortuste Quiroga HP, Zammit PS, Hinits Y, Hughes SM. 2018. Myogenin promotes myocyte fusion to balance fibre number and size. Nat Commun. 9:4232. doi: 10.1038/s41467-018-06583-6

Gerhalter T, Carlier PG, Marty B. 2017. Acute changes in extracellular volume fraction in skeletal muscle monitored by $23 \mathrm{Na}$ NMR spectroscopy. Physiol. Rep. 5: e13380. doi: 10.14814/phy2.13380

Gerhalter T, Gast LV, Marty B, Martin J, Trollmann R, Schüssler S, Roemer F, Laun FB, Uder M, Schröder R, Carlier PG, Nagel AM. 2019. ${ }^{23} \mathrm{Na}$ MRI depicts early changes in ion homeostasis in skeletal muscle tissue of patients with Duchenne muscular dystrophy. J Magn Reson Imaging. 50:1103-1113. doi: 10.1002/jmri.26681

Guharay F, Sachs F. 1984. Stretch-activated single ion channel currents in tissue-cultured embryonic chick skeletal muscle. J Physiol. 352:685-701. doi: 10.1113/jphysiol.1984.sp015317

Guharay F, Sachs F. 1985. Mechanotransducer ion channels in chick skeletal muscle: the effects of extracellular pH. J Physiol. 363:119-134. doi: 0.1113/jphysiol.1985.sp015699

Hamada K, Matsuura H, Sanada M, Toyoda F, Omatsu-Kanbe M, Kashiwagi A, Yasuda H. 2003. Properties of the $\mathrm{Na}^{+} / \mathrm{K}^{+}$pump current in small neurons from adult rat dorsal root ganglia. $\mathrm{Br} \mathrm{J}$ Pharmacol. 138:1517-1527. doi: 10.1038/sj.bjp.0705170

Hammon M, Grossmann S, Linz P, Kopp C, Dahlmann A, Janka R, Cavallaro A, Uder M, Titze J. 2015. 3 Tesla (23)Na magnetic resonance imaging during aerobic and anaerobic exercise. Acad Radiol. 22:1181-1190. doi: 10.1016/j.acra.2015.06.005

Harris AJ, Duxson MJ, Butler JE, Hodges PW, Taylor JL, Gandevia SC. 2005. Muscle fiber and motor unit behavior in the longest human skeletal muscle. J Neurosci. 25:8528-8533. doi: 10.1523/JNEUROSCI.0923-05.2005

Heiny JA, Cannon SC, Difranco M. 2019. A four-electrode method to study dynamics of ion activity and transport in skeletal muscle fibers. J Gen Physiol. 151:1146-1155. doi: 10.1085/jgp.201912398 
Heiny JA, Kravtsova VV, Mandel F, Radzyukevich TL, Benziane B, Prokofiev AV, Pedersen SE, Chibalin AV, Krivoi II. 2010. The nicotinic acetylcholine receptor and the $\mathrm{Na}, \mathrm{K}-\mathrm{ATPase}$ alpha2 isoform interact to regulate membrane electrogenesis in skeletal muscle.J Biol Chem. 285:28614-28626. doi: 10.1074/jbc.M110.150961

Helfman G, Collette B, Facey DE. 2009. The Diversity of Fishes: Biology, Evolution and Ecology, $2^{\text {nd }}$ ed.. Blackwell Science, Malden, MA. pp. 48-49. ISBN: 978-1-405-12494-2

Hille, B. 2001. Ion Channels of Excitable Membranes. $3^{\text {rd }}$ edition Sinauer Associates, Sunderland, Massachusetts. ISBN: 978-0-87893-321

Hotfiel T, Freiwald J, Hoppe MW, Lutter C, Forst R, Grim C, Bloch W, Hüttel M, Heiss R. 2018. Advances in delayedonset muscle soreness (DOMS): Part I: Pathogenesis and diagnostics. Sportverletz Sportschaden. 32:243-250

Hostrup M, Bangsbo J. 2017. Limitations in intense exercise performance of athletes - effect of speed endurance training on ion handling and fatigue development. J Physiol. 595:2897-2913. doi: 10.1113/JP273218

Hotfiel T, Freiwald J, Hoppe MW, Lutter C, Forst R, Grim C, Bloch W, Hüttel M, Heiss R. 2018. Advances in delayedonset muscle soreness (DOMS): Part I: Pathogenesis and diagnostics. Sportverletz Sportschaden. 32:243-250. doi: 10.1055/a-0753-1884

Hübel N, Schöll E, Dahlem MA. 2014. Bistable dynamics underlying excitability of ion homeostasis in neuron models. PLoS Comput Biol. 10:e1003551. doi: 10.1371/journal.pcbi.1003551

Janssen I, Heymsfield SB, Wang ZM, Ross R. 2000. Skeletal muscle mass and distribution in 468 men and women aged 18-88 yr. J Appl Physiol 89:81-88. doi: 10.1152/jappl.2000.89.1.81

Jeng CJ, Fu SJ, You CY, Peng YJ, Hsiao CT, Chen TY, Tang CY. 2020. Defective gating and proteostasis of human CIC-1 chloride channel: molecular pathophysiology of myotonia congenita. Front Neurol. 11:76. doi: 10.3389/fneur.2020.00076

Jentsch TJ, Pusch M. 2018. ClC chloride channels and transporters: structure, function, physiology, and disease. Physiol Rev. 98:1493-1590. doi: 10.1152/physrev.00047.2017

Johnstone AJ, Ball D. 2019. Determining ischaemic thresholds through our understanding of cellular metabolism. In: Mauffrey C, Hak DJ, Martin III MP, editors. Compartment Syndrome: A Guide to Diagnosis and Management (SpringerOpen), Chapter 4. doi: 10.1007/978-3-030-22331-1_4

Johnston IA, Bower NI, Macqueen DJ. 2011. Growth and the regulation of myotomal muscle mass in teleost fish. J Exp Biol. 214:1617-1628

Joos B, Barlow BM, Morris CE. 2018. Calculating the consequences of left-shifted Nav channel activity in sick excitable cells. Handb Exp Pharmacol.; 246:401-422 (Review). doi: 10.1007/164_2017_63

Kager H, Wadman WJ, Somjen GG. 2000. Simulated seizures and spreading depression in a neuron model incorporating interstitial space and ion concentrations. J Neurophysiol. 84:495-512. doi: 10.1152/jn.2000.84.1.495

Kay AR. 2017. How cells can control their size by pumping ions. Front. Cell Dev. Biol. 5:41. doi: $10.3389 /$ fcell.2017.00041

Kuba K, Nohmi M. 1987. Role of ion conductance changes and of the sodium-pump in adrenaline-induced hyperpolarization of rat diaphragm muscle fibres. $\mathrm{Br} J$ Pharmacol. 91:671-681. doi:10.1111/j.14765381.1987.tb11261.x 
Lansman JB. 2015. Utrophin suppresses low frequency oscillations and coupled gating of mechanosensitive ion channels in dystrophic skeletal muscle. Channels (Austin) 2015 9: 145-160.

doi: 10.1080/19336950.2015.1040211

Lasek RJ, Dower WJ. 1971. Aplysia californica: analysis of nuclear DNA in individual nuclei of giant neurons. Science. 172:278-280. doi: 10.1126/science.172.3980.278

Lauf PK, Sharma N, Adragna NC. 2019. Kinetic studies of K-Cl cotransport in cultured rat vascular smooth muscle cells. Am J Physiol Cell Physiol. 316:C274-C284. doi: 10.1152/ajpcell.00002.2017

Li RW, Deng Y, Pham HN, Weiss S, Chen M, Smith PN. 2020. Riluzole protects against skeletal muscle ischaemiareperfusion injury in a porcine model. Injury. 51:178-184. doi: 10.1016/j.injury.2019.12.030

Lindinger MI, Leung M, Trajcevski KE, Hawke TJ. 2011. Volume regulation in mammalian skeletal muscle: the role of sodium-potassium-chloride cotransporters during exposure to hypertonic solutions. J Physiol. 589:2887-2899. doi: 10.1113/jphysiol.2011.206730

Lo HP, Hall TE, Parton RG. 2016. Mechanoprotection by skeletal muscle caveolae. Bioarchitecture. 6:22-27. doi: 10.1080/19490992.2015.1131891

Lorenzo LE, Godin AG, Ferrini F, Bachand K, Plasencia-Fernandez I, Labrecque S, Girard AA, Boudreau D, Kianicka I, Gagnon M, Doyon N, Ribeiro-da-Silva A, De Koninck Y. 2020. Enhancing neuronal chloride extrusion rescues a2/ $\alpha 3$ GABAA-mediated analgesia in neuropathic pain. Nat. Commun.11:869. doi: 10.1038/s41467-019-14154-6

Lu B, Su Y, Das S, Liu J, Xia J, Ren D. 2007. The neuronal channel NALCN contributes resting sodium permeability and is required for normal respiratory rhythm. Cell. 129:371-383. doi: 10.1016/j.cell.2007.02.041

Lutas A, Lahmann C, Soumillon M2, Yellen G. 2016. The leak channel NALCN controls tonic firing and glycolytic sensitivity of substantia nigra pars reticulata neurons. Elife. 5:e15271. doi: 10.7554/eLife.15271

Machado RD, Miguens FC, Esquibel MA. 1983. Scanning electron microscopy of the electric organs of Electrophorus electricus L. I. Main organ. Cell Tissue Res. 234:641-653. doi: 10.1007/BF00218657

Mackie GO. 1990. Giant axons and control of jetting in the squid Loligo and the jellyfish Aglantha. Canadian Journal of Zoology 68: 799-805. doi: 10.1139/290-115

Manoharan P, Song T, Radzyukevich TL, Sadayappan S, Lingrel JB, Heiny JA. 2019. KLF2 in myeloid lineage cells regulates the innate immune response during skeletal muscle injury and regeneration. Science. 17:334-346. doi: 10.1016/j.isci.2019.07.009

McElhanon KE, Bhattacharya S. 2018. Altered membrane integrity in the progression of muscle diseases. Life Sci. 192:166-172. doi: 10.1016/j.Ifs.2017.11.035

Methfessel C, Witzemann V, Takahashi T, Mishina M, Numa S, Sakmann B. 1986. Patch clamp measurements on Xenopus laevis oocytes: currents through endogenous channels and implanted acetylcholine receptor and sodium channels. Pflugers Arch. 407:577-88. doi: 10.1007/BF00582635

Metzger S, Dupont C, Voss AA, Rich MM. 2020. Central role of subthreshold currents in myotonia. Ann Neurol. 87:175-183. doi: 10.1002/ana.25646

Miller C. 2015. In the beginning: a personal reminiscence on the origin and legacy of $\mathrm{ClC}-0$, the 'Torpedo $\mathrm{Cl}^{-}$channel'. J Physiol. 593:4085-4090. doi: 10.1113/jphysiol.2014.286260 
Mink JW, Blumenschine RJ, Adams DB. 1981. Ratio of central nervous system to body metabolism in vertebrates: its constancy and functional basis. Am J Physiol. 241:R203-R212. doi: 10.1152/ajpregu.1981.241.3.R203

Morris CE, Horn R. 1991. Failure to elicit neuronal macroscopic mechanosensitive currents anticipated by singlechannel studies. Science. 251:1246-1249. doi: 10.1126/science.1706535

Morris CE. 2012. Why are so many channels mechanosensitive? In N. Sperelakis (Ed.) Cell Physiology Source Book, 4th Edn, pp 493-505. Elsevier. ISBN: 0-12-656977-0

Morris CE, Boucher P-A, Joós B. 2012. Left-shifted Nav channels in trauma-damaged bilayer: primary targets for neuroprotective Nav antagonists? Frontiers in Pharmacology 3, 19. doi: 10.3389/fphar.2012.00019

Morris CE. 2018. Cytotoxic swelling of sick excitable cells - impaired ion homeostasis and membrane tension homeostasis in muscle and neuron. Curr Top Membr 81:457-496. doi: 10.1016/bs.ctm.2018.06.001

Morris CE, Wheeler JW, Joos B. Donnan dominated ion homeostasis and the longevity of ischemic $\mathrm{Na}^{+}-$loaded dystrophic skeletal muscle (submitted)

Nielsen OB, Clausen T. 1997. Regulation of $\mathrm{Na}^{+}-\mathrm{K}^{+}$pump activity in contracting rat muscle. J Physiol. 503:571-581. doi: 10.1111/j.1469-7793.1997.571bg.x

Novak KR, Norman J, Mitchell JR, Pinter MJ, Rich MM. 2015. Sodium channel slow inactivation as a therapeutic target for myotonia congenita. Ann Neurol. 77:320-332. doi: 10.1002/ana.24331

Pedersen TH, Macdonald WA, de Paoli FV, Gurung IS, Nielsen O. 2011. Comparison of regulated passive membrane conductance in action potential-firing fast- and slow-twitch muscle. J Gen Physiol. 134:323-337. doi: 10.1085/jgp.200910291

Pedersen TH, Riisager A, de Paoli FV, Chen TY, Nielsen OB. 2016. Role of physiological ClC-1 Cl-ion channel regulation for the excitability and function of working skeletal muscle. J Gen Physiol. 147:291-308. doi: 10.1085/jgp.201611582

Pérez-Pinzón MA, Rosenthal M, Sick TJ, Lutz PL, Pablo J, Mash D . 1992. Downregulation of sodium channels during anoxia: a putative survival strategy of turtle brain. Am J Physiol 262:R712-R715. doi: 10.1152/ajpregu.1992.262.4.R712

Philippart F, Khaliq ZM. 2018. $\mathrm{G}_{\mathrm{i} / \mathrm{o}}$ protein-coupled receptors in dopamine neurons inhibit the sodium leak channel NALCN eLife 7: e40984. doi: 10.7554/eLife.40984

Pickar JG, Spier SJ, Snyder JR, Carlsen RC. 1991. Altered ionic permeability in skeletal muscle from horses with hyperkalemic periodic paralysis. Am J Physiol. 260:C926-C933. doi: 10.1152/ajpcell.1991.260.5.C926

Pirkmajer S, Chibalin AV. 2016. Na,K-ATPase regulation in skeletal muscle. Am J Physiol Endocrinol Metab. 311:E1E31. doi: 10.1152/ajpendo.00539.2015

Rakowski RF, Gadsby DC, De Weer P. 1997. Voltage dependence of the Na/K pump. J Membr Biol. 155:105-112. doi:10.1007/s002329900162

Rahmat S, Gilland E. 2014. Comparative anatomy of the carotid-basilar arterial trunk and hindbrain penetrating arteries in vertebrates. The Open Anatomy Journal 6:1-26. doi: 10.2174/1877609401406010001 
Raman R, Cvetkovic C, Uzel SG, Platt RJ, Sengupta P, Kamm RD, Bashir R. 2016. Optogenetic skeletal musclepowered adaptive biological machines. Proc Natl Acad Sci U S A. 113:3497-3502. doi: 10.1073/pnas.1516139113

Raman R, Grant L, Seo Y, Cvetkovic C, Gapinske M, Palasz A, Dabbous H, Kong H, Pinera PP, Bashir R. 2017. Damage, healing, and remodeling in optogenetic skeletal muscle bioactuators. Adv Healthc Mater. 6:e1700030. doi: 10.1002/adhm.201700030

Raman R. 2019. Modeling muscle. Science. 363:1051. doi: 10.1126/science.aaw3611

Reinl EL, Zhao P, Wu W, Ma X, Amazu C, Bok R, Hurt KJ, Wang Y, England SK. 2018. Na+-Leak Channel, NonSelective (NALCN) regulates myometrial excitability and facilitates successful parturition. Cell Physiol Biochem. 48:503-515. doi: 10.1159/000491805

Rolfe DF, Brown GC. 1997. Cellular energy utilization and molecular origin of standard metabolic rate in mammals. Physiol Rev. 77:731-758. doi: 10.1152/physrev.1997.77.3.731

Ross JA, Levy Y, Svensson K, Philp A, Schenk S, Ochala J. 2018. SIRT1 regulates nuclear number and domain size in skeletal muscle fibers. J Cell Physiol. 233:7157-7163. doi:10.1002/jcp.26542

Ruff RL. 2011. Endplate contributions to the safety factor for neuromuscular transmission. Muscle Nerve 44:854861. doi: 10.1002/mus.22177

Rungta RL, Choi HB, Tyson JR, Malik A, Dissing-Olesen L, Lin PJC, Cain SM, Cullis PR, Snutch TP, MacVicar BA. 2015. The cellular mechanisms of neuronal swelling underlying cytotoxic edema. Cell 161:610. doi: 10.1016/j.cell.2015.03.029

Schroeder TBH, Guha A, Lamoureux A, VanRenterghem G, Sept D, Shtein M, Yang J, Mayer M. 2017. An electric-eelinspired soft power source from stacked hydrogels. Nature 552:214-218. doi: 10.1038/nature24670

Schwartz IR, Pappas GD, Bennett MVL. 1975. The fine structure of electrocytes in weakly electric teleosts. J Neurocytol. 4:87-114. ISSN: 1573-7381, 0300-4864

Schwartz LM, Brown C, McLaughlin K, Smith W, Bigelow C. 2016. The myonuclear domain is not maintained in skeletal muscle during either atrophy or programmed cell death. Am J Physiol Cell Physiol. 311:C607-C615. doi:10.1152/ajpcell.00176.2016

Senatore A, Spafford JD. 2013. A uniquely adaptable pore is consistent with NALCN being an ion sensor. Channels (Austin). 7:60-68. doi: 10.4161/chan.23981

Sinha B, Köster D, Ruez R, Gonnord P, Bastiani M, Abankwa D, Stan RV, Butler-Browne G, Vedie B, Johannes L, Morone N, Parton RG, Raposo G, Sens P, Lamaze C, Nassoy P. 2011. Cells respond to mechanical stress by rapid disassembly of caveolae. Cell. 144:402-413. doi:10.1016/j.cell.2010.12.031

Sperelakis N (2012) Origin of resting membrane potentials. In N. Sperelakis (Ed.) Cell Physiology Source Book, 4th Edn, pp 121- 145. Elsevier. ISBN: 0-12-656977-0.

Steinmeyer K, Ortland C, Jentsch TJ. 1991. Primary structure and functional expression of a developmentally regulated skeletal muscle chloride channel. Nature. 354:301-304. doi: 10.1038/354301a0.

Suchyna TM. 2017. Piezo channels and GsMTx4: Two milestones in our understanding of excitatory mechanosensitive channels and their role in pathology. Prog Biophys Mol Biol. 130:244-253. doi:10.1016/j.pbiomolbio.2017.07.011 
Surkar SM, Bland MD, Mattlage AE, Chen L, Gidday JM, Lee JM, Hershey T, Lang CE. 2020. Effects of remote limb ischemic conditioning on muscle strength in healthy young adults: A randomized controlled trial. PLoS One. 15: e0227263. doi: 10.1371/journal.pone.0227263

Thoma A, Akter-Miah T, Reade RL, Lightfoot AP. 2020. Targeting reactive oxygen species (ROS) to combat the agerelated loss of muscle mass and function. Biogerontology 21:475-484. doi: 10.1007/s10522-020-09883-x

Tian R, Losilla M, Lu Y, Yang G, Zakon H. 2017. Molecular evolution of globin genes in Gymnotiform electric fishes: relation to hypoxia tolerance. BMC Evol Biol. 17:51. doi: 10.1186/s12862-017-0893-3

Traeger LL, Sabat G, Barrett-Wilt GA, Wells GB, Sussman MR. 2017. A tail of two voltages: Proteomic comparison of the three electric organs of the electric eel. Sci Adv. 3: e1700523. doi: 10.1126/sciadv.1700523

Usher-Smith JA, Huang CL, Fraser JA. 2009. Control of cell volume in skeletal muscle. Biol Rev Camb Philos Soc. 84:143-59. doi: 10.1111/j.1469-185X.2008.00066.x

Vandorpe DH, Small DL, Dabrowski AR, Morris CE. 1994. FMRFamide and membrane stretch as activators of the Aplysia S-channel. Biophys J. 66:46-58. doi: 10.1016/S0006-3495(94)80749-0

Wang X, Engisch KL, Li Y, Pinter MJ, Cope TC, Rich MM. 2004. Decreased synaptic activity shifts the calcium dependence of release at the mammalian neuromuscular junction in vivo. J. Neurosci. 24:10687-10692. doi: 10.1523/JNEUROSCI.2755-04.2004

Webb J, Wu FF, Cannon SC. 2009. Slow inactivation of the NaV1.4 sodium channel in mammalian cells is impeded by co-expression of the beta1 subunit. Pflugers Arch. 457:1253-1263. doi: 10.1007/s00424-008-0600-8

Weber MA, Nielles-Vallespin S, Huttner HB, Wöhrle JC, Jurkat-Rott K, Lehmann-Horn F, Schad LR, Kauczor HU, Essig $\mathrm{M}$, Meinck HM. 2006. Evaluation of patients with paramyotonia at ${ }^{23} \mathrm{Na} \mathrm{MR}$ imaging during cold-induced weakness. Radiology 240:489-500. doi: 10.1148/radiol.2401050737

Yu N, Morris CE, Joós B, Longtin A. 2012. Spontaneous excitation patterns computed for axons with injury-like impairments of sodium channels and $\mathrm{Na} / \mathrm{K}$ pumps. PLoS Comput Biol. 8:e1002664. doi: 10.1371/journal.pcbi.1002664

Yu JG, Liu JX, Carlsson L, Thornell LE, Stål PS. 2013. Re-evaluation of sarcolemma injury and muscle swelling in human skeletal muscles after eccentric exercise. PLoS One 8:e62056. doi: 10.1371/journal.pone.0062056

Zhang Y, Hamill OP. 2000. On the discrepancy between whole-cell and membrane patch mechanosensitivity in Xenopus oocytes.J Physiol. 523:101-115. doi: /10.1111/j.1469-7793.2000.00101.x

Zhang Y, Gao F, Popov VL, Wen JW, Hamill OP. 2000. Mechanically gated channel activity in cytoskeleton-deficient plasma membrane blebs and vesicles from Xenopus oocytes. J Physiol. 523:117-130. doi: 10.1111/j.14697793.2000.t01-1-00117.x

Zhang B, Wang C, Wang H, Kong H, Gao F, Yang M, Zhang J. 2020. Feasibility of MRI based oxygenation imaging for the assessment of acute limb ischemia. Ann Transl Med. 8:315. doi:10.21037/atm.2020.02.139 


\section{Table 1 Pump-Leak/Donnan models for excitable cells}

\begin{tabular}{|c|c|c|c|c|}
\hline & Item: $\quad$ Model name: & SM-CD & WD-CD & CN-CD \\
\hline 1 & $\begin{array}{c}\text { P-L/D model } \\
\text { an "ion homeostatic unit" } \\
\text { (i.e., same membrane } C_{m} \\
\text { for each) depicting:--- }\end{array}$ & $\begin{array}{l}\text { one "slice" of the many needed } \\
\text { to comprise a multinucleate } \\
\text { skeletal muscle fiber } \\
\text { (explained in Figure } 8 \mathrm{C}, \mathrm{D} \text { ) }\end{array}$ & $\begin{array}{c}\text { a counterfactual } \\
\text { computational "tool" } \\
\text { (a Pump-Leak dominated } \\
\text { analog of SM-CD) }\end{array}$ & $\begin{array}{c}\text { a roundish soma of a } \\
\text { cortical neuron in brain-slice } \\
\text { (Dijkstra et al 2016) } \\
\text { (termed CN-CD here) }\end{array}$ \\
\hline 2 & in ancestral vertebrates & SMFs $>40 \%$ of body mass $*$ & --- & brain $<0.2 \%$ of body mass $*$ \\
\hline 3 & in humans & $\begin{array}{l}\text { SMFs } \sim 40 \% \text { of body mass } \\
\text { (e.g. Rolfe et al 1997) }\end{array}$ & --- & $\begin{array}{l}\text { brain } 2 \% \text { of body mass } \\
\text { (Mink et al 1981) }\end{array}$ \\
\hline 4 & $\begin{array}{l}\text { "electrophysiological } \\
\text { life-style" served }\end{array}$ & $\begin{array}{c}\text { low excitability } \\
\text { low duty-cycle, } \\
\text { "off-on-off" AP signal }\end{array}$ & (same as SM-CD) & $\begin{array}{c}\text { high excitability, } \\
\text { high duty-cycle, } \\
\text { complex nuanced } V_{m} \text { signalling }\end{array}$ \\
\hline 5 & dominant st-state fluxes & ANIONS $\left(\mathrm{Cl}^{-}\right)$ & CATIONS $\left(\mathrm{Na}^{+}, \mathrm{K}^{+}\right)$ & CATIONS $\left(\mathrm{Na}^{+}, \mathrm{K}^{+}\right)$ \\
\hline 6 & $\begin{array}{c}\text {....hence...TYPE of st-st } \\
\text { ion homeostasis }\end{array}$ & $\begin{array}{l}\left(\left[\text { big } P_{c l}\right]\left[\text { small } I_{\text {Naleak }}\right]\right) \\
\text { Donnan dominated }\end{array}$ & $\begin{array}{l}\left(\left[\text { small } P_{c l}\right]\left[\text { big } I_{\text {Naleak }}\right]\right) \\
\text { Pump-Leak Dominated }\end{array}$ & $\begin{array}{l}\left.\text { ( [small } P_{c l}\right]\left[\text { big } I_{\text {Naleak }}\right] \text { ) } \\
\text { Pump-Leak dominated }\end{array}$ \\
\hline 7 & model complexity & MINIMAL P-L D system & $\begin{array}{c}\text { minimal } \\
\text { (like SM-CD) }\end{array}$ & $\begin{array}{c}\text { NON-minimal P-L D } \\
\text { (has } \mathrm{K} / \mathrm{Cl} \text { co-transporter)** }\end{array}$ \\
\hline 8 & $P_{c l}$ (molecular identity) & mostly CIC-1 & $\begin{array}{ll}--- \\
\end{array}$ & unclear (Rungta 2015) \\
\hline 9 & $P_{K} \quad$ (molecular identity) & $\begin{array}{l}\text { girKs (DiFranco et al 2015), } \\
\text { K-ATP, others (needs work) }\end{array}$ & --- & $\begin{array}{l}\text { diverse, including } 2 \text { pore } \\
\text { domain } \mathrm{K}^{+} \text {channels }\end{array}$ \\
\hline 10 & $P_{N a}$ (molecular identity) & UNKNOWN & --- & NALCN, in part \\
\hline
\end{tabular}

* The teleost bodyform is broadly similar to that of the extinct lobefin fishes close to the common ancestors of mammals and teleosts (see Casane and Laurenti, 2013) and so, finding no estimates for ancestral vertebrates, \%-ranges here for them are conservatively gauged from data for extant adult teleosts (typically $\sim 60 \%$ and $~ 0.15 \%$ of total body mass for skeletal muscle (Johnston et al 2011; Helfman et al 2009) and an extant lobefin, whose is brain occupies $<<0.15 \%$ of body mass (Dutel et al 2019).

**The $\mathrm{K} / \mathrm{Cl}$ cotransporter of $\mathrm{CN}-\mathrm{CD}$ is eliminated in $\mathrm{MN}-\mathrm{CD}$ (Minimal Neuron"-CD) for which $\mathrm{V}_{\text {rest }}=\mathrm{E}_{\mathrm{Cl}}$; Table 2 gives parameters and steady-state values for both. Steady-state comparisons show: the cotransporter strongly hyperpolarizes $\mathrm{E}_{\mathrm{Cl}}$, reduces $\mathrm{Vol}_{\text {cell }}$ and minimally affects $\left[\mathrm{K}^{+}\right]_{\mathrm{i}},\left[\mathrm{Na}^{+}\right]_{\mathrm{i}}, \mathrm{V}_{\text {rest }}$, ATPconsumption (as appropriate, the impacts of adding (e.g.) various $\mathrm{Na}^{+}$-transporters to $\mathrm{SM}-\mathrm{CD}$ could similarly be probed). 
bioRxiv preprint doi: https://doi.org/10.1101/2020.11.20.391813; this version posted November 20, 2020. The copyright holder for this preprint

(which was not certified by peer review) is the author/funder, who has granted bioRxiv a license to display the preprint in perpetuity. It is made available under aCC-BY-NC-ND 4.0 International license.

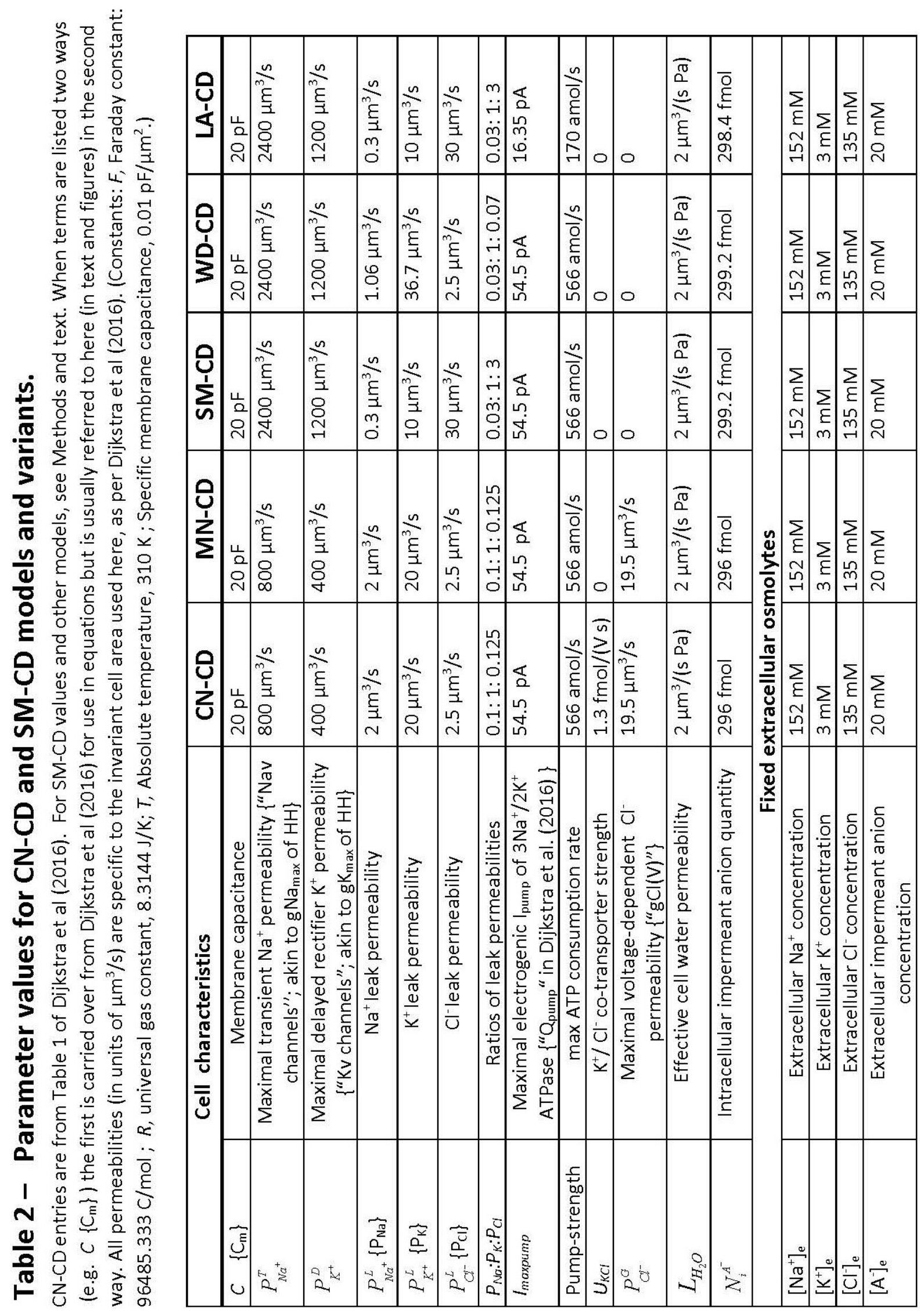




\begin{tabular}{|c|c|c|c|c|c|c|c|c|c|c|c|c|c|c|c|c|c|c|c|c|c|c|c|c|}
\hline$\frac{0}{4}$ & \begin{tabular}{|c|}
$\sum$ \\
$\xi$ \\
0 \\
$\vec{m}$ \\
\end{tabular} & & $\begin{array}{c}\Sigma \\
\xi \\
0 \\
m \\
m\end{array}$ & 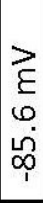 & 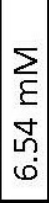 & 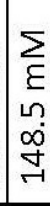 & $\begin{array}{l}\sum \\
\xi \\
\text { Ln } \\
\text { Ln }\end{array}$ & 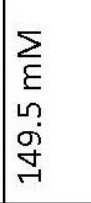 & 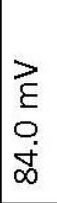 & $\begin{array}{l}\vec{E} \\
\text { N } \\
\dot{\Xi} \\
\stackrel{Y}{Y}\end{array}$ & $\begin{array}{l}\not{E} \\
\omega \\
\dot{\infty} \\
\dot{\infty}\end{array}$ & 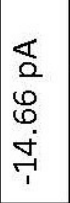 & 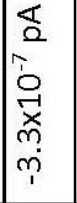 & 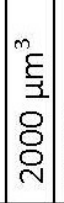 & $\begin{array}{l} \\
8 \\
8 \\
\\
\end{array}$ & $\begin{array}{l} \\
8 \\
8 \\
\\
-\end{array}$ & 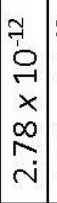 & 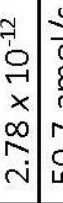 & 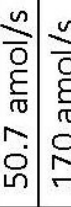 & 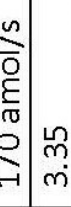 & & 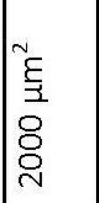 & 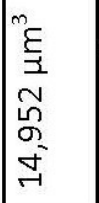 & 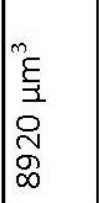 \\
\hline $\begin{array}{l}\text { U } \\
\text { อे }\end{array}$ & \begin{tabular}{|c|}
$\Sigma$ \\
$\xi$ \\
0 \\
$\vec{m}$ \\
\end{tabular} & $=$ & $\begin{array}{l}\Sigma \\
\xi \\
0 \\
m \\
m\end{array}$ & $\begin{array}{l}Z \\
\varepsilon \\
0 \\
\dot{0} \\
\infty \\
1\end{array}$ & $\begin{array}{l}\sum \\
\xi \\
\infty \\
0 \\
0\end{array}$ & $\begin{array}{l}\sum \\
\varepsilon \\
\sim \\
\infty \\
\infty \\
+ \\
\sim\end{array}$ & $\begin{array}{l}\sum \\
\xi \\
\partial \\
\vdots \\
\text { ம } \\
\end{array}$ & 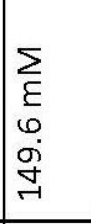 & 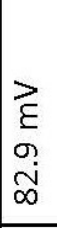 & $\begin{array}{l}\vec{E} \\
\text { N } \\
\dot{\Xi} \\
\stackrel{-}{1}\end{array}$ & $\begin{array}{l}Z \\
\xi \\
0 \\
\mathscr{0} \\
0 \\
1\end{array}$ & 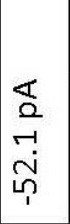 & 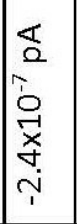 & 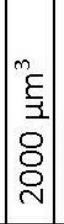 & $\begin{array}{l} \\
8 \\
8 \\
\end{array}$ & $\begin{array}{l} \\
8 \\
8 \\
\\
\end{array}$ & $\begin{array}{l} \\
8 \\
\\
\\
-i\end{array}$ & 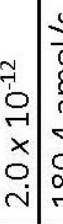 & 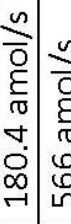 & 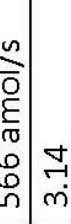 & & |로 & 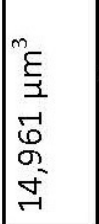 & 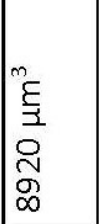 \\
\hline$\sum_{n}^{0}$ & \begin{tabular}{|c|}
$\Sigma$ \\
$\xi$ \\
0 \\
$\vec{m}$ \\
\end{tabular} & 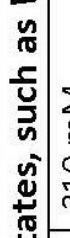 & \begin{tabular}{|c|}
$\Sigma$ \\
$\xi$ \\
0 \\
$\stackrel{-}{m}$ \\
\end{tabular} & $\begin{array}{l}\vec{E} \\
\xi \\
0 \\
\dot{0} \\
\infty \\
1 \\
\end{array}$ & $\begin{array}{l}\Sigma \\
\xi \\
n \\
m \\
\end{array}$ & $\begin{array}{l}\Sigma \\
\xi \\
m \\
\sim \\
\stackrel{-}{n} \\
\sim\end{array}$ & $\begin{array}{l}\sum \\
\xi \\
\nabla \\
\text { ம் }\end{array}$ & 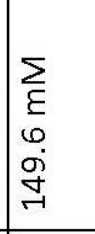 & $\begin{array}{l}\vec{\xi} \\
\text { N̦ } \\
\sigma \\
\sigma\end{array}$ & 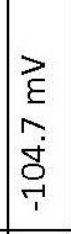 & $\begin{array}{l}\text { Z } \\
0 \\
\stackrel{0}{0} \\
0 \\
1\end{array}$ & 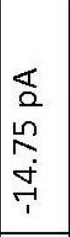 & 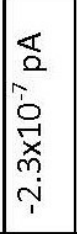 & 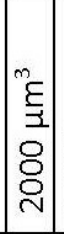 & $\begin{array}{l} \\
8 \\
8 \\
\\
\end{array}$ & $\begin{array}{l} \\
\\
8 \\
8 \\
- \\
-i\end{array}$ & 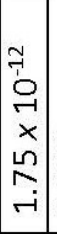 & 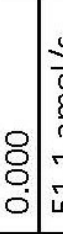 & 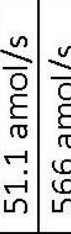 & 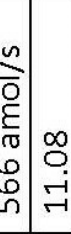 & & 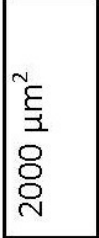 & 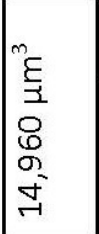 & 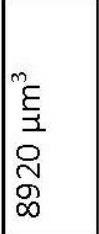 \\
\hline $\begin{array}{l}0 \\
\frac{1}{2} \\
\Sigma\end{array}$ & \begin{tabular}{|c|} 
\\
$\varepsilon$ \\
0 \\
\\
$m$ \\
\end{tabular} & 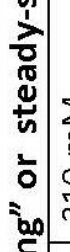 & $\begin{array}{l}\sum_{1} \\
\xi \\
\circ \\
\stackrel{1}{m} \\
\end{array}$ & 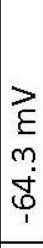 & \begin{tabular}{|l|}
$\sum$ \\
$\Sigma$ \\
$\vdots$ \\
$\infty$ \\
$\sigma$ \\
\end{tabular} & \begin{tabular}{l}
$\Sigma$ \\
$\xi$ \\
$\sim$ \\
ñ \\
\multirow{+}{*}{}
\end{tabular} & 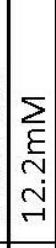 & 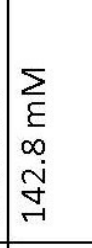 & 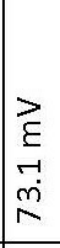 & $\begin{array}{l}\geq \\
\underline{E} \\
0 \\
\dot{D} \\
0 \\
\end{array}$ & $\begin{array}{l}\text { ऐ } \\
m \\
\tilde{\dot{\theta}} \\
\dot{1}\end{array}$ & 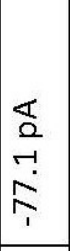 & $\mid \begin{array}{l}\frac{1}{\Omega} \\
\stackrel{d}{d} \\
\stackrel{+}{0} \\
i\end{array}$ & 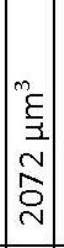 & \begin{tabular}{|c|} 
\\
$m$ \\
\\
0 \\
0 \\
\end{tabular} & \begin{tabular}{|l} 
\\
$\infty$ \\
$\infty$ \\
0 \\
0
\end{tabular} & 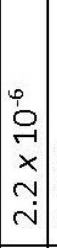 & 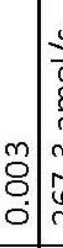 & 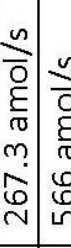 & 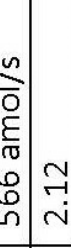 & & 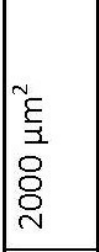 & 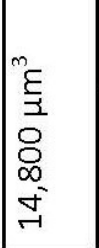 & 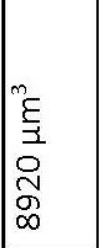 \\
\hline $\begin{array}{l}0 \\
\frac{1}{Z}\end{array}$ & \begin{tabular}{|c|}
$\Sigma$ \\
$\Sigma$ \\
$\vdots$ \\
0 \\
$m$ \\
$m$
\end{tabular} & 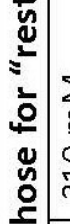 & \begin{tabular}{|l|}
$\Sigma$ \\
$\xi$ \\
0 \\
$m$ \\
$m$ \\
\end{tabular} & 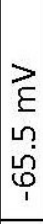 & 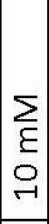 & 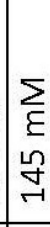 & $\sum_{\xi}$ & $\mid$\begin{tabular}{l}
$\sum$ \\
$\xi$ \\
$\infty$ \\
\multirow{+}{+}{} \\
\end{tabular} & $\begin{array}{l}\vec{z} \\
\mathfrak{E} \\
0 \\
\mathfrak{N} \\
\end{array}$ & $\begin{array}{l}\vec{Z} \\
\underline{0} \\
0 \\
\ddot{n} \\
0 \\
\stackrel{Y}{1}\end{array}$ & 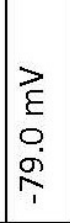 & 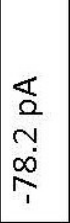 & 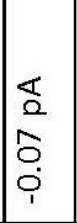 & 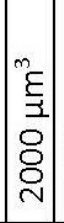 & \begin{tabular}{|c|} 
\\
$m$ \\
\\
0 \\
0 \\
\end{tabular} & \begin{tabular}{|} 
\\
$\infty$ \\
$\infty$ \\
$\sigma$ \\
0
\end{tabular} & $\begin{array}{c}0 \\
0 \\
\stackrel{1}{r} \\
x \\
\sim \\
\end{array}$ & 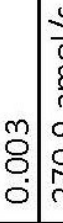 & 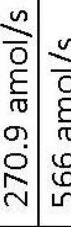 & 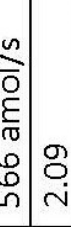 & 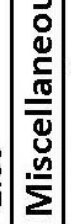 & 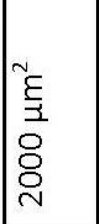 & 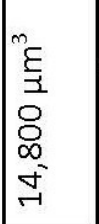 & 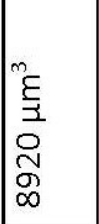 \\
\hline 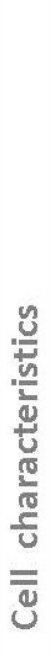 & 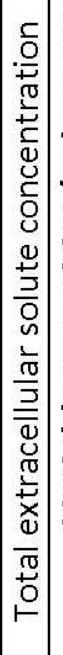 & 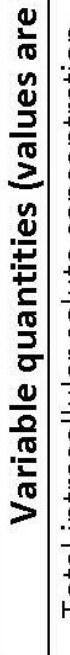 & 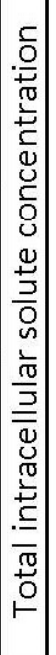 & 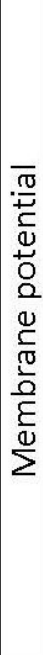 & 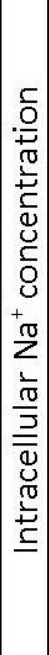 & 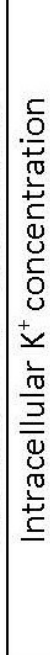 & 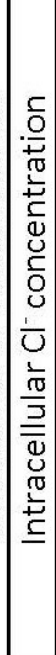 & 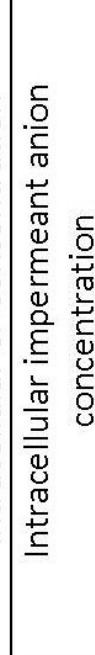 & 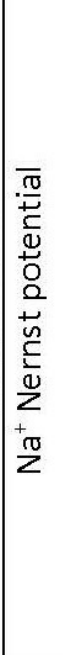 & 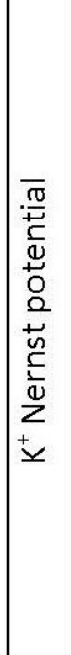 & 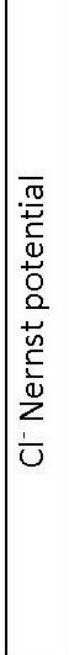 & 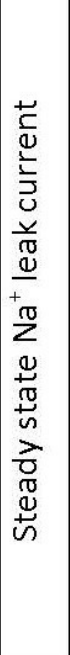 & 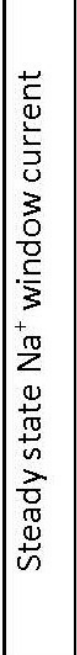 & 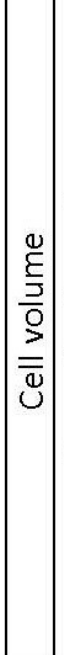 & 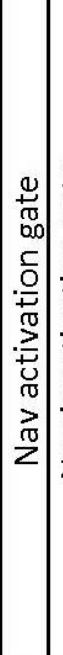 & 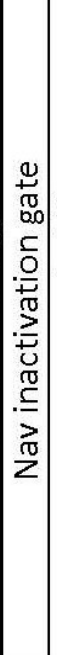 & $\begin{array}{l}\frac{7}{3} \\
\frac{1}{0} \\
\frac{0}{0} \\
\frac{0}{0} \\
\frac{0}{0} \\
\frac{1}{0} \\
\frac{0}{0} \\
\frac{1}{0} \\
\frac{\pi}{2}\end{array}$ & 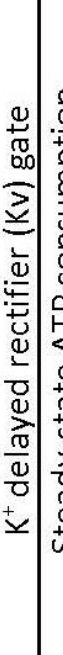 & 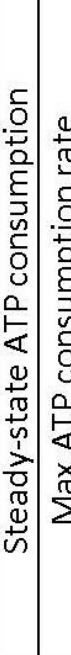 & 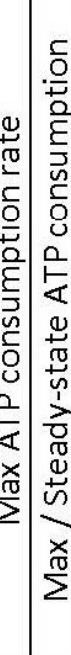 & & 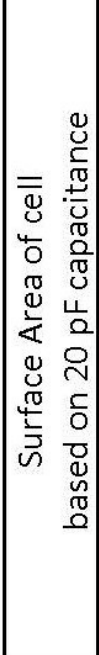 & 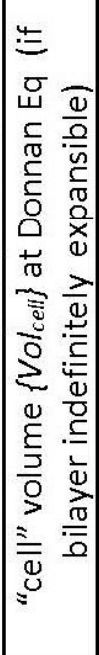 & 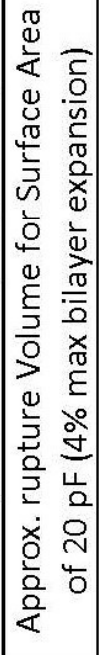 \\
\hline & $\stackrel{\sim}{\sim}$ & & $\bar{\omega}$ & $i_{3}$ & & 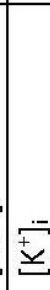 & $\bar{U}$ & 安 & 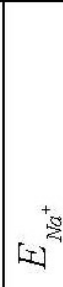 & $\mid[x]^{\infty}$ & {$[ \pm 1$} & 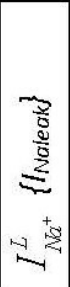 & $z^{2}$ & $\left|\begin{array}{l}0 \\
0 \\
3 \\
3\end{array}\right|$ & & $\leqslant 1$ & है & & 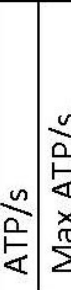 & 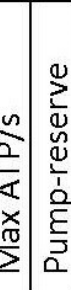 & & 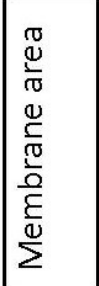 & 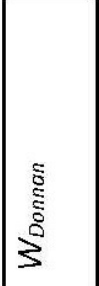 & $\mid \frac{2}{5}$ \\
\hline
\end{tabular}


Table 3 Some operational attributes of the P-L/D models and new queries

\begin{tabular}{|c|c|c|c|c|}
\hline & Model name & al & VND-CD & \\
\hline & $\begin{array}{l}\text { P-L/D model } \\
\text { depicts }\end{array}$ & $\begin{array}{l}\text { "slice" of multinucleate SMF } \\
\text { (estimated to be } \sim 1 \\
\text { myonuclear domain volume) }\end{array}$ & $\begin{array}{l}\text { a counterfactual "tool"; } \\
\text { P-L dominated } \\
\text { analog of SM-CD }\end{array}$ & $\begin{array}{l}\text { a roundish soma of a } \\
\text { cortical neuron in brain-slice } \\
\text { (Dijkstra et al 2016) }\end{array}$ \\
\hline 1 & $\begin{array}{c}\text { ATP-consumption } \\
\text { (or, relative to SM-CD) }\end{array}$ & $\begin{array}{c}51.1 \mathrm{amol} / \mathrm{s} \\
(1 \mathrm{X})\end{array}$ & $\begin{array}{c}180.4 \mathrm{amol} / \mathrm{s} \\
(3.5 \mathrm{X})\end{array}$ & $\begin{array}{c}270.9 \mathrm{amol} / \mathrm{s} \\
(5.3 \mathrm{X})\end{array}$ \\
\hline 2 & pump-reserve & 11.1-fold & 3.1-fold & 2.1-fold \\
\hline 3 & $\begin{array}{l}\text { rate-limiting } P \text { for } \Delta V(t) \\
\text { as anoxic rundown starts }\end{array}$ & $\mathrm{P}_{\mathrm{Na}}\left(=0.3 \mu \mathrm{m}^{3} / \mathrm{s}\right)$ & $\begin{array}{c}\mathrm{P}_{\mathrm{Cl}}\left(=2.5 \mu \mathrm{m}^{3} / \mathrm{s}, \text { and, }\right. \\
\left.\text { at } \mathrm{t}=0, \mathrm{~V}_{\mathrm{m}}=\mathrm{E}_{\mathrm{Cl}}\right)\end{array}$ & $\begin{array}{c}\mathrm{P}_{\mathrm{Cl}}\left(=2.5 \mu \mathrm{m}^{3} / \mathrm{s}, \text { and }, \text { at } \mathrm{t}=0\right. \\
\left.\mathrm{V}_{\mathrm{m}} \text { positive to } \mathrm{E}_{\mathrm{Cl}}\right)\end{array}$ \\
\hline 4 & $\begin{array}{l}\text { time till ectopic firing } \\
\text { during anoxic rundown }\end{array}$ & $\begin{array}{c}22.7 \text { minutes } \\
\text { (rundown at: } 10 \mathrm{mV} \text { per } 12 \\
\mathrm{~min} \text { ) }\end{array}$ & $\begin{array}{c}6 \text { minutes } \\
\text { (10 } \mathrm{mV} \text { per } 2.9 \mathrm{~min})\end{array}$ & $\begin{array}{l}<100 \text { milliseconds } \\
\text { (triggered by pump-off dep'n) }\end{array}$ \\
\hline 5 & $\begin{array}{l}\text { no } V \text {-gated channels }\left({ }^{*}\right) \\
--20 \text { min into anoxic } \\
\text { rundown: } V_{m}, V_{c e l l}\end{array}$ & $\begin{array}{c}\text { (SM*-CD) } \\
\text { depolarized by } 19 \mathrm{mV} \\
\text { swollen } 1.05 \text {-fold }\end{array}$ & --- & $\begin{array}{c}\left(\mathrm{CN}^{*} \text {-CD) }\right. \\
\text { depolarized by } 45 \mathrm{mV} \\
\text { swollen 1.4-fold }\end{array}$ \\
\hline 6 & $\begin{array}{c}\text { saddle-node pump- } \\
\text { strength \& }\left[\mathrm{Na}^{+}\right]_{\mathrm{i}}\end{array}$ & $\begin{array}{c}\text { 7.9\% pump-strength, } \\
{\left[\mathrm{Na}^{+}\right]_{\mathrm{i}}=88 \mathrm{mM}}\end{array}$ & $\begin{array}{l}\text { 26.5\% pump-strength, } \\
\qquad\left[\mathrm{Na}^{+}\right]_{\mathrm{i}}=92 \mathrm{mM}\end{array}$ & $\begin{array}{c}\text { 65\% pump-strength, } \\
{\left[\mathrm{Na}^{+}\right]_{I}=42}\end{array}$ \\
\hline 7 & $\begin{array}{c}\text { patho-physio threshold } \\
\text { pump-strength }\end{array}$ & $\begin{array}{l}\text { 339\% pump-strength } \\
\left(\mathrm{V}_{\text {pathological }}=-34 \mathrm{mV}\right)\end{array}$ & & $\begin{array}{l}\text { 185\% pump-strength } \\
\left(\mathrm{V}_{\text {pathological }}=-37 \mathrm{mV}\right)\end{array}$ \\
\hline 8 & $\begin{array}{c}\text { examples of conditions } \\
\text { to examine } \\
\text { ion homeostatically }\end{array}$ & $\begin{array}{c}\text { hibernation onset/offset, } \\
\text { compartment syndrome, } \\
\text { delayed onset muscle soreness, } \\
\text { Nav \& other channelopathies, } \\
\text { muscular dystrophies }\end{array}$ & $\begin{array}{l}\text { (a WD-CD/SM hybrid) } \\
\text { the "P } \mathrm{P}_{\mathrm{Cl}} \text { disease", } \\
\text { myotonia -mutant CIC-1 } \\
\rightarrow \text { excitable SMFs with } \\
{\left[\text { small } \mathrm{P}_{\mathrm{CI}}\right]\left[\text { small } \text { I }_{\text {Naleak }}\right]}\end{array}$ & $\begin{array}{l}\text { ischemia, migraines, epilepsy } \\
\text { (Dijkstra et al 2016), optimizing } \\
\text { analgesic protocols for } \\
\text { neuropathic pain } \\
\text { (see Lorenzo et al 2020) }\end{array}$ \\
\hline 9 & $\begin{array}{l}\text { examples of relevant } \\
\text { physiological/biological/ } \\
\text { evolutionary questions } \\
\text { (re SM-CD and CN-CD) }\end{array}$ & $\begin{array}{c}\text { ClC-1 underlies [big } \mathrm{P}_{\mathrm{CI}} \text { ]. Does } \\
\text { this channel's very small } \\
\text { unitary-g somehow benefit } \\
\text { SMF ion homeostasis? }\end{array}$ & $\begin{array}{l}\text { can smooth muscle (Lauf } \\
\text { et al 2019) be modeled } \\
\text { by modifying WD-CD } \\
\left(\mathrm{Ca}^{2+}-\mathrm{gCl} \& \mathrm{gK}, \mathrm{co}-\mathrm{K} / \mathrm{Cl}\right) \text { ? }\end{array}$ & $\begin{array}{l}\text { did early vertebrate hindbrain } \\
\text { vascularization (Rahmat \& } \\
\text { Gilland 2014) prioritize fuelling } \\
\text { of central neurons? }\end{array}$ \\
\hline
\end{tabular}




\section{Table 4}

\section{Voltage-dependent rates for $\mathrm{H}-\mathrm{H}$ gating variables ${ }^{*}$}

\begin{tabular}{|c|c|c|}
\hline \multicolumn{1}{|c|}{ Term } & Expression & Description \\
\hline$\alpha_{m}(V)$ & $\frac{0.32(V+52 \mathrm{mV})}{1-\exp \left(-\frac{V+52 \mathrm{mV}}{4 \mathrm{mV}}\right)} \frac{\mathrm{kHz}}{\mathrm{mV}}$ & $\begin{array}{c}\text { Activation rate for transient } \\
\mathbf{N a}^{+} \text {channel }\end{array}$ \\
\hline$\beta_{m}(V)$ & $\frac{0.28(V+25 \mathrm{mV})}{\exp \left(-\frac{V+25 \mathrm{mV}}{5 \mathrm{mV}}\right)-1} \mathrm{kHz}$ \\
\hline$\alpha_{h}(V)$ & $0.128 \exp \left(-\frac{V+53 \mathrm{mV}}{18 \mathrm{mV}}\right) \mathrm{kHz}$ & $\begin{array}{c}\text { Deactivation rate for } \\
\text { transient } \text { Na }^{+} \text {channel }\end{array}$ \\
\hline$\beta_{h}(V)$ & $\frac{\begin{array}{c}\text { Inactivation rate for transient } \\
\mathbf{N a}^{+} \text {channel }\end{array}}{1+\exp \left(-\frac{V+30 \mathrm{mV}}{5 \mathrm{mV}}\right)} \mathrm{kHz}$ & $\begin{array}{c}\text { Recovery from inactivation } \\
\text { rate for transient Na } \text { channel }\end{array}$ \\
\hline$\alpha_{n}(V)$ & $\frac{0.016(V+35 \mathrm{mV})}{1-\exp \left(-\frac{V+35 \mathrm{mV}}{5 \mathrm{mV}}\right)} \mathrm{kHz}$ & $\begin{array}{c}\text { Activation rate for delayed } \\
\text { rectifier } \mathrm{K}^{+} \text {channel }\end{array}$ \\
\hline$\beta_{n}(V)$ & $0.25 \exp \left(-\frac{V+50 \mathrm{mV}}{40 \mathrm{mV}}\right) \mathrm{kHz}$ & $\begin{array}{c}\text { Deactivation rate for delayed } \\
\text { rectifier } \mathrm{K}^{+} \text {channel }\end{array}$ \\
\hline
\end{tabular}

\footnotetext{
Based on Kager et al (2000) but as used in Dijkstra et al (2016) with one typographical error corrected.
} 


\section{FIGURES}

\section{ION HOMEOSTASIS : A PUMP-LEAK/DONNAN FEEDBACK PROCESS}

A sensor/effector feedbacks

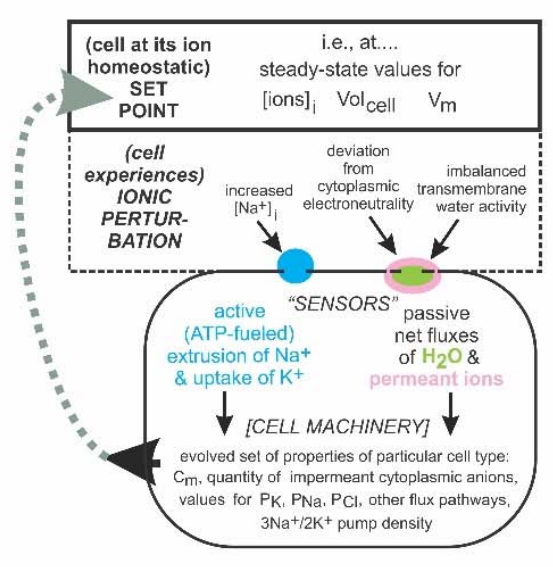

$B$ steady-states ... each compartment is electroneutral and water activity in each is the same (no osmotic pressure) minimal P-L/D systems $\left(\mathrm{E}_{\mathrm{Cl}}=\mathrm{V}_{\text {rest }}\right)$

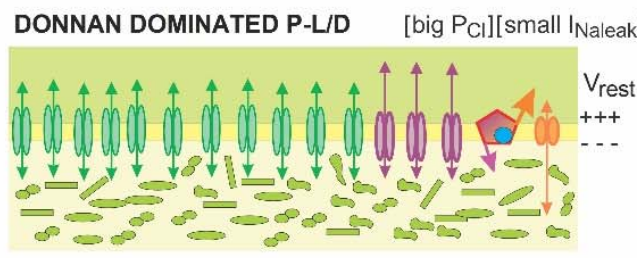

PUMP-LEAK DOMINATED P-L/D [small P PI][big I Naleak $_{\text {] }}$

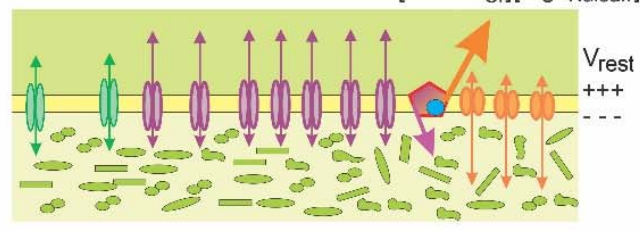

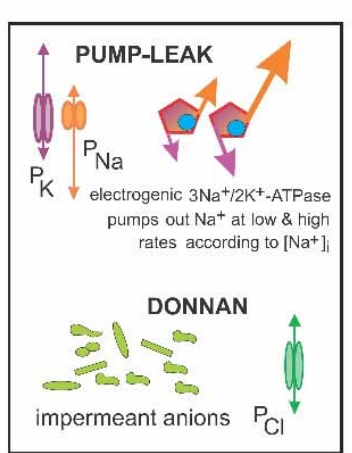

FIGURE 1 Fundamentals. A. Ion homeostasis as an autonomous Pump-Leak/Donnan (PL/D) feedback process with two sensor/effector mechanisms $P-L / D$ systems cannot sense deviations from their "set point" values. The otherwise blind-to-system-values $3 \mathrm{Na}^{+} / 2 \mathrm{~K}^{+}$-pump functions as a sensor/effector by actively extruding $\mathrm{Na}^{+}$faster (thus hyperpolarizing $\mathrm{V}_{\mathrm{m}}$ ) when $\left[\mathrm{Na}^{+}\right]_{i}$ is higher (as per Figure 9Ai,ii) while the (Donnan-effectors)/ $\mathrm{P}_{\mathrm{Cl}}$ combination, via thermodynamics/electrostatics, functions as a sensor/effector that prevents osmo-imbalance and maintains compartment neutrality. (The weak V-dependence of Na/K-pumps (Rakowski et al 1997) is not modeled here).

B. Minimal P-L/D systems at steady-state Implied but not depicted: 1) the membrane has an $\mathrm{H}_{2} \mathrm{O}$ permeable bilayer of capacitance, $C_{m}$, that can store charge until $\sim V_{m} \pm 200 \mathrm{mV}, 2$ ) compartments are neutral, osmo-balanced and iso-potential, 3) the cellular surface-area-to-volume (SA:V) ratio handles normal swelling perturbations without bilayer-rupture, 4) ATP is available ad libitum, 5) average Donnan effector valence $=-1,6$ ) the exterior is infinite/invariant. V-gated channels are not depicted because normally they do not contribute to steady-state. Impermeant cytoplasmic anions (mostly proteins) act as Donnan effectors; Donnan effectors passively influence the transmembrane distributions of permeant ions and $\mathrm{H}_{2} \mathrm{O}$. Animal cells' electrogenic $3 \mathrm{Na}^{+}$out $/ 2 \mathrm{~K}^{+}$in-ATPases cycle faster at $\uparrow\left[\mathrm{Na}^{+}\right]_{\mathrm{i}}$. ([K+ $]_{\mathrm{e}}$ is invariant here, so pump sensitivity to $\left[\mathrm{K}^{+}\right]_{\mathrm{e}}$ is not modeled). At ion homeostatic steady-state, the hyperpolarizing pump-flux precisely counterbalances in/out fluxes across $\mathrm{P}_{\mathrm{Na}}$ and $\mathrm{P}_{\mathrm{k}}$. For these minimal systems, $V_{m}=V_{\text {rest }}=E_{C l}$ because in/out anion flux across $P_{c l}$ balances at $V_{\text {rest. }}$. In minimal systems, moreover, the

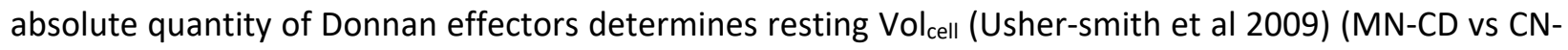
CD offers a simple minimal vs non-minimal comparison; see Table 1 footnotes $(* *))$. For self-regulating $\mathrm{P}-\mathrm{L} / \mathrm{D}$ ion homeostasis, these are the minimal components. In the top and bottom minimal systems, $\mathrm{P}_{\mathrm{Na}}: \mathrm{P}_{\mathrm{K}}: \mathrm{P}_{\mathrm{Cl}}$ ratios differ, as does the steady-state pump-rate (implied by arrow-size). For the steady-state (net fluxes $=0$ ) at top, influx/efflux is predominantly anions $\left(\mathrm{Cl}^{-}\right)$passively balanced by Donnan effectors, and at bottom, influx/efflux is predominantly cations actively counterbalanced by $\left[\mathrm{Na}^{+}\right]_{i}$-sensitive energyconsuming pump work. The top P-L/D ion homeostatic steady-state we describe as "Donnan dominated" ([big $\left.P_{\text {cl }}\right]\left[s\right.$ small $\left.I_{\text {Naleak }}\right]$ ), the lower one as "Pump-Leak dominated" ([small $\left.P_{c l}\right]\left[\right.$ big $\left.I_{\text {Naleak }}\right]$ ). 

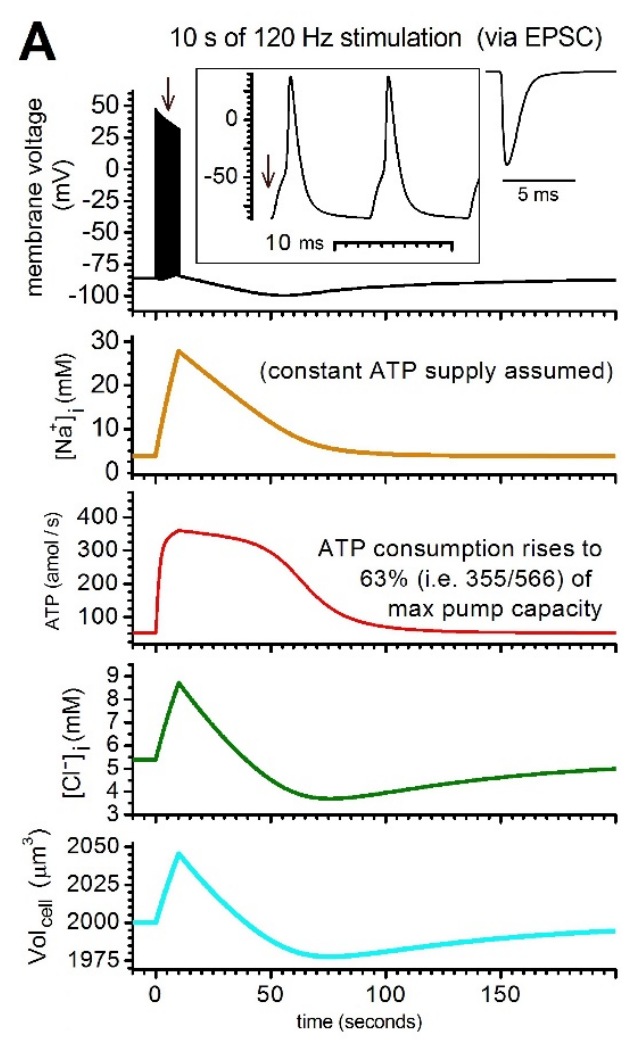
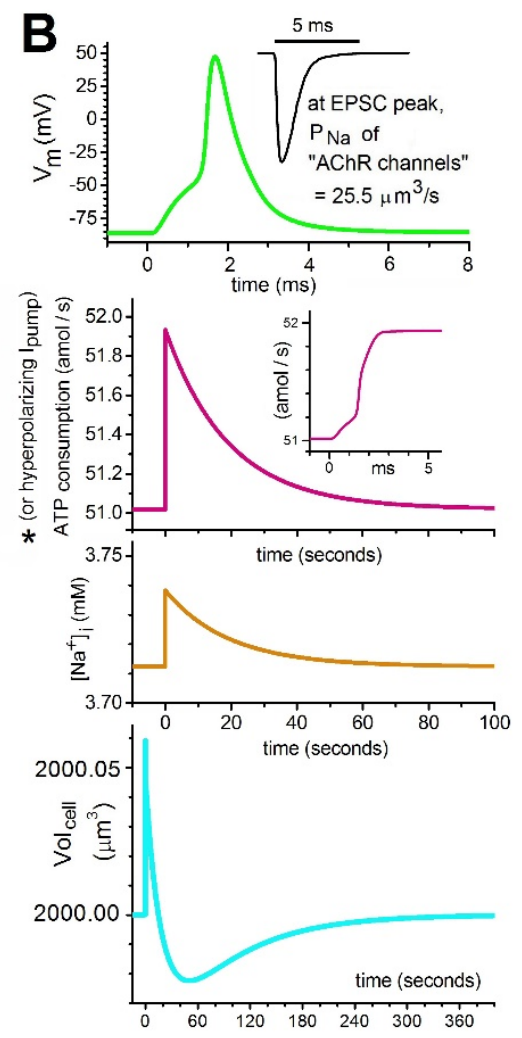

FIGURE 2

The P-L/D model, SM-CD, handling a reallife ion homeostatic stress-test

A. SM-CD undertaking a stresstest based on a rat soleus muscle experiment (Nielsen and Clausen 1997). SM-CD parameters are in Tables 2. H-H properties of the $\mathrm{Nav}$ and $\mathrm{Kv}$ channels are as depicted in Figure 9C, with rate constants as in Table 4. AP heights decline during the train. $\left[\mathrm{Na}^{+}\right]_{i}$ rises, eliciting $\uparrow$ ATPconsumption, $\uparrow\left[\mathrm{Cl}^{-}\right]_{i}, \uparrow V_{\text {ol }}$ cell and (not shown) $\downarrow\left[\mathrm{K}^{+}\right]_{i}$. The expanded inset shows APs at $\sim 5$ seconds. When EPSCs stop, $V_{m}$ hyperpolarizes and $\left[\mathrm{Na}^{+}\right]_{i}$ decays steadily due to electrogenic $\mathrm{Na}^{+}-$

extrusion (hyperpolarizing $I_{\text {pump }}$ ). ATP-consumption, having $\uparrow \sim 7$-fold (engaging $\sim 2 / 3$ of SM-CD's $\sim 11$-fold pump-reserve) remains high for $\sim 40$ seconds ("11-fold" refers to the maximal/resting ratio for ATPconsumption (i.e., 566/51.1; see Figure 9A). $\mathrm{Na}^{+}$-extrusion, $\left(I_{\text {pump }}(t)\right)$ hyperpolarizes $\mathrm{V}_{\mathrm{m}}$ until $\left[\mathrm{Na}^{+}\right]_{i}$ returns to steady-state (Table 2 gives models' steady-state values). During the AP train, SM-CD steadily swells though by $<2.5 \%$; depending on a SMF's geometry and mechanics, this might engage its caveolar tensionbuffer (see Sinha et al 2011.; Morris 2018), a system not included in SM-CD. Once AChR, Nav, and Kv channel activity ceases, fluxes are strictly ion homeostatic. For $\sim 2 \mathrm{~min},\left[\mathrm{Cl}^{-}\right]_{i}$ and Vol $\mathrm{Vell}_{\text {ll }}$ undershoot, then converge on steady-state. Though $\Delta \mathrm{Vol}_{\text {cell }}$ is small $\left[\mathrm{Cl}^{-}\right]_{i}$ almost doubles; new techniques (DiFranco et al 2019) would make this measurable. SM-CD's very small $P_{\mathrm{Na}}$ ensures that the transiently-large $I_{\text {pump }}$ is not undermined by a concurrently large $I_{\text {Naleak. }}$. The passive ion homeostatic processes, obeying the constraints set by Donnan effector electrostatics/thermodynamics (rapidly, thanks to SM-CD's [big P $\left.P_{\mathrm{CI}}\right]$ ), entrain to the $\left[\mathrm{Na}^{+}\right]_{i}$-dependent $\mathrm{Na}^{+}$-pumping. $\mathrm{H}_{2} \mathrm{O}$ permeability is high enough for swelling to be effectively instantaneous; very small driving forces on $\mathrm{Cl}^{-}$explain why (in spite of [big $\mathrm{PCl}_{\mathrm{Cl}}$ ) $\left[\mathrm{Cl}^{-}\right]_{i}$ is slowest to converge back to steady-state. Vol cell $(\mathrm{t})$ mirrors $\left[\mathrm{Cl}^{-}\right]_{i}(\mathrm{t})$. It would lag volume only if $\mathrm{H}_{2} \mathrm{O}$ permeability was ratelimiting. B. For a single AP, precisely the same phenomena are seen; notice that the time scale for Vol cell is the longest (not shown in this case, but identical to $\left[\mathrm{Cl}^{-}\right]_{i}(\mathrm{t})$ ). Notice the reminder $\left({ }^{*}\right)$ that ATP-

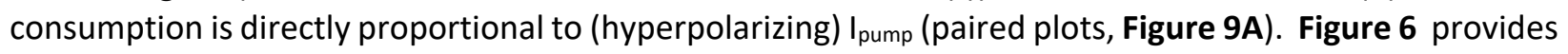
further biophysical details. 

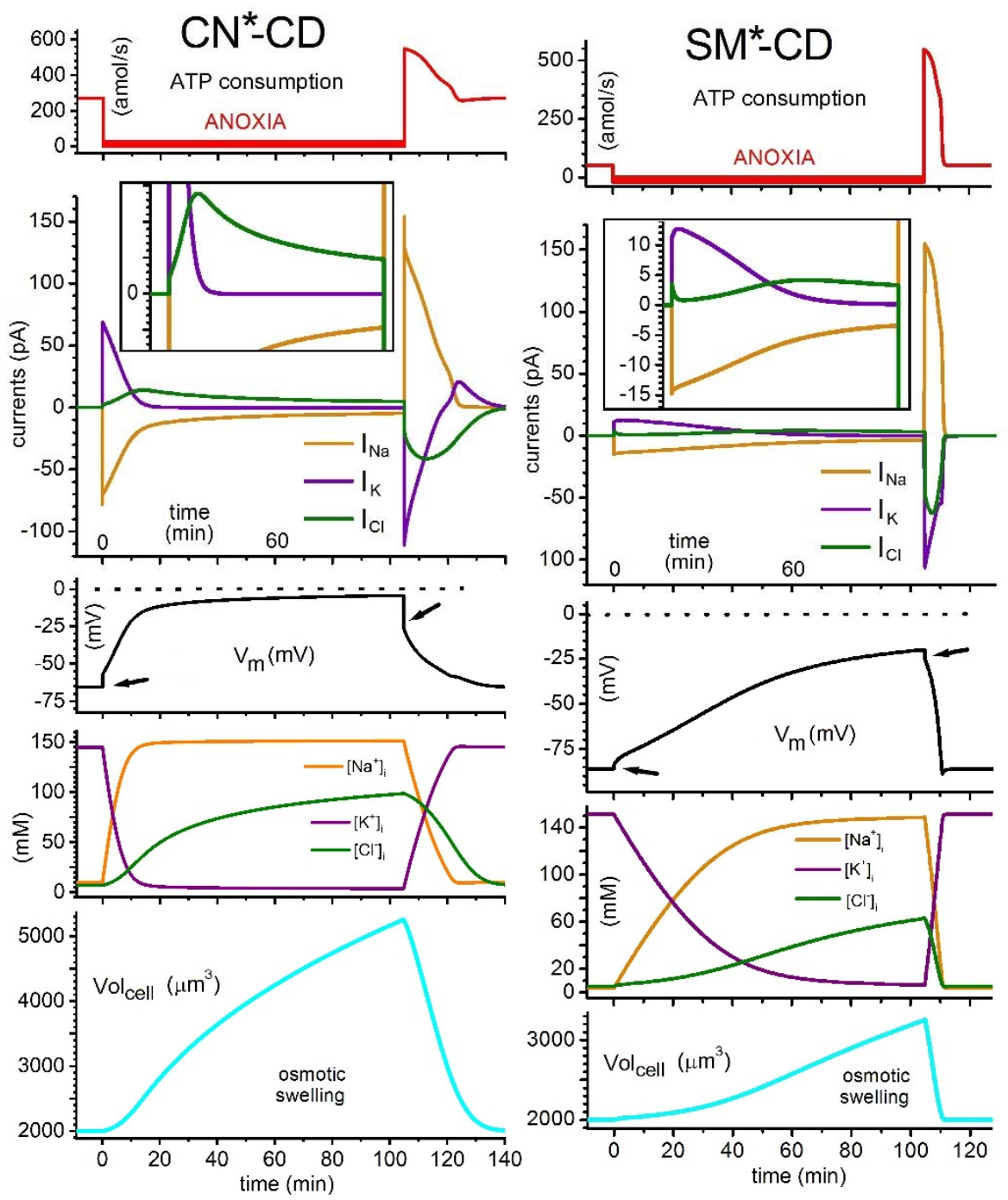
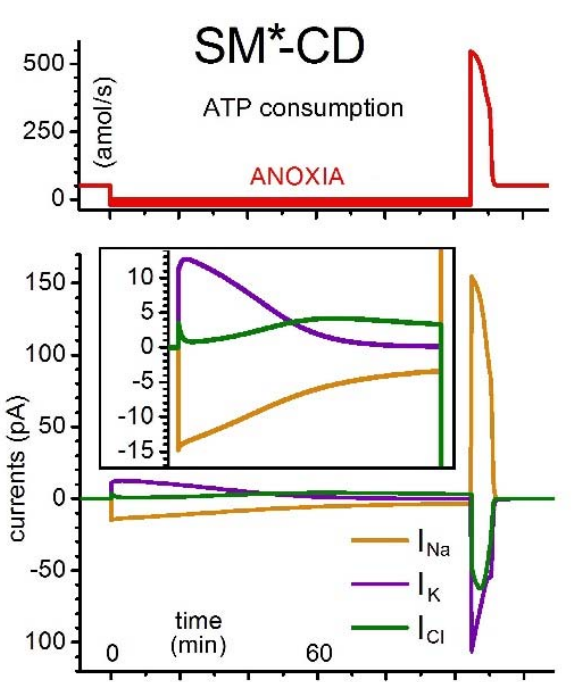

FIGURE 3

Anoxic rundown in inexcitable neuron and SMF models

A. $C N^{*}-C D$ and B. $S M^{*}-C D$ are $\mathrm{CN}-\mathrm{CD}$ and $\mathrm{SM}-\mathrm{CD}$ with V-gated channels (gNav, gKv plus "gCl(V)" in CN-CD) zeroed. Systems (nonminimal $\mathrm{CN}^{*}-\mathrm{CD}$, minimal $\mathrm{SM}^{*}$-CD) start at steadystate. In $V_{m}$ panels, arrows highlight the $\Delta V_{m}$ at $I_{\text {pump }}{ }^{-}$ off and I Iump -on. Pump-off depolarizes $\mathrm{CN}^{*}$-CD by 8 $\mathrm{mV}, \mathrm{SM}^{*}$-CD by $<2 \mathrm{mV}$ (for excitable CN-CD, the pumpoff $\Delta V_{m}$ triggers APs; see Figure 4A). The $S M^{*}$ - $C D$ rundown resembles Fig. 2 of Fraser and Huang (2004) (inexcitable amphibian SMF, $V_{\text {rest }}=-90 \mathrm{mV}$, more complex pump formulation). At $t=0$, driving forces are small on $\mathrm{Cl}^{-}$and $\mathrm{K}^{+}$, large on $\mathrm{Na}^{+}$. Current trajectories show fluxes through $\mathrm{P}_{\mathrm{Na}}$ and $\mathrm{P}_{\mathrm{K}}$

(both bigger-valued in $\mathrm{CN}^{*}-\mathrm{CD}$ than in $\mathrm{SM}^{*}-\mathrm{CD}$ ) dominating early rundown (though initially $\mathrm{K}^{+}$feels the smaller driving force, $I_{\text {Naleak }}$ through $\mathrm{P}_{\mathrm{Na}}$ is the limiting cation flux). Swelling $\left(\right.$ Vol cell tracks $\left[\mathrm{Cl}^{-}\right]_{\mathrm{i}}$ ) is checked far more effectively by $\mathrm{SM}^{*}$-CD's extremely small $\mathrm{P}_{\mathrm{Na}}$ than by $\mathrm{CN}^{*}-\mathrm{CD}^{\prime}$ s [small $\mathrm{P}_{\mathrm{Cl}}$ ]; $\mathrm{CN}^{*}$-CD swells $1.4 \mathrm{X}$ in $20 \mathrm{~min}$, while $\mathrm{SM}^{*}-\mathrm{CD}$ swells $1.4 \mathrm{X}$ in $76 \mathrm{~min}$. At $105 \mathrm{~min}$ (at pump-on) [ $\left.\mathrm{Na}^{+}\right]_{i}$ maximally activates (566 amol/s) pumps in $\mathrm{CN}^{*}$-CD. To reach the same loss of gradient as $\mathrm{CN}^{*}-\mathrm{CD}$ at $105 \mathrm{~min}$, anoxic rundown in $S M^{*}-C D$ would need to be extended to $15.5 \mathrm{hrs}$. Mainly because of its greater rundown at $105 \mathrm{~min}$, recovery is slower in $\mathrm{CN}^{*}-\mathrm{CD}$. Both models also recover fully at pump-on when anoxia is imposed for a total of 272 minutes (not shown). If recovery had been started at the same membrane voltage in both systems, $\mathrm{CN}^{*}-\mathrm{CD}$ would still recover more slowly because of its larger $\mathrm{P}_{\mathrm{Na}}$. 

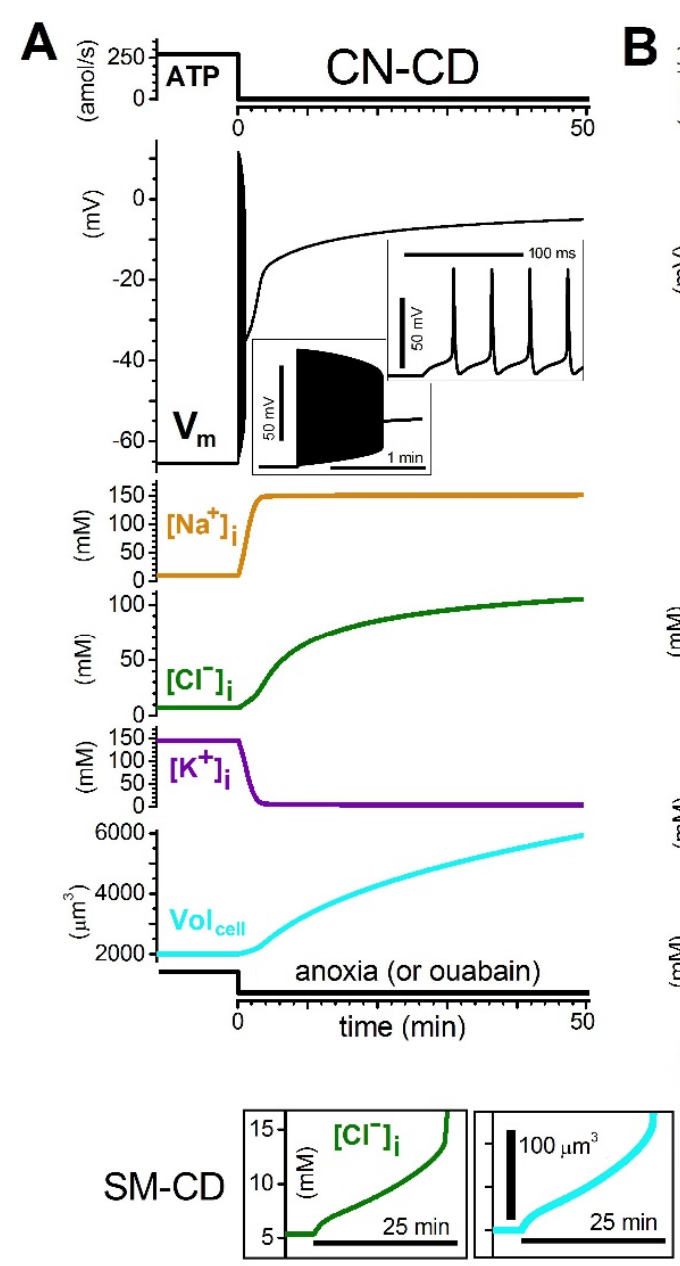

B
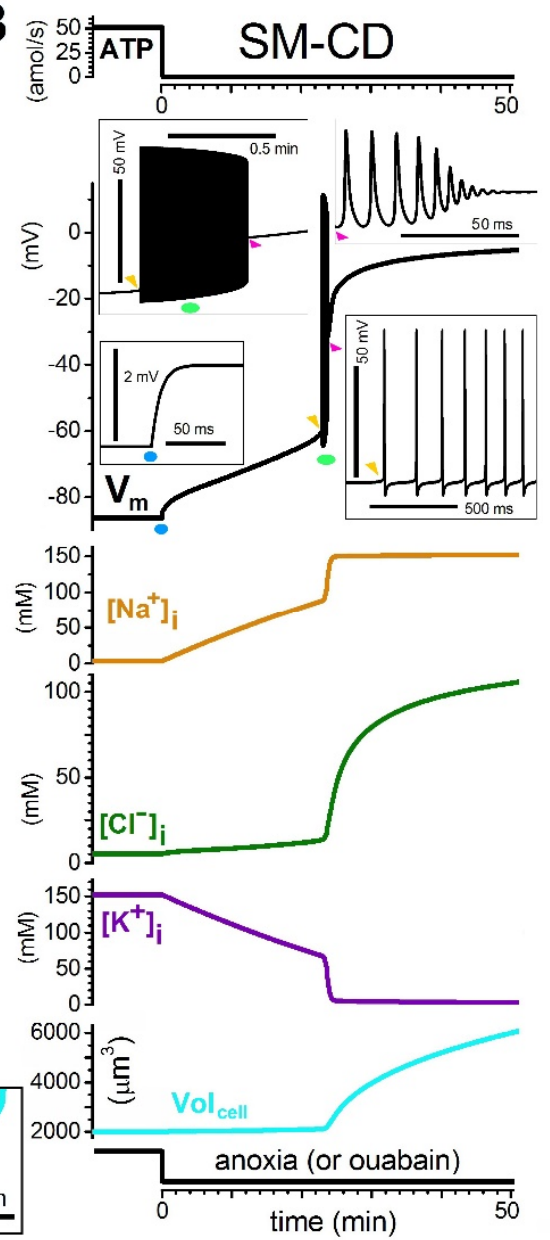

FIGURE 4

Anoxic rundown of CN-CD and SM-CD

$V_{m}(t)$ panels in $\mathbf{A}$ and $\mathbf{B}$ include expanded insets; the main trace in $\mathbf{B}$ (SMCD) flags several insets. The blue dot expansion box shows that SM-CD switch-off of hyperpolarizing I I pump causes a depolarizing " $R C$ " response in contrast to CN-CD's larger pump-off depolarization which (A, inset) triggers ectopic APs. The $50 \mathrm{mV}$ scale, lower right inset, B, applies also for the upper right inset. A) switch-off of CN-CD's large steady-state hyperpolarizing I I pump triggers ectopic APs; the

pump-off depolarization (readily evident in $\mathrm{CN}^{*}-\mathrm{CD}$, Figure $3 \mathrm{~A}$ ) triggers ectopic APs that continue for $<1$ minute. Nav and Kv channels precipitously dissipate the cation gradients. This already-dire situation is exacerbated by the (pathological) opening at $\sim-20 \mathrm{mV}$, of a depolarization-activated $\mathrm{Cl}^{-}$pathway (Rungta at a 2015; Dijkstra et al 2016). CN-CD continues swelling, degrading towards DE. B) In SM-CD, I I ump switchoff produces a $\sim 2 \mathrm{mV} \mathrm{RC}$ response (as in Figure 3, where this is too fast to be temporally-resolved) then a very slow $V_{m}$ rundown whose rate is limited by small $P_{\mathrm{Na}}$. [Big $\mathrm{P}_{\mathrm{Cl}}$ ] lets $\mathrm{E}_{\mathrm{Cl}}$ rapidly track $\mathrm{V}_{\mathrm{m}}$. Because $\mathrm{P}_{\mathrm{K}} \gg>\mathrm{P}_{\mathrm{Na}}, \mathrm{K}^{+}$efflux mostly neutralizes $\mathrm{Na}^{+}$influx. Slight swelling reflects the extent of $\left[\mathrm{Na}^{+}+\mathrm{Cl}^{-}\right]_{i}$ entry, osmobalanced by $\mathrm{H}_{2} \mathrm{O}$ influx (but the $\mathrm{Cl}^{-}$driving force is negligible). Ectopic firing starts at 22.7 minutes. SM$C D$ Nav and Kv density is $3 X$ greater than in $C N-C D$, so gradient dissipation is even more precipitous. As $E_{K}$ decreases during APs, $\mathrm{Na}^{+}$influx is neutralized increasingly by $\mathrm{Cl}^{-}$influx, and since the $\left[\mathrm{Na}^{+}+\mathrm{Cl}^{-}\right.$ ]influx $\rightarrow\left[\mathrm{Na}^{+}+\mathrm{Cl}^{-}+\mathrm{H}_{2} \mathrm{O}\right]$ influx, $\mathrm{Vol}_{\text {cell }}$ suddenly increases. Ectopic firing tapers abruptly, the small $\mathrm{V}_{\mathrm{m}}$ oscillations reflecting $V$-gating $\left(S M-C D\right.$, pink triangle, $V_{m}$ inset). When $\left[\mathrm{Na}^{+}\right]_{i}$ and $\left[\mathrm{K}^{+}\right]_{l}$ attain external values, $V_{m}$ is still $<0 \mathrm{mV}$ and $\left[\mathrm{Cl}^{-}\right]_{1}<\left[\mathrm{Cl}^{-}\right]_{\mathrm{e}}$ so net $\mathrm{Cl}^{-}$entry continues, accompanied by $\mathrm{H}_{2} \mathrm{O}$ for osmo-balance; compartment neutrality is retained during swelling (ongoing $\uparrow \mathrm{H}_{2} \mathrm{O}$ ) because $\uparrow\left[\mathrm{Cl}^{-}\right]_{i}$ compensates for $\downarrow[\text { impermanent anion] }]_{\text {. }}$ The system would rupture before converging on DE (see Table 1). 


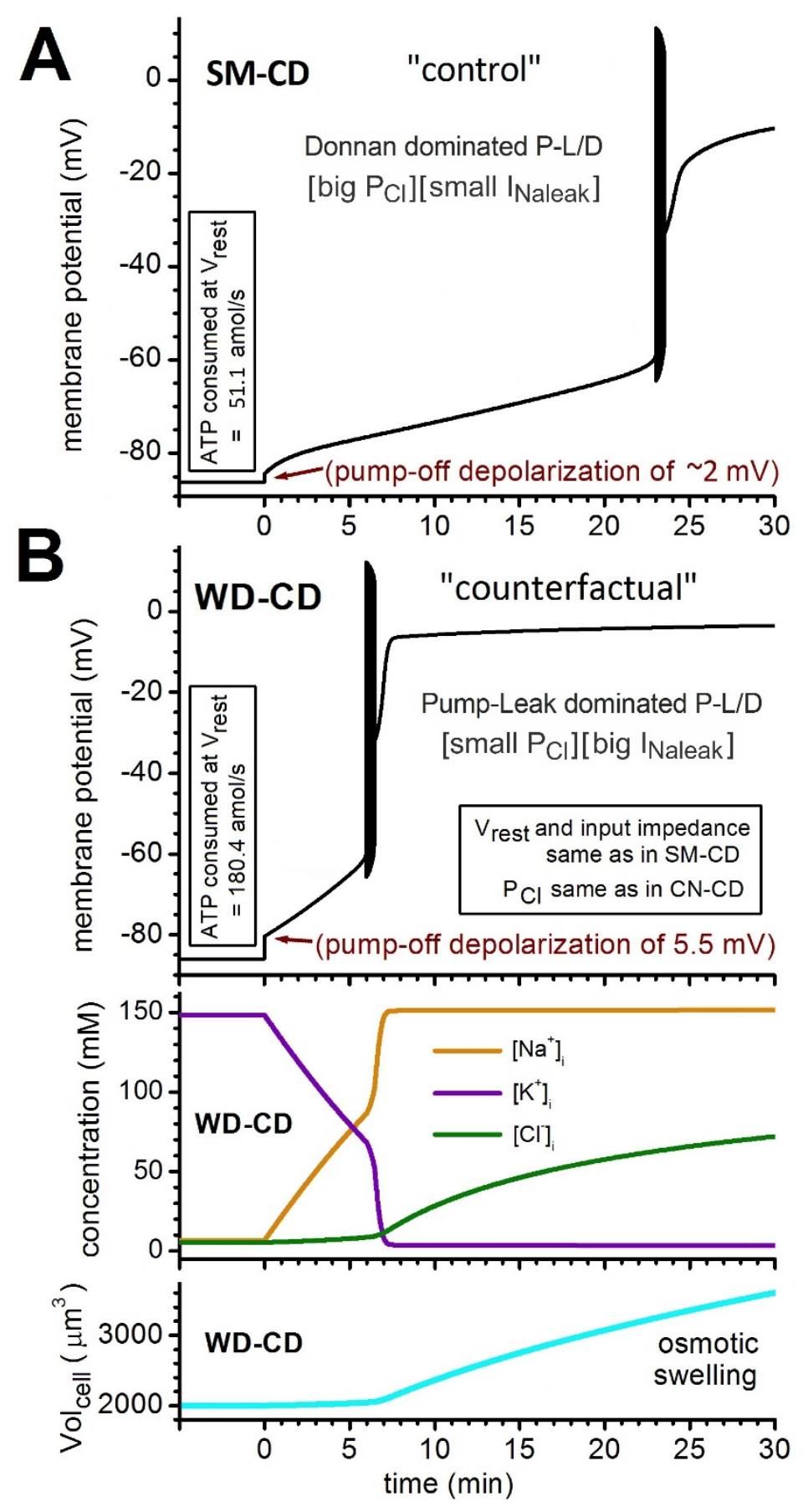

\section{FIGURE 5}

WD-CD, a counterfactual analog of SM-CD

To clarify how [big $\left.\mathrm{P}_{\mathrm{Cl}}\right]$ plays out in the context of SM-CD's other ion homeostatic elements (beyond its electrophysiological role of "big input conductance"), anoxic rundown is compared in WD-CD, a minimal P-L/D model with big $P_{K}$ as "big input conductance". A ("control") is the SM-CD anoxic rundown of $V_{m}$ (for other parameters, see Figure 4B). B, as labeled is the WD-CD anoxic rundown. WD-CD's ion homeostatic response to an EPSCtriggered AP is shown in Figure 6. WD-CD was subjected to the Figure 2A stress test (see Figure Supp01C). 

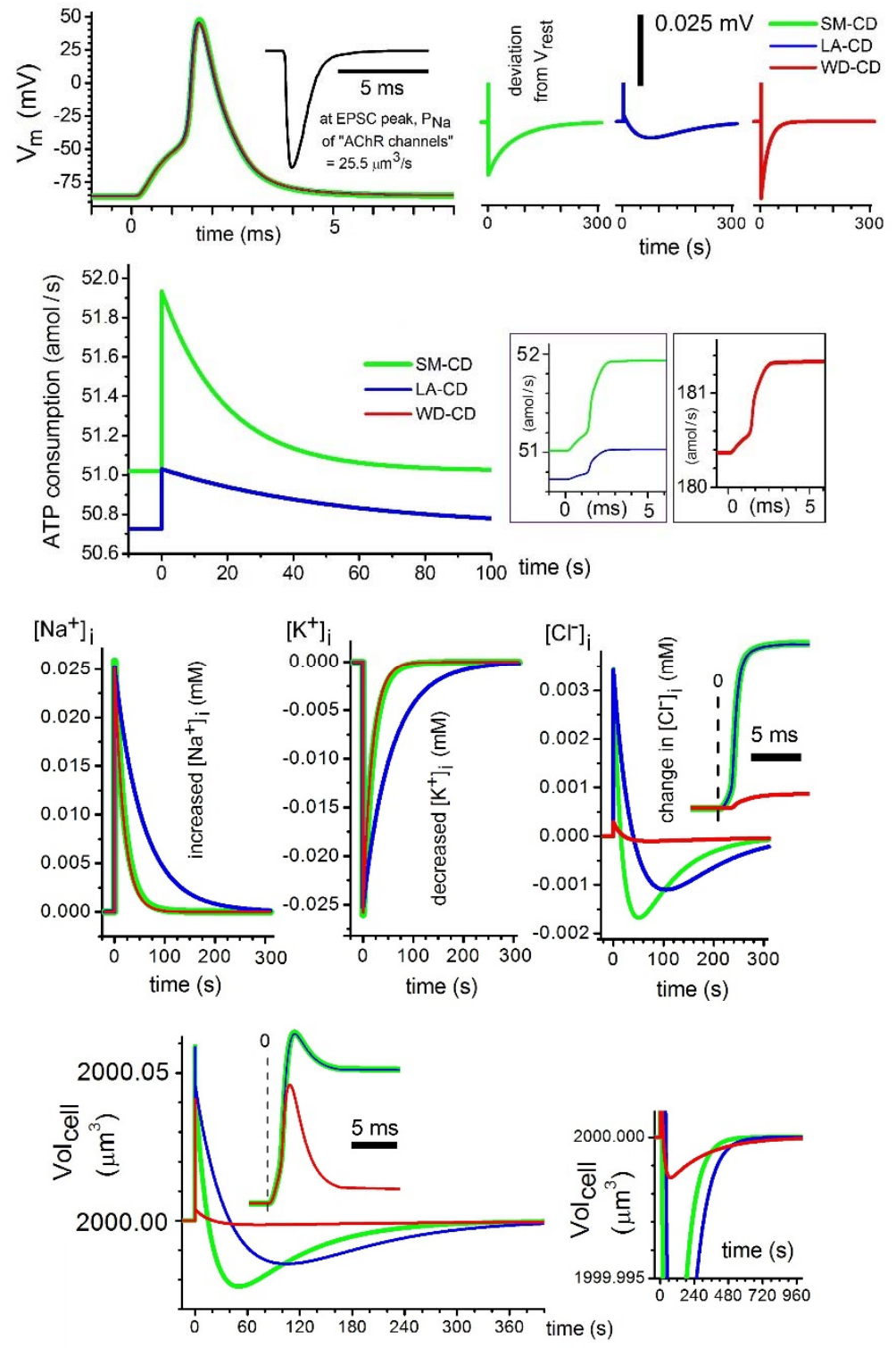

FIGURE 6

Biophysics of

Donnan dominated

and

Pump-Leak dominated systems

Ion homeostasis is scrutinized comparatively for 3 related minimal P-L/D systems: they are the normal version and an ischemic version (LA-CD; 30\% pump-strength) of $S M-C D$, both of which are Donnan dominated systems, and SMCD's Pump-Leak dominated counterfactual analog, WDCD. In addition to the APs and subsequent $\Delta V_{m}, \quad$ ATPconsumption (directly proportional to $\left.\mathrm{I}_{\text {pump }}\right), \Delta[\text { ion }]_{\mathrm{i}}$ for $\left(\mathrm{Na}^{+}, \mathrm{K}^{+}\right.$and $\left.\mathrm{Cl}^{-}\right)$and $\mathrm{Vol}_{\text {cell }}$ are plotted. In each system, ion homeostatic restoration to steady-state involves a volume oscillation commencing with AP-induced " $\mathrm{H}_{2} \mathrm{O}$ blips" which are abrupt $\uparrow V_{\text {coll }}$ (grey arrow) whose amplitude reflects the magnitude of

excess $\mathrm{Na}^{+}$entry (i.e., the $\mathrm{Na}^{+}$-entry demanding osmo-balance because it is unaccompanied by $\mathrm{K}^{+}$-exit). This excess is greater in SM-CD and LA-CD (whose blips overlap) than in WD-CD (whose bigger $\mathrm{P}_{\mathrm{K}}$ explains its smaller blip). The amplitude of the models' immediate Donnan-responses (see millisecond resolution trajectories for the $\uparrow\left[\mathrm{Cl}^{-}\right]_{i}(\mathrm{t})$ ) depend on what fraction of the "electro-neutralization-of-excess-Na+-entry" task is achieved by $\mathrm{Cl}^{-}$entry (for [big $\mathrm{P}_{\mathrm{CI}}$ ] SM-CD and $\mathrm{LA}-\mathrm{CD}$, most of it; for [small $\mathrm{P}_{\mathrm{Cl}}$ ] WD-CD, very little of it). The AP perturbation ends in milliseconds but ion homeostatic feedback continues for minutes, the pump sensor/effector process actively extruding $\mathrm{Na}^{+}$(=hyperpolarizing $I_{\text {pump }}$ ) at a rate proportional to $\left[\mathrm{Na}^{+}\right]_{\mathrm{i}}$, while the passive Donnan sensor/effector feedback mechanism supports $\mathrm{Cl}^{-}$and $\mathrm{H}_{2} \mathrm{O}$ fluxes that keep in/out $\mathrm{H}_{2} \mathrm{O}$ activities balanced and the cytoplasm electroneutral. 

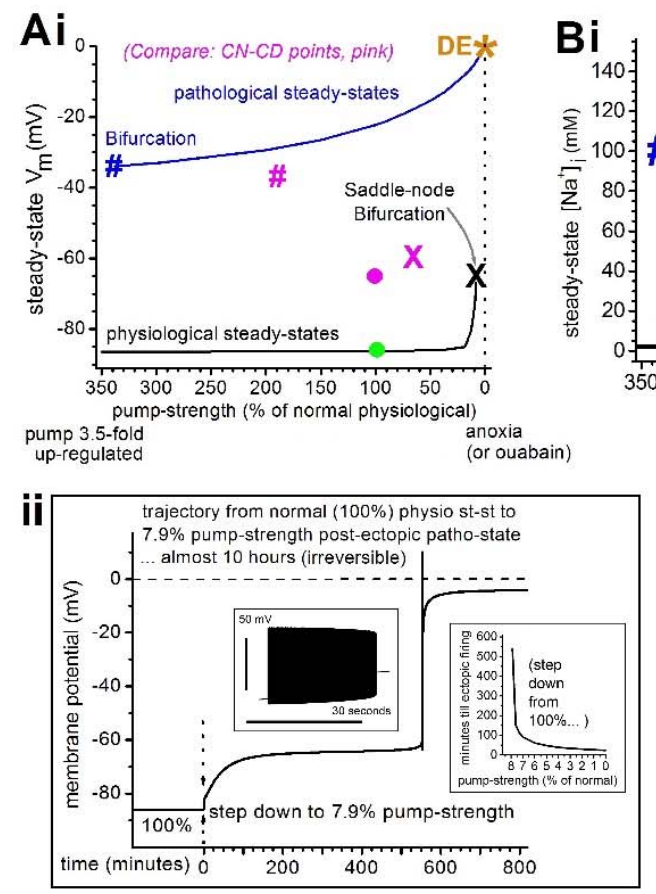
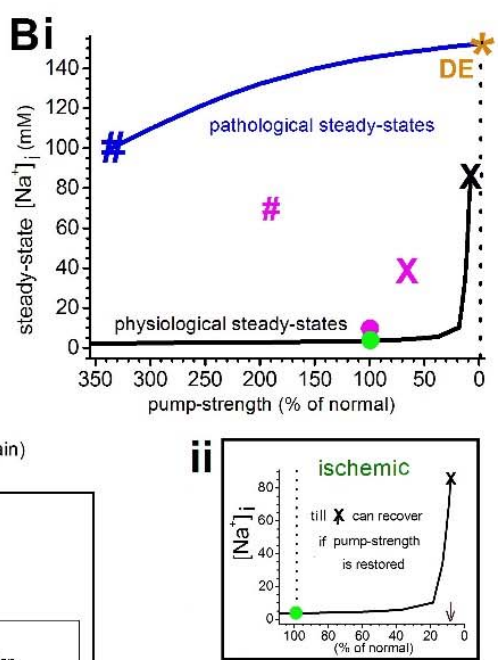

iii

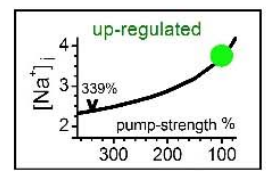

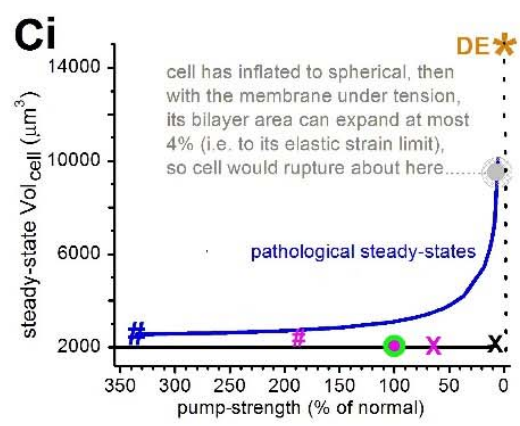
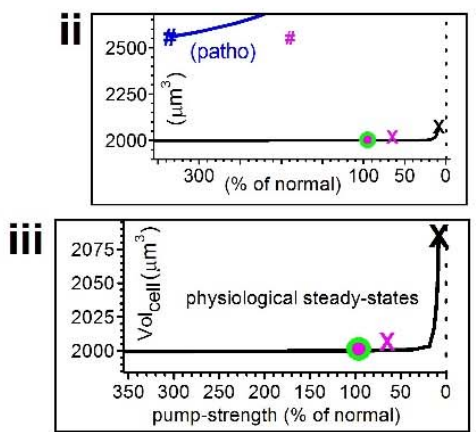

\section{FIGURE 7}

SM-CD bistability: bifurcation plots $\mathrm{Ai}, \mathrm{Bi}, \mathrm{Ci}$ are $\mathrm{SM}-\mathrm{CD}$ bifurcation plots, as labeled (Figure Supp 02A,B has $\left[\mathrm{K}^{+}\right]_{i}$ and $\left[\mathrm{Cl}^{-}\right]_{i}$, bifurcation plots). Exit from the physiological continuum occurs at the "saddle-node" marked $\mathbf{X}$; exit from the pathological continuum occurs at the unstable point marked \#. Parts of $\mathbf{B i}$ and $\mathbf{C i}$ are expanded (Bii,iii and $\mathbf{C i i}, \mathbf{i i i}$ ). Aii is the $V_{m}(t)$ trajectory for $100 \% \rightarrow 7.9 \%$ pump-strength (i.e. saddle-node); it takes $\sim 10$ hours for SM-CD to depolarize to firing threshold (inset expands ectopic burst) and then re-stabilize in a pathological steady-state. For bigger pump-strength drops, time-toectopic-firing falls sharply (inset plot), converging on the anoxic (0\%) rundown time (22.7 minutes) (see Figure 4A). For patho-physiological comparisons, we recomputed the CN-CD (Dijkstra et al 2016) bifurcation plots (we report Vol cell, not cross-sectional area); $C N-C D$ 's threshold and normal steady-state points are included, as indicated. Although notional Donnan Equilibrium (DE) is marked in $\mathbf{A i}, \mathbf{B i}, \mathbf{C i}$, rupture would occur prior to attaining $\mathrm{DE}$ (as per $\mathrm{Ci}$ ) unless bilayer area was augmented $\left(\uparrow \mathrm{C}_{\mathrm{m}}\right.$ ). 


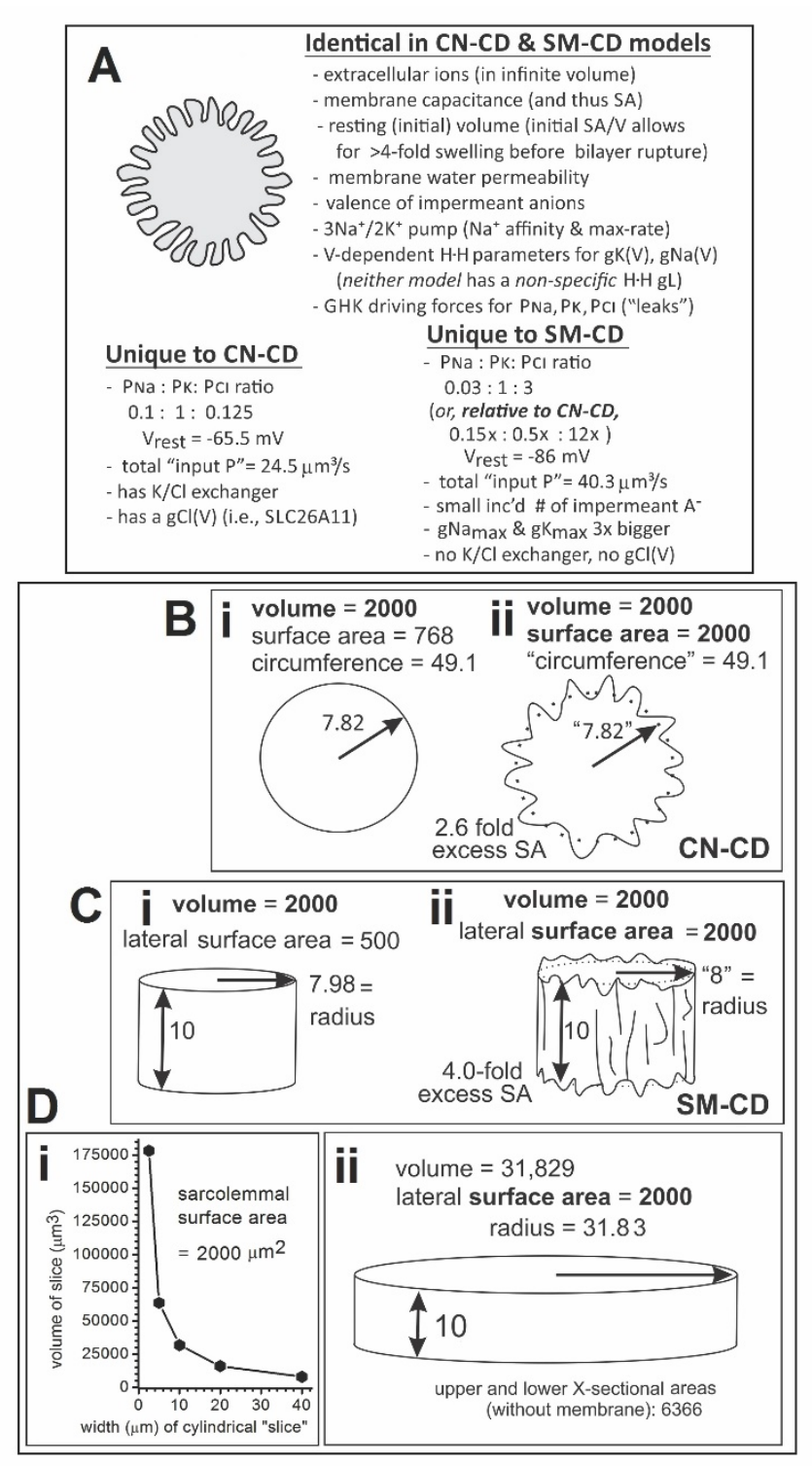

\section{Figure 8}

\section{Model building.}

A. From CN-CD to SM-CD SM-CD was devised for direct comparison against $\mathrm{CN}-\mathrm{CD}$, an established cortical neuron model (Dijkstra et al 2016). Where possible the two are identical. Differences reflect the distinctive electrophysiological "lifestyles" of neurons (Dijkstra et al 2016) and SMFs (Fraser and Huang, 2004; Fu et al 2011; Ruff 2011; Pedersen et al 2011; Novak et al 2015). The Dijkstra et al (2016) model addressed cortical neurons in brainslice preparations. As an indicator of Volcell they reported confocallyimaged cross-sectional neuronal areas; we recalculated to obtain spherical volumes from those $X$-areas. $B, C, D$. From $C N-C D$ to SM-CD to SMF-like cytomorphology To foster comparisons, Vol cell $=2000 \mu \mathrm{m}^{3}$ and $S A=2000 \mu m^{2}$ from CN-CD (Dijkstra et al 2016) was used for SM-CD so there is excess $S A$ beyond what is required to enclose a sphere of $2000{\mu m^{3}}^{3}$, but neuron and SMF cytomorphologies differ, so $\mathbf{B i}, \mathbf{i i}$, and $\mathbf{C i}, \mathbf{i i}$ sketches the disposition of the excess SA (as per A) for each. Additionally, $\mathbf{C}$ indicates that for SM-CD, the $2000 \mu \mathrm{m}^{3} V_{\text {Vol }}$ cell would represent one cross-sectional slice "ion homeostatic unit" through a cylindrical multinucleate myofiber. The $2000 \mu \mathrm{m}^{2}$ of sarcolemma would encircle, not enclose, myoplasm. Cii is thus "SM-CD" as modeled here $\left(V_{\text {ol }} \mathrm{cell}_{\mathrm{c}}=2000 \mu \mathrm{m}^{3}, \mathrm{SA}=2000 \mu \mathrm{m}^{2}\right)$. The P-L/D models are not, however, 3-dimensional, so the difference noted in the excess SA for CN-CD and SM-CD does not affect computations here. However, as Di shows, for cylindrical geometry, $2000 \mu \mathrm{m}^{2}$ of sarcolemma disposed as a smooth (no excess-SA) ring of SA could encircle vastly more than Vol cell $=2000 \mu^{3}$, depending on slice width. For example, the $10 \mu \mathrm{m}$ slice depicted in Dii would enclose almost $32,000 \mathrm{\mu m}^{3}$ of myoplasm. Or, for an example with a little excess SA, $2000 \mu \mathrm{m}^{2}$ could be disposed, say, as follows (not shown): a $15 \mu \mathrm{m}$ radius cylinder of $20 \mu \mathrm{m}$ "slice width" with a lateral $S A=1885 \mu \mathrm{m}^{2}$ encircling $14,137 \mu \mathrm{m}^{3}$ with $115 \mu \mathrm{m}^{2}$ added to bring the slice to $S A=2000 \mu \mathrm{m}^{2}$ and providing a small (1.06-fold) tension-buffering excess SA. Throughout the figure, linear, area and volume dimensions have units of $\mu \mathrm{m}, \mu \mathrm{m}^{2}$ and $\mu \mathrm{m}^{3}$ respectively. Schematics are not to scale. For reference, Fraser and Huang (2004) modeled a $75 \mu \mathrm{m}$ diameter fiber with $\mathrm{SA} / \mathrm{Vol}_{\text {cell }}=5 \times 10^{5} \mathrm{~cm}^{2} /$ liter; the Dii slice has $\mathrm{SA} / \mathrm{Vol}_{\text {cell }}=6 \mathrm{X} 10^{5} \mathrm{~cm}^{2} /$ liter (for $\mathrm{SM}-\mathrm{CD}$ as per Cii, SA/Vol cell $=25 \times 10^{5} \mathrm{~cm}^{2} /$ liter). 

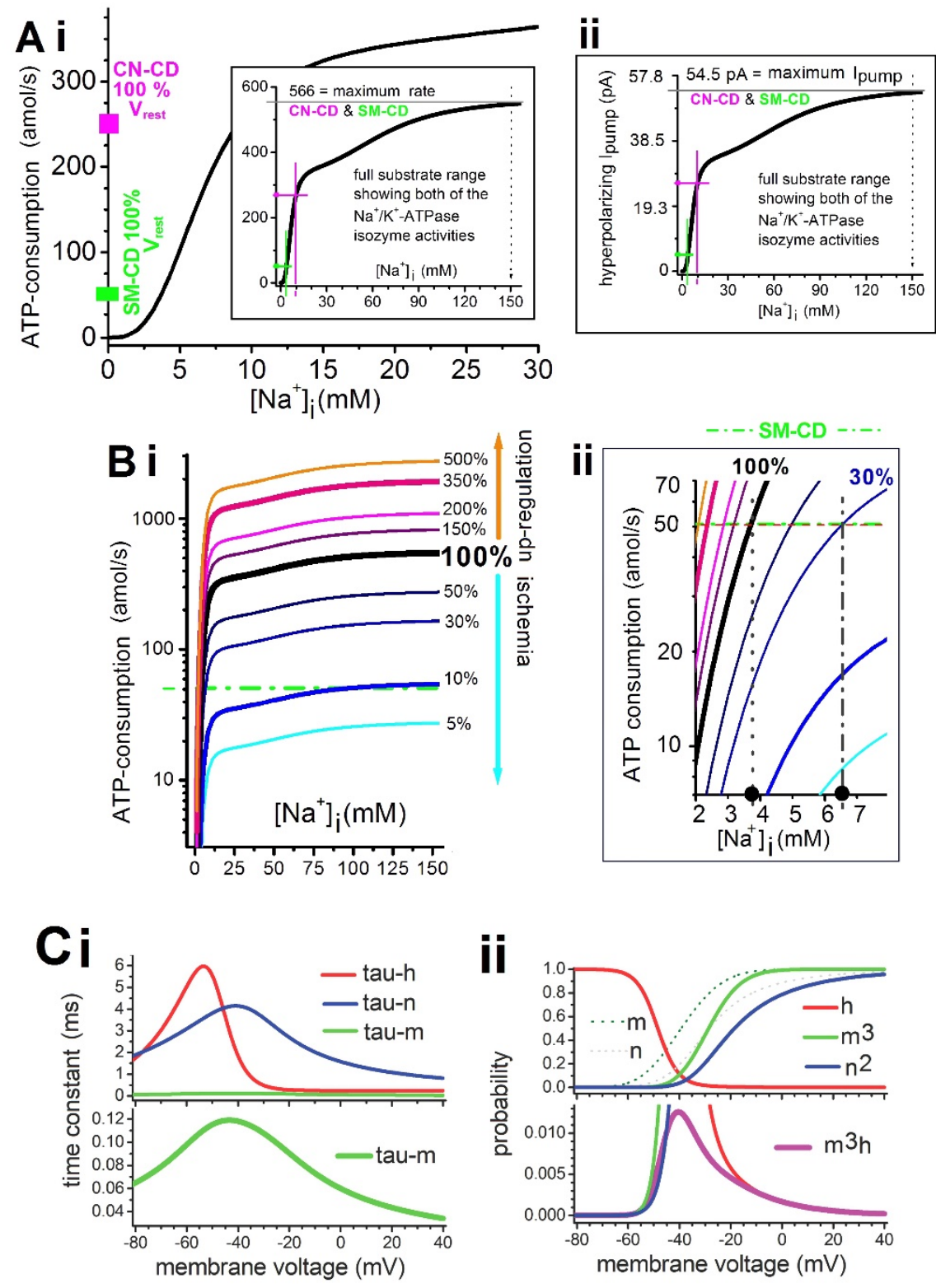

Figure 9

Pump and Excitability.

A,B. The pump: ATP-consumption (or hyperpolarizing lpump $_{\text {p }}$ as $\left[\mathrm{Na}^{+}\right]_{i}$ varies

Ai. For the pump (Hamada et al 2003) used in all models here, ATP-consumption as a function of $\left[\mathrm{Na}^{+}\right]_{i}$; normal pump-strength for $\mathrm{CN}-\mathrm{CD}$ and $S M-C D$ as indicated on two scales (0-30 mM, and inset, 0$160 \mathrm{mM}$ ). Aii replots the inset, but for hyperpolarizing I pump, showing its direct proportionality to ATPconsumption. Bi. Using a logarithmic Y-axis, ischemia and pump up-regulation are depicted by scaling the $100 \%$ pump-strength curve as labeled. Bii. Lower left region $\mathbf{B i}$, expanded. Typically for enzyme kinetics plots, the abscissa is the independent variable ("Given $\left[\mathrm{Na}^{+}\right]_{\mathrm{i}}$, what is the ATPconsumption?"), but for PL/D systems at steady-state,

the pump kinetics plot used "in reverse" gives a read-out of steady-state $\left[\mathrm{Na}^{+}\right]_{1}$ as illustrated here for SMCD and LA-CD. In the P-L/D systems, - I Naleak $=$ hyperpolarizing $I_{\text {pump }}$ and so, via Equation 19 a model's $I_{\text {Naleak }}$ converts to steady-state ATP-consumption. See dashed green line at 51.1amol/s (SM-CD) and almostoverlapping dashed red line at $50.7 \mathrm{amol} / \mathrm{s}$ (LA-CD); where these intersect their models' pump-strength curve (100\% for SM-CD; $30 \%$ for LA-CD), the X-co-ordinate (black dots, below) indicates steady-state $\left[\mathrm{Na}^{+}\right]_{i}$. Likewise for $\mathrm{CN}-\mathrm{CD}$ (X-axis crossing, magenta "crosshairs", Ai inset). Ci,ii. Nav and Kv channels' electrical excitability in the P-L/D models Hodgkin-Huxley $(\mathrm{H}-\mathrm{H})$ plots for the V-dependent channels used here, calculated using Equation 7 and kinetic constants given in Table 4. The excitable (action potential competent) P-L/D models here provide explicit leak permeabilities $\left(\mathrm{P}_{\mathrm{Cl}}, \mathrm{P}_{\mathrm{K}}\right.$ and $\left.\mathrm{P}_{\mathrm{Na}}\right)$; there is, therefore, no non-specific " $\mathrm{H}-\mathrm{H}$ gLeak". Also unlike standard $\mathrm{H}-\mathrm{H}$ formulations, driving forces are all electrodiffusive (not ohmic) (see Methods, Equations 2 and 3). 

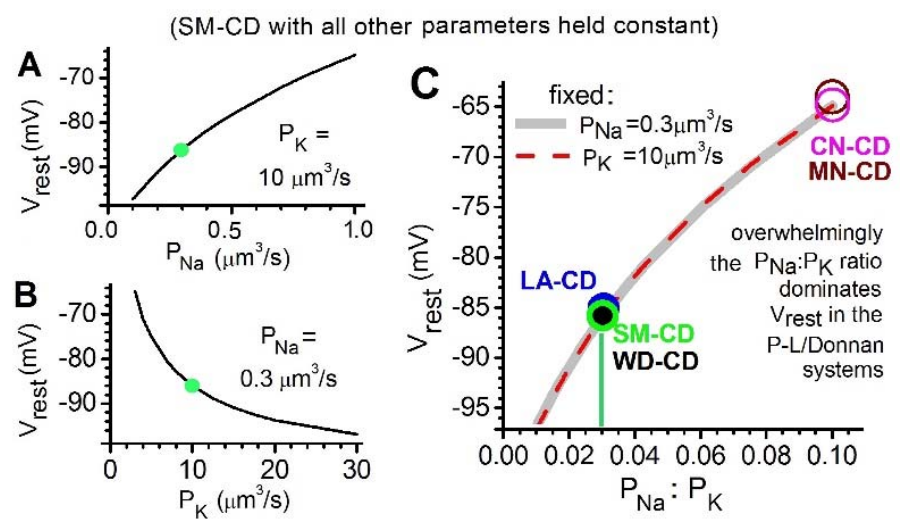

\section{Figure 10}

\section{Cation Permeabilities and $\mathbf{V}_{\text {rest }}$}

With SM-CD's other parameters held constant, $A$ and $B$ plot $V_{\text {rest }}$ as $P_{\mathrm{Na}}$ or $P_{\mathrm{K}}$ vary (green dots, normal SM-CD $V_{\text {rest }}$ ) as they might, say, as a consequence of hormonal modulation. In $C$, plots $\mathbf{A}$ and $\mathbf{B}$ coalesce, giving $\boldsymbol{V}_{\text {rest }}$ as $\mathrm{P}_{\mathrm{Na}}: \mathrm{P}_{\mathrm{K}}$ varies. Green cross-hairs $\left(\mathrm{P}_{\mathrm{Na}}: \mathrm{P}_{\mathrm{K}}=\right.$ $0.3)$ indicate $S M-C D$ normal $V_{\text {rest }}(-86.0$ $\mathrm{mV}$ ) with other $\mathrm{P}-\mathrm{L} / \mathrm{D}$ models $\mathrm{V}_{\text {rest }}$ also indicated at the $P_{\mathrm{Na}}: P_{\mathrm{K}}$ appropriate for each model. The models vary enormously in their $\mathrm{PCl}$ values, and $\mathrm{CN}-\mathrm{CD}$ (but not $\mathrm{MN}-\mathrm{CD}$ ) has a $\mathrm{K} / \mathrm{Cl}$ cotransporter that modifies $\mathrm{E}_{\mathrm{Cl}}$. Nevertheless, $\mathrm{V}_{\text {rest }}$ is overwhelmingly dominated by the $\mathrm{P}_{\mathrm{Na}}: \mathrm{P}_{\mathrm{K}}$ ratio. These calculations all assume normal pump strength. As per Figure 7Ai, increasing SM-CD pump-strength above the normal (100\%) negligibly affects $V_{\text {rest }}$ but if pump strength falls below $\sim 20 \% V_{\text {rest }}$ depolarizes (due to diminished hyperpolarizing I pump plus depolarizing Nav window current). 


\section{Supplemental Figures}
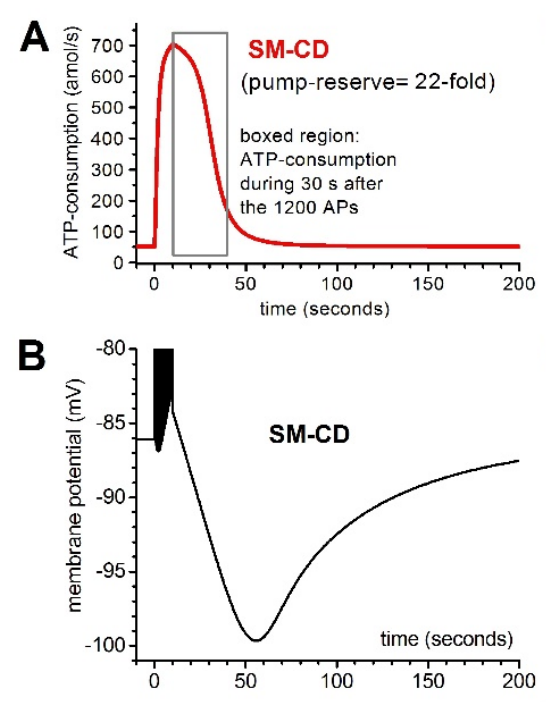
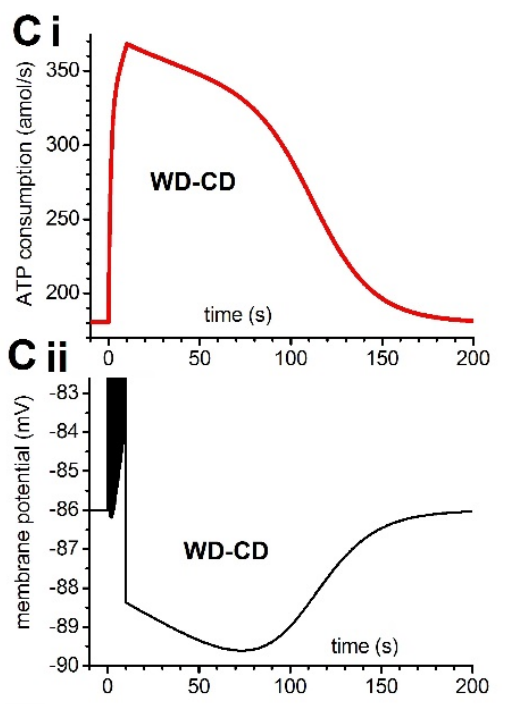

\section{Figure Sup 1}

Stress-test A. By 30 seconds after APs stop in SM-CD, ATPconsumption ( $\mathrm{Na}^{+}$-extrusion) it almost back to steady-state when pump-strength $=200 \%$ (maximum ATP-consumption $=2 \times 566=1,132$ $\mathrm{amol} / \mathrm{s}$ or $\mathrm{I}_{\text {pumpmax }} 2 \times 54.5=109$ pA) i.e., when pump-reserve= 22.2-fold.

B. $V_{m}(t)$ for $S M-C D$ (pump-strength 100\%) from Figure 2A but expanded to emphasize the effect of hyperpolarizing $I_{\text {pump }}$ during ion

homeostatic recovery, post-1200 APs. Ci. For the same 1200 AP stress-test performed by SM-CD (Figure 2A), ATP-consumption by WD-CD. Cii. $V_{m}(t)$ for WD-CD expanded over the voltage range relevant to ion homeostatic recovery. At 10 seconds (immediately post-1200 APs) $\mathrm{V}_{\mathrm{m}}$ goes to $-88.5 \mathrm{mV}$ (then, to -89.8 $\mathrm{mV}$ before returning to steady-state). Also at $\mathrm{t}=10$ seconds, ATP-consumption peaks at $370 \mathrm{amol} / \mathrm{s}$ while (not shown), $\left[\mathrm{Na}^{+}\right]_{i}=32 \mathrm{mM},[\mathrm{Cl}-] \mathrm{i}=5.75 \mathrm{mM}$, and $\mathrm{Vol}_{\mathrm{cell}}=2004.5 \mu \mathrm{m}^{3}$.
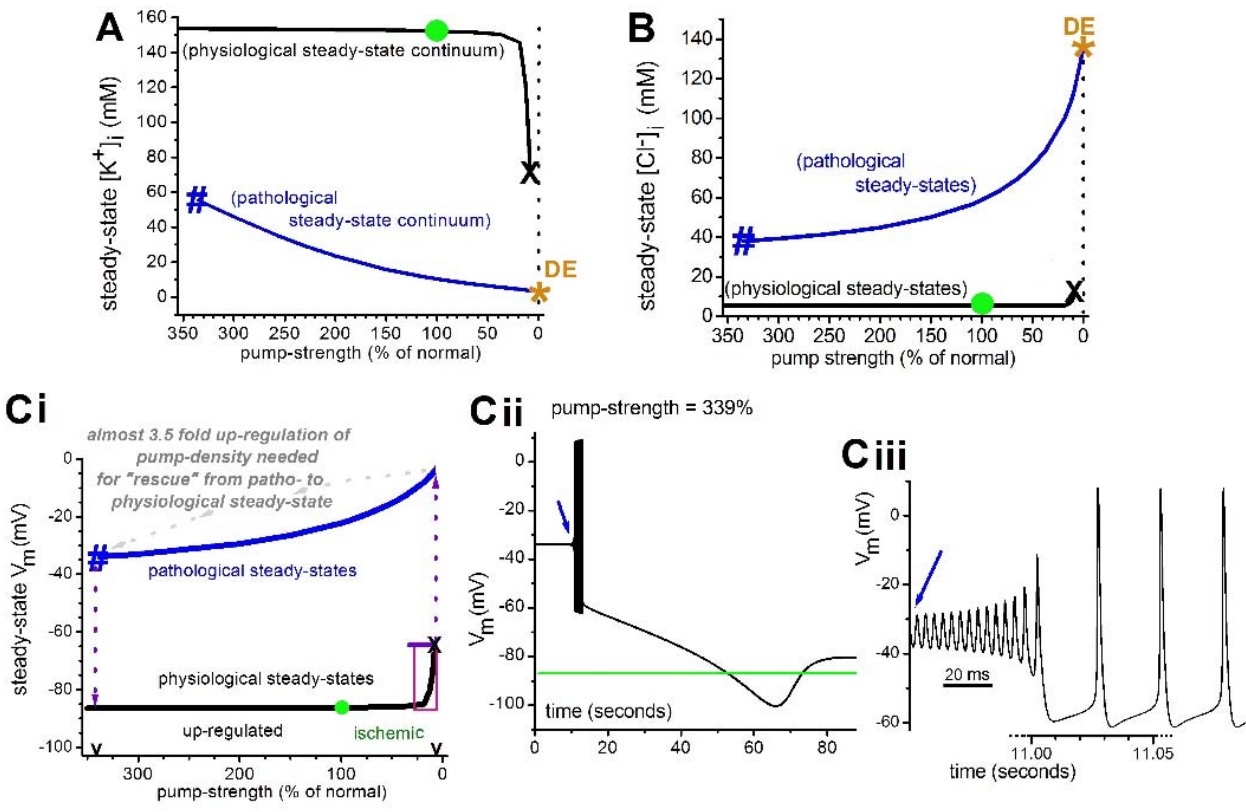

\section{Figure Sup 2}

\section{Bifurcation}

analysis $A, B$, from the same SM-CD bifurcation analysis as in Figure

7A,B,C plots for steadystate $\left[\mathrm{K}^{+}\right]_{\mathrm{i}}$ and $\left[\mathrm{Cl}^{-}\right]_{\mathrm{i..}} \mathrm{Ci}$, the SM-CD V $m$

bifurcation plot showing the location of \#, the unstable threshold on the pathophysiological steady-state continuum. The equivalent bifurcation point in $\mathrm{CN}$ CD is called a Hopf bifurcation by Dijkstra

et al (2016). ii,iii At $t=0$, SM-CD (on the pathological continuum) pump-strength is stepped from $338 \%$ to $339 \%$. The resulting trajectory is plotted (ii), with a portion expanded (iii). 